Portland State University

PDXScholar

7-1-1992

\title{
Effective Middle School Teaching: Factors that Promote and Maintain It
}

Judith Ann Smith

Portland State University

Follow this and additional works at: https://pdxscholar.library.pdx.edu/open_access_etds

Part of the Elementary Education Commons, and the Secondary Education Commons Let us know how access to this document benefits you.

Recommended Citation

Smith, Judith Ann, "Effective Middle School Teaching: Factors that Promote and Maintain It" (1992). Dissertations and Theses. Paper 1371.

https://doi.org/10.15760/etd.1370

This Dissertation is brought to you for free and open access. It has been accepted for inclusion in Dissertations and Theses by an authorized administrator of PDXScholar. Please contact us if we can make this document more accessible: pdxscholar@pdx.edu. 
EFFECTIVE MIDDLE SCHOOL TEACHING:

FACTORS THAT PROMOTE AND MAINTAIN IT

by

JUDITH ANN SMITH

A dissertation submitted in partial fulfillment of the requirements for the degree of

\author{
DOCTOR OF EDUCATION \\ in \\ EDUCATIONAL LEADERSHIP: \\ ADMINISTRATION AIND SUPERVISION
}

Portland State University

1992 


\section{TO THE OFFICE OF GRADUATE STUDIES:}

The members of the Committee approve the dissertation of Judith Ann Smith presented July 1, 1992.
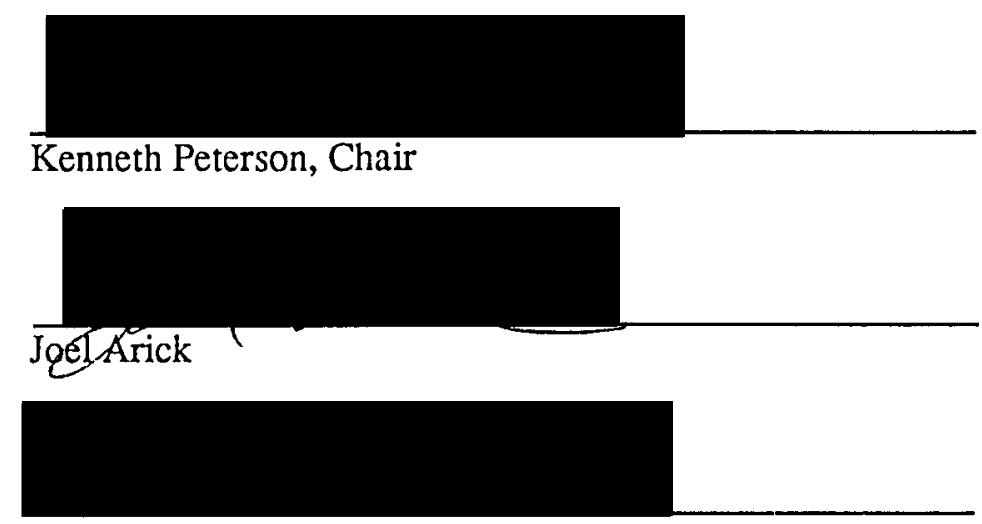

Carol Burden

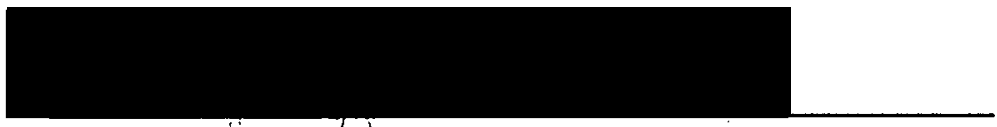

Dilafruz Williams?

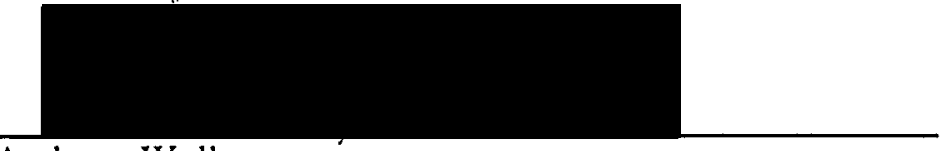

Anthony Wolk

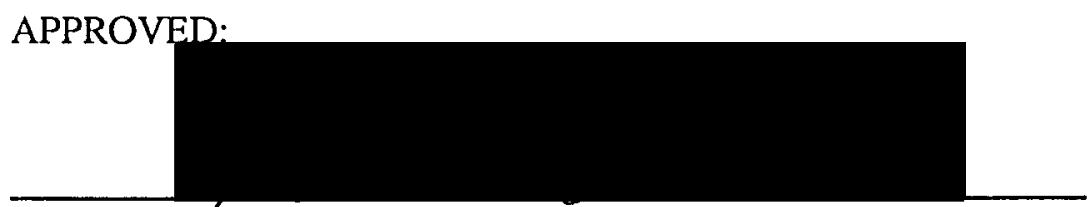

Robert B. Everhart, Dean, School of Education

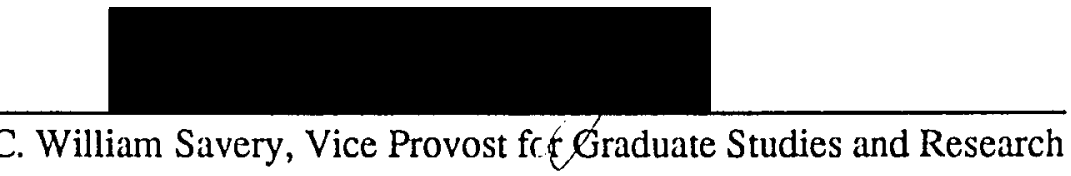




\section{ACKNOWLEDGMENTS}

Completing this dissertation fills me with great satisfaction in that, among other things, it symbolizes my life motto: On with the dance! This is particularly meaningful when I consider how the dance almost stopped in October of 1990 when my husband Joe was diagnosed with terminal cancer. He lived, however, and with his life came daily support and encouragement and a tenacious refusal to let me quit. I will be forever indebted to this man I married.

A very special thank you goes to Dr. Ken Peterson who willingly accepted me as his advisee early in my journey toward a doctorate. He has assisted me every step of the way. In addition to his knowledge and guidance, his ability to encourage me through positive and enthusiastic feedback made me feel a doctoral degree was attainable and that my dissertation had a valuable contribution to make to the world of middle school education.

I am grateful to my committee: Dr. Joel Arick who made the research sequence such a painless learning experience; Dr. Carol Burden who will always have a special place in my heart for being so sensitive and caring; Dr. Dilafruz Williams who shares the same passion I do for the need to provide the best teachers possible for early adolescents; and Dr. Tony Wolk who models the importance of allowing all to experience a sense of success when they have given their best.

I am also indebted to Sue Parker, the principal at Kellogg Middle School. I worked with her first as an administrative intern and I have been teaching with her for five years. 
As a friend, mentor, and middle school "expert," she has contributed to this dissertation both by her knowledge and by her constant support and "mini-celebrations" along the way.

A final world of appreciation and my deepest respect go to the middle school teachers who gave so willingly of their time to share their feelings and expertise about teaching early adolescents. At the close of each interview, usually late in the afternoon following a long day in the classroom, these teachers would continue to radiate enthusiasm about what they did and would want to share their commitment to having a positive impact on students at the most critical times in their lives. Our world will be a better place because of teachers like these. 
TABLE OF CONTENTS

PAGE

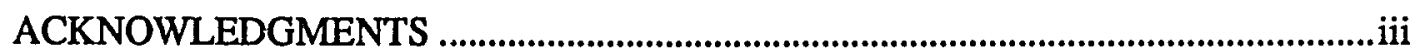

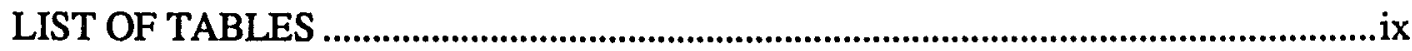

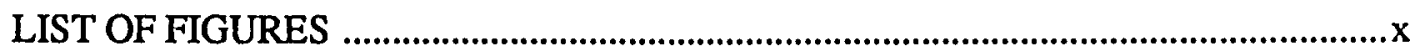

\section{CHAPTER}

I INTRODUCTION TO THE STUDY ......................................................

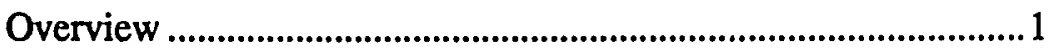

Statement of the Problem ...................................................................

Rationale for the Study .....................................................................

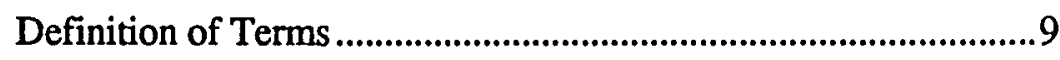

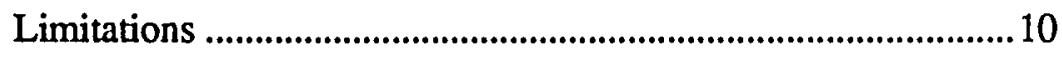

II REVIEW OF THE LITERATURE .........................................................

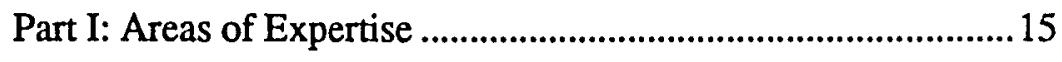

Understanding the Early Adolescent ..............................................15

Physical Growth

Emotional Growth

Social Growth

Intellectual Growth

Conclusion: Must Maintain Balance 
Teaching and Learning Strategies ........................................20

Teaching and Physical Development

Teaching and Emotional/Social Dynamics

Teaching and Moral/Ethical Development

Teaching and Intellectual Development

Teaching and Social/Intellectual Independence

Teaching and Motivation

Assessment and Evaluation

Key: Understanding the Student

Critical Elements of Middle School Organizational Structure ...29

Teaming

Interdisciplinary and Integrated Instruction

Generalist and/or Specialist

Advisory Role

Discipline

Attitude and Commitment

Part II: Enablers of Effective Teaching ......................................36

Professional Training .............................................................39

Pre-service Training

In-service Training

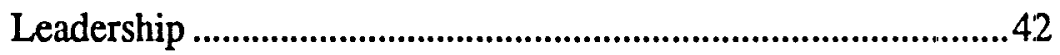

Peer Collegiality and Collaboration ..........................................44

Time and Reflectivity......................................................45

Attitude, Self-Concept, and Commitment................................48

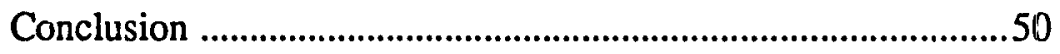




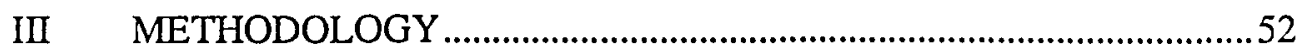

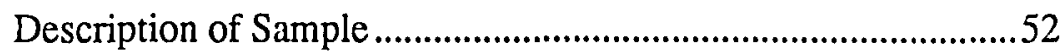

Questionnaire Subjects

Interview Subjects

Setting

Research Design and Procedures .............................................56

Design

Data

Data Gathering

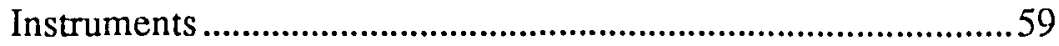

Pilot Questionnaire

Questionnaire

Interview

Limitations

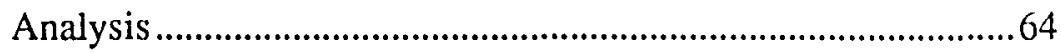

Two-Phase Analysis

Questionnaire Analysis

Interview Analysis

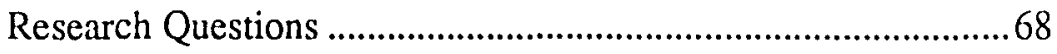

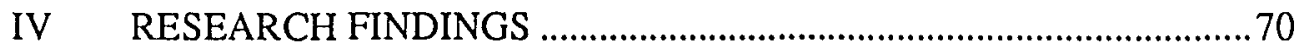

Questionnaire Findings ....................................................... 70

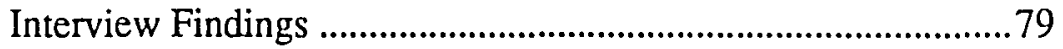

Introductory Questions and Responses

Elite Sample Defines Effective Middle School Teaching

Interviewees Perceive Selves as Effective

Most Critical Enablers of Effective Middle School Teaching

Other Important Factors

Less Frequently Mentioned Factors 
Strong Opinion and Level of Agreement

Principal, Teaming, Advisory, and Staff Development

Teacher Training Institutions which Produce Effective Middle School Teaching

A Middle School Certificate

V SUMMARY AND DISCUSSION

Questionnaire Instrument

Interview Instrument ................................................................

The Research Questions ................................................................110

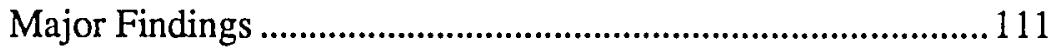

Common Philosophy

Desire to Work with Early Adolescents

Teaching and Classroom Strategies based on Needs of Early Adolescent

Middle School Teachers Need High Sense of Self-Esteem

Principal as Enabler

Effective Teaming

Advisory

Staff Development Must Involve Teachers

Teacher Training

Conclusion

Implications

Potential Applications

SELECTED BIBLIOGRAPHY

\section{APPENDICES}

A QUESTIONNAIRE

B INTERVIEW GUIDE 


\section{LIST OF TABLES}

TABLE

PAGE

I Item Analysis of Survey Instrument .............................................73

II Correlation Matrix of Survey Items ...............................................74

III Underlying Factors of Survey Instrument .........................................76 


\section{LIST OF FIGURES}

FIGURE

PAGE

1. Flow Chart Showing the Research Procedure..........................................57

2. Distribution of Instrument Total Scores................................................77

3. Differences Between Males and Females on Total Instrument Scores, Mean and Standard Deviation .................................................................78 
AN ABSTRACT OF THE DISSERTATION OF Judith Ann Smith for the Doctor of Education in Educational Leadership: Administration and Supervision presented July 1, 1992.

Title: Effective Middle School Teaching: Factors that Promote and Maintain It APPROVED BY THE MEMBERS OF THE DISSERTATICN COMMITTEE:

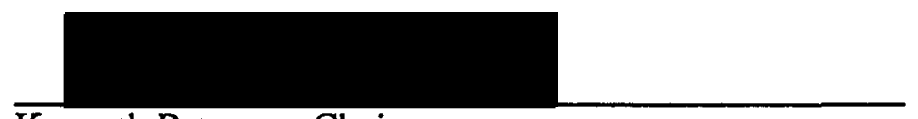
Kenneth Peterson, Chair

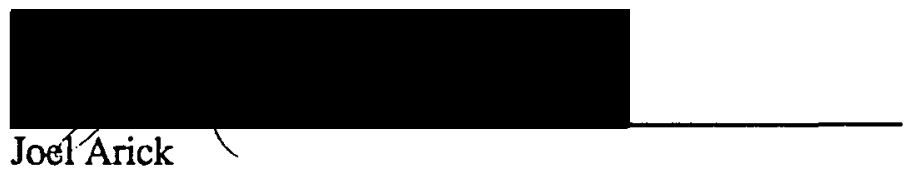
Joel Arick

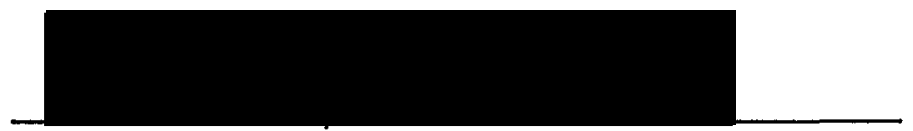

Carol Burden

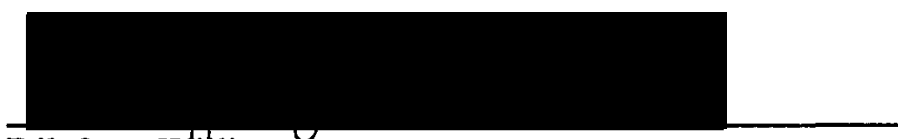

Dilafruz Witliams

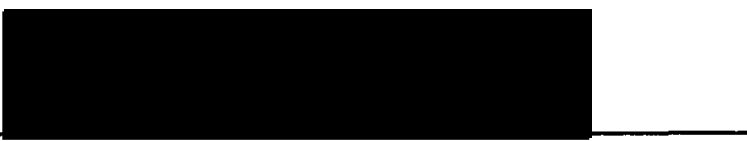

Anthony Wolk

The past thirty years has seen the middle school as an organization come of age and with it a renewed emphasis on meeting the needs of the early adolescent student. Although many current studies have addressed middle school issues, one of the most significant was the Carnegie Council on Adolescent Development's Turning Points: Preparing Youth for the 21st Century (1989). It claimed that the middle school is the 
"last best chance" to turn young lives toward a meaningful future and, in order to do so, schools must be staffed with "expert" teachers.

Once one knows what an "expert" teacher is, the major question that is raised is what factors promote and maintain such "experts?" Paying attention to these factors should increase the numbers of effective middle school teachers and therefore help meet the challenge issued by Turning Points. The purpose of this study was to learn what these factors are by listening to the "experts." Knowing these factors, their hierarchy of importance, and their potential for replication have serious implications for pre-teacher and staff training programs, hiring practices, and district policy making.

The subjects were teachers from 17 middle schools in an urban school district which started its conversion to middle schools in the 1970s. The study was conducted in two phases using a questionnaire and an interview. The questionnaire was based on the literature and developed to determine the respondent's knowledge, practices, attitudes, and beliefs about middle school teaching. The 19 top scoring teachers who agreed to follow-up interviews formed the subsequent interview group. The semi-structured one-on-one interviews elicited opinions from these self-reported "experts" regarding what they perceived to be the most significant personal and organizational factors which enable them to be effective in their teaching.

The results of the 307 valid questionnaires were reported by scale score, mean, and range, and their validity and reliability tested by Spearman-Brown, Coefficient Alpha, correlation matrix, and factor analysis. The content of the interview data was analyzed by a frequency count of reported factors.

Major findings were that "expert" teachers identified the following factors as most critical to promoting and maintaining effective middle school teaching:

1. Being able to balance academic and affective concerns;

2. Having a genuine liking, commitment, and empathy for the early adolescent; 
3. Ability to use a broad repertoire of teaching and learning strategies;

4. A concerned, listening principal who knows how to take action;

5. Team compatibility and commitment and adequate team planning time;

6. A strong belief in the advisory concept and the ability to build trust;

7. Participatory choice and teacher involvement in staff development;

8. A thorough knowledge of early adolescent needs and development.

9. Multiple exposure to and extensive experience with early adolescents during pre-teacher training. 


\section{CHAPTER I}

\section{INTRODUCTION TO THE STUDY}

This chapter presents an overview and clarification of the question: What are the most significant factors which practicing middle school teachers perceive as promoting and maintaining effective middle school teaching? It will build the rationale that, because the middle school is now considered such a critical place in which to make a difference in children's lives and it is so critical to staff the schools with increasing numbers of "experts" (Carnegie Council on Adolescent Development, 1989), researchers need to seek out these "experts" to determine which factors most enable them to be effective middle school teachers. Chapter I also defines the terms and presents limitations to the research.

\section{OVERVIEW}

Several recent studies and major reports have claimed that the young adolescent is at a unique transitional age and must be taught by middle grade specialists who are expert at dealing with this clientele. This conclusion sounds simple. However, it raises two questions:

1. What is an expert middle school teacher?

2. How does one become an expert middle school teacher?

To answer the first question, the researcher reviewed the literature to compile an inventory of purported effective middle school knowledge, practices, attitudes, and beliefs. In Phase I of the study, this inventory was synthesized and presented in a teacher 
survey which was the primary instrument in determining an elite group of effective middle school teachers who became the subjects for the interview protocol. These indepth follow-up interviews formed the content for Phase II in which the research problem was specifically addressed. In this phase, members in the elite group were asked to identify what they perceived to be the most significant factors in promoting and sustaining effective middle school teaching.

The rationale was two-fold. First, knowing these factors should better enlighten teacher training institutions, school administrators, staff development specialists, and policy makers. Second, it seemed logical that the most valid responses would come from practicing teachers. Who would better know what promotes and maintains effective teaching than those involved in the daily challenge of doing so?

\section{STATEMENT OF THE PROBLEM}

Middle schools have become a national phenomenon only in the last two decades. During the past 20 years, they have increased in number by over $200 \%$, while junior high schools have declined by about 53\% (George, Stevenson, Thomason, \& Beane, 1992). Although they were born largely to help desegregate existing schools, resolve population changes, or to help high schools meet demands for stricter graduation standards, the middle schools of today represent a unique organizational structure whose major purpose is to meet the needs of the early adolescent. Distinct from the traditional junior high school which functions more like a mini-high school, the middle school embraces a holistic philosophy of teaching which looks negatively on tracking, homogeneous grouping, impersonalization, and emphasizing academic over affective concerns. The middle school is, by now, the most widely accepted configuration between the elementary and secondary levels. 
Along with a new middle tier, however, has also emerged the need for a distinct kind of teacher. These teachers are holistic in their attitudes toward their students. They are empathetic and committed to these young people who are undergoing the most potentially turbulent years of their lives. These teachers are also creative and responsive in their instruction so that they can best meet all the varying needs and characteristics of the young adolescents. They are self-confident and comfortable in their multiple roles as teacher, teammate, colleague, advisor, and leader.

The Carnegie report, Turning Points: Preparing America's Youth for the 21st Century (1989), recommends that middle schools today must be staffed by teachers who are experts at teaching early adolescents. This recommendation is at the root of this study. Any observer of middle school classrooms can spot those who might be described as "expert." Every school has them. However, the challenge of the Carnegie report is to increase the numbers of effective middle school teachers so that only experts are teaching these young people.

How does one develop this expertise? This question presents the central research problem with which this study deals. The problem requires that one be able to define the expert middle school teacher and then determine how such teachers are developed and sustained.

A review of the literature reveals that a thorough knowledge of early adolescent needs and development is critical to effective teaching. This knowledge informs and shapes the practitioner's teaching and learning strategies, curriculum, discipline and management methods, and classroom climate. However, few teacher training institutions offer a middle school certificate or separate program designed just for middle school teachers. If such training is rarely found at the pre-professional level, is it being given through staff development programs? If so, what specific components of these in-service educational opportunities do teachers identify as promoters of more effective practice? 
Expert middle school teaching also demands an understanding of and commitment to the middle school concept with its unique organizational structure, competency in counseling early adolescents, human skills for working collegially with other adults, and individual attributes which contribute to being a positive model in action and attitude. What factors help teachers adapt and commit to the middle school organization? How does one develop the skills and attitudes which are purported to enable one to be an effective teacher-counselor, adult model, or team player?

In examining this problem, several more specific questions are asked. The literature points out the importance of the principal in promoting teacher expertise. Do practicing teachers agree that the principal is a major factor? Do téachers perceive their peers or collegial relationships as significant in any way? What is the relative importance of having adequate time for planning or reflection?

The questions above concern external factors, but what about internal ones? Is effective teaching a result of a teacher's personal attitude and commitment to the early adolescent? To what extent do teachers attribute their expertise to maturity or years of experience? To what degree is effective teaching the result of a combination of all the above? Is there a hierarchy of factors? Are they replicable?

Most educators agree that teaching is both a science and an art. Some might argue that teaching early adolescents is much more of an art than a science-that if the human connections are not made first, subject matter expertise may be irrelevant (Elkind, 1981; George, et al., 1992). In Phase I of this study, the researcher will examine factors which represent both the art and the science of middle school teaching and in Phase II she will attempt to reach a consensus as to which factors are the most significant enablers of effective middle school teaching. She hopes that the findings will have powerful implications for pre-professional training institutions, school districts, staff development programs, school administrators, and policy developers. 


\section{RATIONALE FOR THE STUDY}

During the past two decades, a general sense of public discontent with America's schools has spurred copious studies and reports now known as "effectiveness literature." A significant result of these reports was a "back to the basics" mentality and a narrow definition of teacher "effectiveness" which was determined largely by student test data. However, dropout rates and the number of students classified as "at risk" continued to escalate at an alarming rate. In some urban districts, $40-50 \%$ of the teens dropped out before high school graduation (Henry, 1990). In A Profile of the American Eighth Grader (1988), a national longitudinal study, researchers wrote, "Although most estimates are between one-fifth and one-fourth, some believe as many as one-third of the children are at risk (p. 12)." Meanwhile, national and state legislatures, school boards, and educators have scrambled to find solutions.

This problem is not simple. America's public school system is being scrutinized seriously and issues of school "choice" are now part of the national agenda. Growing numbers of at-risk children are forcing educators and policy makers to reexamine educational institutions. By and large, schools of the $90 \mathrm{~s}$ are expected to replace the home and church as traditional educational forces. Moreover, while society cries for higher standards and improved academic performance, it also expects schools to meet more and more other goals. Goodlad's (1984) research resulted in a composite list of goals for schools which include academic achievement; vocational-career awareness; social, civic, and cultural understandings; aesthetic and creativity enhancement; and emotional and physical well-being. What an awesome challenge to schools and teachers! Attempts to meet these goals are infused into educational programs with varying degrees of emphasis from preschool through high school. 
In the middle of this continuum, a relatively new organizational concept called the "middle school" has emerged. It has been created especially for early adolescent students ranging roughly between the ages of 10 and 15 . Fundamentally different from the traditional junior high school, the middle school has unique organizational characteristics, unique teaching requirements, and a distinctly unique student population. Recently, needed attention has been focused on this age. Educators and researchers are beginning to recognize that the middle grades may be the most critical level in which to accomplish the larger goals of education, succeed in keeping students in school, and make the greatest impact, either negative or positive, on students' lives.

An Agenda for Excellence at the Middle Level (National Association of Secondary School Principals, 1985), it suggested that middle school has the greatest potential as an organization which would be likely to meet the needs of early adolescents, offer instruction especially designed to be responsive to the early adolescent, and include advisories and teacher teams. The California State Department of Education's Caught in the Middle (1987) claimed that the key to success in the current educational reform movement depends on meeting the needs of middle grade students. It is at the middle school, the report insisted, that most of the youth are either turned off to school or are led to commit themselves to academic values and future lives that are meaningful and productive. The Carnegie Council on Adolescent Development's report Turning Points (1989) specifically stated that the middle level was the students' "last best chance."

Although middle schools may take many different forms, the common denominator in all the schools is the teacher. The teacher is the single most critical variable and holds the key to transforming early adolescent lives. One can argue that teachers are the key whether they teach at the elementary, middle, or high school level. However, this study will present the middle school teacher as not only the key, but also a specialist uniquely trained for and committed to the early adolescent. Although good teaching at any level 
requires many similar attributes, at the middle school it demands the humanistic qualities of the elementary teacher and the subject-oriented expertise of the high school teacier. The middle school teacher must be able to balance precariously between the two levels, constantly sensitive to when and how much emphasis to place on either.

Epstein and MacIver (1989) surveyed principals of schools where seventh graders attended to determine the most highly desired qualities in seventh grade teachers. The three most highly desired qualities were (a) command of subject area, (b) ability to increase student motivation, and (c) understanding of the early adolescent. Clearly, these principals wanted teachers who could balance the emphasis on academics with personal and attitudinal concerns.

In addition to achieving a balance in academic and affective concerns, the dynamics of the early adolescent age require teachers who are committed to this age in particular, who are willing to connect with them emotionally, and who are sensitive and insightful regarding their unique developmental needs and characteristics.

As the middle school is rapidly replacing the traditional junior high school and its organizational characteristics are becoming more clearly defined and accepted, the spotlight has shifted to the teachers who are challenged by knowing they may be the end of the line in turning around a young life. All children at any age are best served by expert teachers, but for the early adolescent such teachers are paramount. Moreover, the basic premise of this study is that not just any effective teacher can teach middle school students effectively. Such effectiveness requires middle school specialists who are truly expert at their job.

This idea is central to the Carnegie Council on Adolescent Development's report (1989). One of its eight major recommendations is that middle schools must be staffed by experts and that training and certifying specially qualified middle school teachers should be a top priority. The authors of The Middle School and Beyond underscored the 
importance of staffing middle school with "experts" when they wrote:

Even the post-Sputnik national urgency for reforming the preparation of science and mathematics teachers pales in the light of the need for expert middle level educators who are prepared for and committed to helping youngsters who are experiencing the life-threatening exigencies of contemporary adolescence. (George, et al., 1991, p. 18)

Assuming that this is true, the implications for research and for educators are profound. Researchers need to examine America's middle schools and the experts who currently teach in them. They need to study what seem to be the most responsive practices with early adolescents. In so doing, perhaps they will learn better how to stimulate, develop, and maintain teaching known to be effective in meeting the academic and affective needs of these young people.

The rationale behind this dissertation is that "expert" teachers themselves are the best source for informing universities and schools as to how best promote and sustain effective practice. Current literature is in strong agreement about the knowledge, practices, attitudes and beliefs which contribute most to effective early adolescent teaching and learning. However, only the teachers function as the primary resource when faced with the question, "What do you perceive are the most critical factors which encourage and sustain effective teaching at the middle school?"

Therefore, this study will invite self-reported effective middle school teachers to share their perceptions on what they believe are the most significant factors that enable them to be better teachers. The researchar hopes that it will be possible to replicate many of these factors. By listening to the voices of those in the trenches, those with vested interests outside the gut realities of the classroom might be better informed and able to respond to the Carnegie report's challenge. Staffing America's middle schools with "experts" should be a top priority for those who share the conviction that the young 
adolescent is at a major turning point in life and needs the very best the educational system can offer.

\section{DEFINITION OF TERMS}

Early adolescent-One who is approximately $10-15$ years old and is characterized by dramatic changes physically, intellectually, emotionally, and socially. This period in the student's life includes the period known as puberty (sometimes referred to as a time of biological upheaval).

Effective middle school teaching-A balance achieved in meeting both the cognitive and affective needs of the middle school student. In effective middle school tenching, the teacher emphasizes academic integrity at the same time an emotional connection is made with the students (Caught in the Middle, 1987). This study assumes that when a teacher meets all of the needs of the whole person and employs the strategies considered most appropriate for use at the middle school, increased student learning will result.

Effective middle school teaching is not defined by statistical data or academic test scores. This study is based on the belief that effective teaching allows students to work up to capacity and produce their personal best (Glasser, 1990), motivates the student to commit to academic values, and capitalizes on this unique transitional age by inculcating and fostering in the student the attitudes and values that assist in the development of a self-actualizing and productive adult.

Enabler-Anything which provides the means, opportunity, power or authority to do something; to make possible or effective (Neufeldt \& Guralnik, 1988, p. 446). This study uses "enabler" as a positive term denoting "a factor which promotes and maintains effective middle school teaching."

Expert teacher-One who has acquired the ability to enhance student development cognitively, effectively, and morally; who can convey knowledge and assess learning 
through multiple paths; who knows how to integrate knowledge; who can work positively with other professionals and parents; and who can match instruction with developmental characteristics and readiness of students (Kramer, McKibbin, \& Dumas, 1990). The "expert" teacher also supports the unique organizational structures and demands of the middle school and is attitudinally committed to teaching middle schoolers. In the context of this work, the term "expert" is synonymous with "effective."

Middle School-A school which is dedicated to meeting the needs of the early adolescent learner (usually grades 6-8) through a comprehensive program that is designed to address physical, social, emotional, and moral concerns in a balanced and successoriented climate (Wiles \& Bondi, 1986a). The middle school commonly has an "advisory" and utilizes teacher teams.

\section{LIMITATIONS}

The subject of this dissertation presents some conceptual limitations in that there is a certain imprecision in the language itself. Although the definition of terms can state the researcher's interpretation of a term, it is possible that for others the term is too abstract or subjective. For example, "effective middle school teaching" and "expert teacher" are terms not tied to a specific variable or even linked to a particular quantifiable outcome. Is a teacher "effective" only when the results are higher student test scores? Is one effective if students end up feeling good about themselves and decide to stay in school? How does one measure these outcomes?

The goal in this dissertation is to link "effective teaching" with what the literature says are the most desirable and successful practices and beliefs. One assumes that teachers who most closely approximate the findings in the literature will have valuable input regarding critical factors that assist them as teachers to meet the multiple demands 
made on them as middle school teachers. In the researcher's opinion, the limitation presented by a lack of precision or measurability of the terms does not seriously threaten this study because they were never intended to be linked to a specific outcome.

The main limitations of the study have to do with methodology. First, the fact that there was only one interviewer disallows inter-rater reliability. Second, the interviewer was a participant-interviewer rather than a neutral observer. Therefore, because the interviewer brought both middle school expertise as well as a vested interest to the interviews, the interviewer was not entirely bias-free. The interviewer might have a tendency to produce a response effect by seeking out the answers that support her preconceived notions. However, the argument might be made that this weakness is also a strength in that the participant-interviewer brings inside knowledge, a common language, and a sensitivity to nuances and descriptions which a totally neutral interviewer might not perceive. This allows for more robust and descriptive interpretation of the interview findings. An insider has a better ability to discuss, prioritize, understand, and describe interviewee responses.

In this study the researcher attempted to minimize response effects by carefully following the interview guide. A conscious effort was made to avoid making comments or gestures of approval or disapproval, and every attempt was made to record each respondent's answers as exactly as possible and to transcribe the notes within 24 hours for later analysis.

A second limitation was that the interview sample was limited and restricted to a single urban school district. It is unlikely, therefore, that this study has ascertained all the factors that promote and enhance effective middle school teaching. However, the goal of this research was to discover some of the factors, not necessarily all of them. This dissertation will make no claims that it accounts for all the factors that promote effective teaching. 
Time and logistics prohibited interviewing a larger sample and restricting the study to one large urban school district was deliberate because: (a) it was a district which had been fully committed to the middle school concept for at least 20 years, (b) it had more than 750 middle school teachers, and (c) the research question required middle schools which were fairly homogeneous organizationally. 


\section{CHAPTER II}

\section{REVIEW OF THE LITERATURE}

The importance of the middle school and those who staff it cannot be underestimated. The middle school is "potentially society's most powerful force to recapture millions of youth adrift," stated the Carnegie report Turning Points: Preparing American Youth for the 21st Century (1989, p. 8). Lounsbury (1990), editor of the Middle School Journal, wrote, "I am convinced that if our society is to be regenerated, if the old values of our society are to be reaffirmed, the middle level school must be the birthplace of this renewal" ( p. 4). Moreover, because early adolescents are still pliable and developing, the middle school is critically important for repairing damage from the previous years, thus avoiding permanent damage which could have serious life-long consequences (Fielder, 1978). Educational consultants Wiles and Bondi (1986a), stressed that the middle school "is the most exciting educational idea ever conceived in the United States" (p. 41).

It is not the grade configuration, the curriculum which must be taught, amount of money spent on the program, demographic factors, nor even the principal which are most critical in the middle school; rather, it is the teacher who holds the key to creating the type of middle school which is most beneficial for emerging adolescents (Wiles \& Bondi, 1986a). Johnston and Markle (1986) pointed out that in spite of the theorists, curriculum specialists, management experts, textbook writers, educational researchers, or school administrators, "there is nothing they can do to affect the classroom learning environment which is not mediated by the classroom teacher" (p. 19). Teachers are the torchbearers and the foundation of the life-transforming middle school. They are the ones who can 
provide constructive interventions, guidance, and education that will have a positive and powerful influence on the lives of early adolescents (Johnston \& Markle, 1986; Lounsbury, 1990; McPartland \& Wu, 1988; Wiles \& Bondi, 1988b).

Turning Points (1989) makes eight recommendations for creating middle level schools which are more effective in teaching young adolescents. One of them is to staff middle grade schools with teachers who are "expert" at teaching 10-to-14-year-olds. What is "expert" teaching? A review of the literature revealed that expert teaching at the middle school includes four major areas: (a) a thorough understanding of the early adolescent, (b) the ability to use multiple learning and teaching strategies known to be effective with adolescents, (c) a willingness to teach within the organizational setting and demands unique to the middle school, and (d) an attitude and commitment embracing the middle school concept. One can assume that effective teaching results when one has a balance of expertise in all four areas.

This assumption raises a second question: What promotes the development of these areas of expertise? Are some factors more important than others? Which factors seem to be the most critical for promoting and maintaining expert teaching?

An examination of these questions is the major purpose of this dissertation. A review of the literature will be the basis for Phase I of this study. A questionnaire, based on a review of the literature, will ask practicing middle school teachers to self-report their knowledge, practices, attitudes, and beliefs about teaching at the middle school. Phase II of this study is an interview instrument which will examine what an elite sample of "effective" middle school teachers report to be the most significant factors which assist them in being effective. The issues developed in this chapter will help inform the interpretation of the interview findings. 


\section{PART I: AREAS OF EXPERTISE}

\section{UNDERSTANDING THE EARLY ADOLESCENT}

Middle school teachers must be aware of problems experienced by early adolescents and be thoroughly grounded in an understanding and appreciation of the years surrounding puberty - the most dramatic and critical period in the human life (Alexander \& McEwin, 1989; Doda, 1991; Eichhorn, 1966; Lounsbury, Maroni, \& Compton, 1980; McEwin \& Thomason, 1989). Early adolescence is a time of transition, excitement and discovery. During this period "changes in interests and attitudes assume formidable proportions" (Eichhom, 1966, p. 67). Beane and Lipka (1986) wrote that adolescents who emerge from this period of transescence are usually very different from the children they were at the onset. A potentially dynamic and satisfying stage in the growth and development of the child, early adolescence is a period which simply cannot be ignored (Eichhorn, 1966). Eichhorn further cautioned that if early-adolescent-stage-related concerns are not addressed and resolved, they will have a great impact on the quality of an adolescent's life now and in the future. Lipsitz (1984) insisted that schools will succeed only when they respond to the diverse developmental needs of the young adolescent—one who is "at once socially younger and biologically older." (p. 6)

\section{Physical Growth}

Puberty occurs for most between the ages of 10 and 15 and involves the period of greatest physical growth. Throughout childhood growth is fairly steady and predictable. However, the early adolescent undergoes a period of accelerated development and upheaval as great as any experienced except during infancy (Eichhorn, 1987). Because pre-adolescents' bone growth is faster than muscle, their bodies are often gangly, their movements awkward. They also have short attention spans, are restless, tend to over- 
exert and fatigue quickly. A tremendous physical variation also exists between middle schoolers; extreme differences in height and weight are often quite comical. These differences in development, however, also frequently cause great anxiety and negative self-concept.

Increases in hormone production and sexual changes result in further developmental differences and have major emotional and social implications. A capacity for sexual activity necessitates a need to redefine the self in terms of both one's sexuality and one's relationship to others (Beane \& Lipka, 1986). This also portends an identity crisis which must be addressed.

\section{Emotional Growth}

A study in contrasts, early adolescents live in a period of emotional turmoil, storm, and stress. They are both egocentric and sensitive, exuberant and depressed; powerful and unlimited, vulnerable and insecure; stable and rational, then irrationally emotional and unstable (Gatewood, 1975). Their emotions play a key role in their behavior as they soar to sudden, passionate love and plunge to intense anger and hate. Early adolescents face chronic stresses which complicate their emotional turmoil. This period of transition itself heightens vulnerability to stress (Strubbe, 1989) and it is imperative that teachers deal with these concerns and help students develop problem solving and decision making skills. Strubbe's (1989) study of the most chronic sources of stress for 3382 students in grades six through eight found that failing a subject was listed as the number two stressor, preceded only by having a close friend die. Flunking a grade was ranked number four, above the stress of having a parent die. This study suggests that middle school teachers have a great deal of control over the emotional well-being of their students and should seriously reexamine the emphasis that is placed on academic achievement over the needs for a caring, supportive environment and the need to experience a high degree of success. 


\section{Social Growth}

During this stage in life, peers also take on great significance. Most early adolescents become more critical of adults and demand greater independence. They try desperately to fit the norm and avoid being "different." They are confronted with the conflict of peer values versus parental values. This conflict results in an "uncomfortable dissonance between the self-perceived need to be an accepted member of the peer group and to retain the security of family membership" (Beane \& Lipka, 1986, p. 21). This dissonance includes teachers, school administrators, and other adults of authority. However, peer interaction is necessary for early adolescents because it enables them to reexamine their precepts and concepts in the light of their peers. Teachers must recognize this. Failure to do so may cause emotional stress for the student and increased discipline problems for the teacher. The challenge to the teacher is to create an environment where peers can interact, thus reducing emotional tension and aiding in the process of emancipation wherein students experience a larger world (Eichhorn, 1966; McEwin \&Thomason, 1989).

\section{Intellectual Growth}

Early adolescence also presents a unique intellectual period. According to Piaget's (1972) research, the child moves from the concrete to the "formal operations" stage somewhere between 10 and 14 years of age. However, as with physical development, intellectual development is greatly varied and unpredictable. Many remain at a concrete level of thinking throughout their middle school years. A recent study by Stefanich (1990) calculated approximate percentages of cognitive levels of the subjects in Piaget's tests which were, reported in 1979 by Epstein, a prominent researcher in brain growth. Stefanich found that approximately $6 \%$ of the 11 -year-olds were at the pre-operational stage, $89 \%$ at the concrete stage, and 5\% were moving toward the formal stage. By 12 years of age $12 \%$ were at the onset of the formal stage, at 13 years there were $13 \%$, and at 
14 years there were $15 \%$. Most middle schoolers remain solidly in the concrete stage throughout their entire early adolescent period. The obvious implication for middle school teachers is that they must relate instruction to the real world and involve much active manipulation and many hands-on experiences.

It is also critical, however, that teachers effectively challenge those who are at more advanced cognitive levels. They need to be stretched and pushed in their intellectual capacity for increased abstraction. According to Bruner (1960), one learns through a series of successively more difficult learning tasks. Structural learning props are removed and new ones constructed as the level of cognitive development increases. Although theories for "concept attainment" are not recommended exclusively for the early adolescent, it is critical that middle level teachers recognize that many of the students are also in the middle of transition cognitively. This phenomenon requires teachers who possess a vast repertoire of teaching strategies and a solid understanding of educational theories.

Rate of brain growth is another area in which early adolescents greatly vary. Rapid brain growth occurs in most 10- and 11-year-olds; however, by age 12 most reach a plateau where there is minimal growth of new brain cells. This may last until 16 years of age. Learning does happen, but the student finds it difficult to deal with new concepts or tasks that are cognitively too complex. Ignoring this dynamic can lead to frustration and the student may develop a self-concept of being "dumb," which in turn leads to a loss of self-esteem (Beane \& Lipka, 1986; Hensley, 1985).

\section{Conclusion: Must Maintain Balance}

A convincing number of educators and researchers stressed the need for teachers who are firmly grounded in an understanding of early adolescent growth and psychology. Effective instruction at the middle level emphasizes academic achievement while making emotional connections with the students. Lounsbury (1991b) wrote, "Education in its 
fullest sense has to involve heart as well as mind, attitude as well as information, spirit as well as scholarship" (p. 5). Young adolescents will respond to academic challenges "in direct proportion to the ability of the school staff to ameliorate their emotional and social anxieties" (Caught in the Middle, p. 91).

Teacher "effectiveness" cannot be reduced to data based on standardized tests. At the middle school "effectiveness" includes a much greater concern-concern for the whole person. Beane (1990) wrote about the early adolescent: "They are not simply variables that make up statistical pictures of an abstract category called 'early adolescent.' Instead they are real people; living participants in an evolving collage of life experiences" (p. 65). If this emerging adult is not nurtured educationally, has low selfesteem, has no connections to positive role models, is not validated as a person, and is turned off to school and society, of what purpose are the textbooks and lessons? That child will fall through the cracks and add one more to the already frightening number of students classified "at risk" (Lounsbury, 1991b).

It is not a question of which comes first-academics or human values-rather it is a matter of balance. All the needs-physical, social/emotional, intellectual-must be met equally. Although this is wise at any school level, it is particularly critical at the middle level. No other period presents such potential for change, whether it be positive or negative (McEwin \& Thomason, 1989). Eichhorn (1966) insisted, "The point is all too clear that educators have a responsibility to consider the transescent's needs as their 'engine' and not the 'caboose"' (p. 23). This belief requires that everything middle school teachers do-teaching strategies they use, classroom climate they create, form of discipline they apply, collegial relationships they develop—must be driven by the intellectual, physical, social, emotional, and moral needs of the students. 


\section{TEACHING AND LEARNING STRATEGIES}

Teaching effectively at the middle school level is not possible without considering the unique cognitive, affective, and psychomotor needs of the students. All teaching and learning strategies are driven by an understanding and genuine concern for early adolescent developmental needs. Therefore, middle school teaching requires a broad repertoire of instructional models which are responsive both to the adolescent and to the values, objectives, and needs of the society (Lounsbury, 1990). Attention must also be given to the fact that middle schoolers increasingly need independence. Once they have left the more structured environment of elementary school, they need to learn more independent study skills, learning strategies, and organizational techniques. Thus, a strong combination of learning strategies and basic study skills help create the foundation necessary to manage successfully the less personalized climate of high school. Whereas in grade school few students question the value of what they learn, in middle school they need to be convinced of its meaning and relevance.

Porter and Brophy (1988) described teachers who teach effectively as those who exercise their own judgment rather than operate as programmed technicians. These are teachers who initiate, plan, think, and adapt curriculum and teaching strategies to fit student needs. They are directors of learning rather than disseminators of knowledge. In surnmary, as middle schoolers evolve in their identities and grow in independence and sophistication, "the need to provide a great variety of learning opportunities while

utillizing many different teaching techniques that recognize the developmental realities of early adolescence becomes a mandate" (McEwin \& Thomason, 1989, p. 17).

\section{Teaching and Pbysical Development}

The first characteristic to consider when teaching the early adolescent is physical changes. Gatewood (1975) referred to problems brought on by the heart developing more 
slowly than the rest of the body, the tendency for blood to pool in the lower extremities, bone growth occurring faster than muscle, and the uneven development of glands and secretion of hormones. These problems, Gatewood continued, contribute to restlessness, drowsiness, fidgeting, dramatic ranges of energy and emotions, and even pain. Effective teaching responds to these problems by allowing much physical movement and by providing a variety of action-oriented hands-on activities which titillate student curiosity and interest (Becker, 1990; Doda, 1991; Lounsbury, et al., 1980; Silvern \& Wiles, 1978; Stefanich, 1990). Effective teaching encourages peer collaboration both formally and informally, and motivates students to become involved in their own learning.

Additionally, effective teaching is flexible and innovative in responding to varying attention spans. It also accommodates individual learning styles by including multiple tactile, visual and auditory experiences throughout the daily lessons. Such teaching creates purposeful opportunities for students to make choices and decisions regarding their learning activities. It allows for those who prefer to work quietly alone and those who need to move about or interact with peers. This flexibility resolves many of the physical problems and behavioral issues, and gives the students more opportunities to assume ownership and responsibility for their own leaming.

\section{Teaching and Emotional/Social Dynamics}

Middle school teachers must also be keenly aware of social and emotional dynamics. Insensitivity to these issues will result in failure in the classroom. Early adolescents experience extreme mood swings which can present major obstacles to learning. Often a teacher must resolve social or emotional problems before moving on to cognitive ones.

Also, because peers are so important to the early adolescent, effective teaching must capitalize on this dynamic by employing teaching strategies which include cooperative learning, peer tutoring, and much group interaction. Studies show that allowing for peer 
interaction results in increased learning, more student satisfaction, and greater positive self-concept. Moreover, cooperative learning creates many opporturities for every student to experience success because students can each make contributions and demonstrate different talents (Lounsbury, et al., 1980; Slavin, 1981).

Glasser (1990) underscored the value of "student-centered classrooms" which meet the early adolescent's basic needs for power, freedom, and fun. Teachers in these classrooms include noncompetitive activities, opportunities for student leadership, and student-made choices such as where to sit and what rules and plans to follow. They provide student-centered discussions, foster self-expression, respect diversity, welcome the whole child, and seek to build strong classroom bonds.

Because this period of transition already creates a heightened vulnerability to stress, middle school teachers must be increasingly aware of personal stressors and attempt to minimize additional stressors such as tests, grades, or "flunking." Teachers need to make certain that the classroom environment is supportive, that multiple and varied opportunities for success are provided, and that students are guided toward problem solving and decision making strategies to help alleviate over-reaction to stress (Strubbe, 1989).

Doda (1991) wrote that middle school teachers must build a "community" which helps students get to know each other, the teacher, and themselves. Rather than allow the characteristics of early adolescents to be obstacles to learning, effective practice capitalizes on the energy, emotions, curiosity, and fascination with the peer culture and allows them to add a fresh dynamic of creativity and excitement to each day's lessons. When these affective and social concerns become basic to the classroom, insisted Doda (1991), it is a teacher's chance to make a real difference, “. . . and to the middle school child, it is the difference" (p. 15). Doda, George \& McEwin (1987) claimed that the 
teachers which middle schools need are those who "work to weasel their way into the hearts of the young adolescents they teach" (p. 5).

\section{Teaching and Moral/Ethical Development}

Middle schoolers are also increasingly searching for moral and ethical meanings. Teachers at the middle school must create lessons which grapple with values, attitudes, and making decisions. Because teachers are also significant role models to these impressionable and questioning emerging adults, their words and actions can have a profound effect on student attitudes (Johnston \& Markle, 1986). After a study with eighth graders, Gilligan (1988) advised teachers to bring together emotional and empathetic responses as well as reflective thinking. This, Gilligan suggested, "may sustain moral sensibilities that are 'at risk' as formal reasoning develops, even as it expands moral awareness" (p. 88).

\section{Teaching and Intellectual Development}

The intellectual develof sent of early adolescence also requires knowledgeable and informed teachers. This is an age of cognitive transition. Stefanich (1990) claimed that according to Piaget's Geneva studies the greatest percentage of middle schoolers remain at some level of concrete thinking. Piaget, Stefanich continued, also found that teachers cannot demand thinking beyond the cognitive level in which the student is functioning. As facilitators of learning, teachers must understand this phenomenon. Concrete learners need active, experiential hands-on activities and real-life situations in which to learn. When that is not feasible, then semi-concrete opportunities must be offered such as visuals, simulations, demonstrations, illustrations, games, field trips, or role playing. If a teacher instructs at a level beyond a student's cognitive abilities, Stefanich (1990) asserted, it will result in frustration, repeated failure, and "learned helplessness"-an attitude that says, "I can't do it, so why try?" Because early adolescents also have 
intense, though short-lived, interests in a wide variety of topics, concepts must be presented at a rapid but attainable pace (McEwin \& Thomason, 1989).

Middle schoolers also need a curriculum which relates to the here and now. Their lives are very egocentric and they have a difficult time relating to their own history much less that of the ancient Greeks and Romans. Thus, teachers must focus on the present and relate instruction to the students' own lives and personal experiences whenever possible. This helps create meaningful learning which can be applied to new situations in the future.

However, educational theorist Ausubel (1960) insisted that although it is desirable to teach by discovery and hands-on, it is still possible to teach effectively by using "advance organizers" which assist concrete learners in visualizing an activity and by creating sequential steps which create an intellectual scaffold on which to "hang" the new concepts. The key to learning is connecting the new concepts to pre-existing knowledge. As more knowledge is acquired, new structures are added to the intellectual scaffold and the learner can climb higher up the cognitive ladder. Teachers are cautioned, however, to limit the speed and number of new concepts; it is easy to overwhelm and frustrate middle schoolers. Teachers also must create multiple exposures to each concept using contextual clues, visuals, and experiential applications whenever possible.

Effective and experienced middle school teachers recognize that because some of the students are at or are transitioning into a formal cognitive level, they need to be encouraged to integrate, synthesize, and evaluate new learnings and abstract concepts. Thus, effective teaching always includes opportunities for cognitive stretching to the extent that every student is intellectually stimulated at the appropriate cognitive level. This means that within each lesson there are activities and levels of learning which challenge every student without creating frustration or boredom. 
Over-reliance on commercially prepared textbooks or materials can be deadly. Too often these are written only at knowledge and comprehension levels of cognition and are routine and boring. Effective middle school teachers utilize a variety of materials as well as models of instruction. In order to accomplish this, teachers must know their subject content and be able to use competently and comfortably many different direct and indirect teaching strategies. A word of caution, however, possessing a broad repertoire of teaching strategies is one thing; knowing when to use them is another. Beane (1990) suggested that schools would be well advised to trust the instincts of experienced effective teachers.

\section{Teaching and Social/ntellectual Independence}

Middle schoolers need teachers who will help them solve problems, think critically, and make informed decisions. At this vulnerable and critical point in early adolescent lives, middle schoolers are moving toward social and intellectual independence and they need significant adults as role models and guides. Aside from possibly the parent, it is the teacher who usually has the most influence on students. In order to develop healthy social and intellectual emancipation, the effective teacher must demand that student opinions be backed by fact, confront misconceptions or prejudice, and model questioning and reasoning behavior. Middle schoolers tend to live in a simplistic world with simplistic solutions-a "just blow them up" attitude. Effective teaching raises complex controversial issues; probes alternative solutions; encourages questions as well as answers; promotes speculation, moral reasoning, and reflective thinking; and raises the collective conscience to a heightened awareness of individual egocentrism and ethnocentrism. Effective teaching also increases in students their ability to make informed aesthetic judgments from literary works to music and the arts (Caught in the Middle, 1987; Johnston \& Markle, 1986). 


\section{Teaching and Motivation}

The final teaching and learning issues upon which early adolescent developmental characteristics have an impact are motivation and assessment. Brophy (1987) places the responsibility of motivating students to learn squarely on the teacher. It is the classroom teacher who must build the supportive environment which enables these extremely peerconscious students to take risks without fear of failure or ridicule.

First, motivation begins with teachers who truly believe that all students can succeed. Mufson, Cooper \& Hall (1989) found that a major factor associated with achievement had to do with this self-fulfilling prophecy: if teachers expect success the student is more likely to experience it. The reverse is also true; the less teachers expect, the less they get (Brophy, 1987; Doda, 1991; Mufson, et al., 1989; Stefanich, 1990). Middle schoolers are so varied in their learning abilities, however, that in order to insure success teachers must be very innovative in creating opportunities and activities which meet this diversity. Strubbe (1989) also cautioned middle school teachers to reexamine the extreme emphasis often placed on academic achievement. If academics are over emphasized without considering other developmental concerns, early adolescent stress and anxiety which already act as barriers to concentration and success will be compounded.

Second, teachers must stimulate motivation by getting their students to care about learning. How can this be done? Teachers can stimulate and motivate by teaching relevant, student-centered, meaningful subject matter. Students must be convinced of the value and usefulness of what they are asked to do. Because most middle schoolers are usually concrete thinkers, effective teaching attempts to relate all lessons to the "real" world and the immediate concerns and interests of early adolescents. Assignments need to have an obvious application to the immediate environment (Beane, 1990; Silvern \& Wiles, 1978). 
Learning experiences further motivate when they relate to students' immediate needs, goals, and purposes. In an article discussing Glasser's "control theory" and what motivates the "workers," Farris (1990) wrote that adolescents have certain needs which, when satisfied, give them a sense of control and thus motivation to maintain that control. Effective teaching recognizes the students' needs for power and freedom by allowing opportunities for student leadership, choices in seating arrangements, and a voice in daily decision making, planning, and studies. Students need to participate in developing classroom rules and procedures. When they are a part of the "management" they are more motivated because they have vested interest in making it work and in maintaining their power and freedom.

Somewhat antithetical to their desire for independence, most middle schoolers have a strong need for love and belonging. Teachers effectively address this need when they actively promote bonding between class members and the teacher, encourage a genuine spirit of caring about each other, build a family ethos, and celebrate success stories big and small. Addressing these issues is enhanced by the frequent use of cooperative learning groups and by intentionally but judiciously creating opportunities for students to socialize.

Finally, middle schoolers have a need for fun. Teachers can help meet this need by encouraging laughter, pleasure, and a sense of satisfaction and success. Effective teachers model energy and enthusiasm and seek ways to make learning creative and enjoyable. They are actively involved in their teaching and, added Doda, et al. (1987), effective middle level teachers do not sit down while they teach. This alone makes a subtle but powerful statement to the students.

\section{Assessment and Evaluation}

Too frequently the great inhibitor to motivation is evaluation. Studies by the United States Department of Education (National Center for Educational Statistics, 1988) 
revealed that self-concept is directly correlated with student grades. Thus, evaluation must always consider the whole child-ability level, effort, extra contributions, search for self and social meanings, improvement-not just isolated statistical data generated from paper and pencil tests. Evaluation must involve multiple sources for assessment such as projects, reports, and portfolios (McDonough, 1991). Moreover, the students should always be a part of the evaluation process (Doda, 1991). As participants in the ongoing evaluation process, students begin to assume more personal responsibility for their own learning and greater independence from the teacher. Evaluation should emphasize formative rather than summative assessments (Stefanich, 1990). In fact, insisted McDonough (1991), grades actually become irrelevant. With constructive and timely feedback, formative evaluation which shows progress along a continuum of learning is more individualized and meaningful, is less threatening, and is itself an important teaching tool. Teachers must remember that the learning objective is more important than just completing an assignment (Doda, 1991; McDonough, 1991).

\section{Key: Understanding the Student}

In summary, to be effective at the middle level, teachers must first know and understand the unique physical, emotional, social, moral, and intellectual developmental characteristics of early adolescents. They must then be able to integrate that knowledge into how and what they teach, how they motivate, and how they evaluate. How do effective teachers do this? To find the answer, Beane (1990) suggested schools would be well advised to study effective and experienced middle school teachers. The answer lies in their beliefs and actions. 


\section{CRITICAL ELEMENTS OF MIDDLE SCHOOL ORGANIZATIONAL STRUCTURE}

The third major area of concern for developing expert teachers has to do with the uniqueness of some of the middle school organizational structures and key practices: teaching in teams, integrating instruction, being both a generalist and a specialist, and functioning as both a counselor and skilled disciplinarian. Many of these practices can be found to varying degrees at both the elementary and secondary levels; however, at the middle level they are critical. The attitude and commitment of the middle school teacher to these practices can be considered the glue which keeps them together as a cohesive whole and makes them work.

\section{Teaming}

Throughout elementary school students usually spend most of their day in one classroom with one teacher. Middle school teachers need to assist students in transitioning from the self-contained classroom to the largely segmented, less personal environment of high school. Middle schools function as a bridge and make this transition smoother by scheduling classes for extended uninterrupted blocks of instructional time and having teachers work together as a team (Alexander \& McEwin, 1988; Caught in the Middle, 1987; Merenbloom, 1986). Most experts on this subject recommend that the team be composed of four or five teachers with different speciality areas or be grade level teams with common cores.

No matter what the makeup of the team, the most essential thing is that the teachers share the same students and have the opportunity to work together with the needs of the common students in mind (George, 1983). Teachers in the team must try to know all the students and the students should know the teachers. Every team member deals with the needs and concerns of individual students and builds connections with them. Team teachers collectively assist with student academic, emotional, and social development. 
These teachers collaborate on team planning, advising, and scheduling. This means, therefore, that middle school teachers need a commitment to the team approach and must have the necessary personal and social skills to work in collegial relationships with other staff members (MacIver, 1990; Buan \& Olson, 1988). If they are an interdisciplinary team, "teachers will be responsible for educating other teachers about the importance of key principles, concepts, and facts within their discipline, and for working with colleagues to find common ground in the subjects that they teach" (Turning Points, 1989, p. 59).

In a research study by Aahar (1990) he found that the benefits of teaming had two positive results: (a) higher academic achievement and (b) stronger social bonding. Out of 2,500 seventh graders in the study, those from interdisciplinary teams scored significantly higher academically and the social bonding was much greater. The author suggested that social bonding might be the antidote to alienation, thus presenting a lowcost intervention for at-risk students.

\section{Interdisciplinary and Integrated Instruction}

A second desired practice in middle schools is to promote interdisciplinary and integrated instruction. Although these concepts are still evolving and their definitions take different forms, recent literature agrees that middle school teachers need to develop relationships among subjects.

Balanced and integrated instruction, wrote Porter and Brophy (1988), is more effective than instruction "that tries to develop knowledge or skills in isolation from one another or that emphasizes certain objectives but slights others that are equally important" (p. 78). Vars (1987) found that forty years of research and more than eighty studies revealed that students who have participated in interdisciplinary instruction perform as well as or better on standardized tests than those exposed only to traditional subject area curricula. 
Beane $(1991,1992)$ went beyond those who argue that there should simply be subject connections. This current guru on integrated instruction insisted that students drive the curriculum. Their questions and concerns should become the basis for curriculum themes and the planning process. Beane maintained that early adolescents especially need this kind of curriculum because at this developmental stage they are searching most for their personal meaning and identity within the larger culture.

The point here is not to defend interdisciplinary or integrative instruction, but to present the fact that these curriculum innovations are a part of the evolving middle school reform movement. Teachers, therefore, need to be knowledgeable about the different approaches and be able to plan thematic units, utilize a variety of resources, and implement them (Beane, 1990; Caught in the Middle, 1987; Porter \& Brophy, 1988; Stefanich, 1990).

Middle schoolers require multiple opportunities to perceive relationships between subjects and to apply complex thinking through involvement in thematic interdisciplinary curricula (Caught in the Middle, 1987). Interdisciplinary integrated instruction also includes the infusion of both analytical and physical/cultural curricula. According to Eichhom (1966), it involves peer interaction, students at all levels of cognition and maturity, physical movement, experiential learning, and evaluation processes which eliminate the need to fail any student.

\section{Generalist and/or Specialist}

The third element of the middle school organization is the need for teachers to be both generalists and specialists. This element requires teachers who are experts in one or two academic disciplines, able to team teach, integrate their instruction, develop their own curricular materials, teach holistically, and nurture middle schoolers in a collaborative interactive environment. This type of expertise is far more demanding than 
being responsible only for one's subject area and dispensing academic knowledge without regard for the emotional, social, physical, and moral development of the child. Yet expertise in one or preferably two academic areas is also recommended for effective middle school teaching. The effective middle level teacher must be far more than simply qualified to teach a subject. A middle school teacher must first be child-centered and then subject-centered. "The success of the transformed middle grade school will stand or fall on the willingness of teachers ... to invest their efforts in the young adolescent students. Teachers must understand and want to teach young adolescents and find the middle school a rewarding place to work" (Turning Points, 1989, p. 58). The California Task Force Report, Caught in the Middle (1987), stressed equally the need for middle grade teachers to be prepared in three ways: (a) specialized knowledge of the core curriculum, (b) acquisition of multiple teaching strategies, and (c) comprehensive knowledge of early adolescent characteristics. The study stated that during the critical, formative middle school years it is particularly important for teachers to have human skills. Middle grade teachers are expected, therefore, to deal with students in one of the most intense periods of change in their lives, and to do so "without compromising the integrity of the curriculum and without any diminishing of student achievement as measured by standardized tests" (Caught in the Middle, p. 127).

\section{Advisory Role}

Fourth, at no other level does the classroom teacher play such a prominent counselor/advisory role than at the middle school. Effective middle school teaching involves helping early adolescents with the social and emotional support they need. This demands teachers who genuinely care about the students; look out for their interests; discuss academic, personal, and family problems; foster career development, selfconfidence and leadership; and counsel them about peer relationships, health, or ethical 
issues. Effective teaching heightens multi-cultural awareness, helps students better understand themselves, helps them be more sensitive to others, and teaches them to exercise a measure of control over their own lives (Gatewood \& Dilg, 1975; MacIver, 1990).

A national survey of middle school practices (Center for Research On Elementary and Middle Schools, 1988) found that $40 \%$ of the nation's middle schools require the teacher to be an advisor to the same students throughout all of their middle school years. In this role, teachers take on much more than just being an advisor/counselor in the classroom. They must be competent referral /agents and effective links between school and home over the course of 3 or 4 years (Alexander \& McEwin, 1988).

Porter and Brophy (1988) contended that less effective teachers tend to turn this advisory role over to others such as the "management specialist," the remediation personnel, or the school counselor. Effective teachers, on the other hand, involve themselves with the students as they struggle with problems, beliefs, and value commitments. These teachers realize the importance of their own moral example and the fact that the basic development of adult values is formed in the middle grade years (Caught in the Middle, 1987). This characteristic of effective middle school teaching emphasizes the unique qualities needed in the teacher and prompts one to ask if teaching at the middle school is more of an art than a science.

\section{Discipline}

The last major area which is critical at the middle school is with discipline. The main thrust in a successful middle school is to assist the students at the onset of adolescence to develop into independent, internally controlled young adults who intrinsically know how to make appropriate choices. This translates into teachers who are far less authoritarian and parental. However, this does not happen the moment the 
student first walks through the schoolhouse doors. Much teacher time is devoted to inculcating behaviors, judgment, and attitudes which will result in greater self-control, responsibility, and autonomy. The process is slow and often misunderstood by outsiders. However, the goal is to wean students away from needing custodial controls and to assist them in becoming self-managers (Beane \& Lipka, 1986).

MacIver (1990a) stressed that as young adolescents grapple with learning how to regulate their behavior, there is a great need for close, caring adult supervision and guidance. As a key figure in the life of middle schoolers, effective teachers first begin by building a humanistic classroom climate. (Beane \& Lipka, 1986, define climate as "the atmosphere or milieu that permeates or underlies all of the transactions and interactions," p. 30.) A humanistic climate is democratic, personal, respectful, flexible, fosters a high degree of interaction and participation, and emphasizes self-discipline. Teachers enhance the development of internal locus of control rather than teacher-imposed controls by moving away from highly structured learning activities to more group, cooperative, student-centered activities whose meanings and expectations are clear (Beane \& Lipka, 1986). Rather than having institutionally imposed rules, teachers and students problem solve together. According to Glasser (1990), this teacher is a "lead manager," one who motivates the students to do as directed because they have been persuaded it is in their best interest to do so. Rather than coerce or punish, this teacher builds positive selfperception and greater internal locus of control by rewarding, accepting, listening, and understanding.

Beane and Lipka (1986) advised middle school teachers to spend less time inventing ways to control students and more time asking such questions as the following: 
"Do I make students feel welcome in school?

Do I accept them regardless of home background and previous school experience?

Do students have a say in what happens here?

Are my curriculum plans interesting and related to the real concerns of learners?"' (p. 37)

Again, the bottom line of effective middle school discipline has nothing to do with following some formula or method created by someone else. Rather, effective discipline is predicated on one's having a thorough knowledge and understanding of early adolescent needs and creatively responding to them in the classroom. Wiles \& Bondi (1986b) summarized:

At no other grade level are students so capable of being uncooperative or disruptive to the teaching-learning process. Teachers who are successful in working with the emerging adolescent often appear to have accomplished a 'magic hold' over their students. Closer analysis, however, reveals that such teachers simply have a greater understanding of their students' development, and have structured discipline procedures to fit the students whom they instruct (pp. $69 \& 70)$.

\section{Attitude and Commitment}

It may seem odd to include abstract concepts such as "attitude" and "commitment" in a section entitled "Areas of Expertise." However, these are the ingredients which act as the glue for all the other areas. Lipsitz (1984) wrote in Successful Schools for Young Adolescents that in addition to instructional expertise, teacher-advisor competence, and ability to personalize and effectively participate in a team, teachers must want to be where they are. Doda (1991) referred to caring as a main ingredient for good middle school teaching. She wrote, "Every middle school child ... should have one adult in his school who knows him better and cares more about him than anyone else" (p. 8). Lounsbury (1991a) described making these connections as "wayside teaching." He maintained that taking advantage of the opportunity to show genuine interest in a student 
takes "preparation of the heart." He alluded to the concept of attitude and commitment when he added, "While the occasion may come up suddenly and unexpectedly, the quality of the relationship preceding the conversation will reflect a bent of heart and spirit that usually was a long time in the making" (p. 30). Students will not long remember the classroom instruction; what they will remember are those teachers who made connections and personally demonstrated their concern, appreciation, understanding, and acceptance (George, et al., 1992; Lounsbury, 1991a).

A teacher's attitude and commitment to the early adolescent emerges out of a thorough knowledge of what this transescent is going through, empathy with the situation, and acceptance of it. Such attitude and commitment results in high academic and behavioral teacher expectations as well as teacher time sacrificed outside the classroom to help students. A teacher's belief that he or she is potentially a lifetransforming force in these young lives results in a compelling commitment which often causes others to shake their heads in disbelief and exclaim, "I don't know how you do it!"

Turning Points: Preparing American Youth for the 21st Century (1989) alluded to the importance of commitment when it declared, "The success of the transformed middle grade school will stand or fall on the willingness of teachers and other staff to invest their efforts in the young adolescent students. Teachers must understand and want to teach young adolescents and find the middle grade school a rewarding place to work" (p. 58).

\section{PART II: ENABLERS OF EFFECTIVE TEACHING}

The evidence supports the fact that the classroom teacher has the major responsibility and the power to transform practice at the middle school. Schools can differ according to grade configurations, organizational constructs, and prescribed curriculum and textbooks. However, the teacher remains the key. Regardless of 
differences in school setting, the young adolescents who walk into the classrooms need teachers who understand and like them, who know how to respond with a variety of teaching strategies appropriate to their clients' unique needs, and who are comfortable with the overall middle school organization. Middle schools need teachers who view their students holistically and their job as much more than simply dispensing academic knowledge.

Who Is the American Eighth Grader? (Office of Educational Research and Improvement, 1990), a report published by the United States Department of Education, stated, "We must make sure those who teach these middle years understand young adolescents and are specifically trained to teach them" (p. 7).

The report of the Camegie Council on Adolescent Development, Turning Points: Preparing American Youth for the 21st Century (1989), listed as one of the eight essential principles for transforming middle schools that teachers must be specifically prepared to teach young adolescents. It also recommended that middle grade education be transformed by developing "expert" teachers. If "expert" teachers are what are needed, then it raises many questions: What is meant by "expert?" How are they developed? Is this a quality one is born with? Does it evolve with experience? Is it teachable? Where should it be taught? Does a person "learn" to have a healthy selfconcept, to work comfortably with peers, to be creative, to like young adolescents, or to be enthusiastic about entering the classroom each day?

Alexander and McEwin (1989) in their study entitled Schools in the Middle: Status and Progress, reported that in spite of this urgent cry for "expert" teachers, only $39 \%$ of the 394 schools in their survey had faculty with any special preparation for teaching in the middle grades. Of those, only $9 \%$ had teachers where more than $75 \%$ had special training. In light of the newness of the middle school reform movement this should not be surprising. Moreover, as of a 1990 study by Goddard (Sparapani, Abel, Edwards, \& 
Herbster, 1991), only 14 states offered any specific credentials for middle school teaching.

Nonetheless, there are many "expert" teachers presently teaching in the nation's middle schools. There are teachers who have found the right balance between meeting students' intellectual, social, and emotional needs. Teachers can be found in the middle schools who are excited about being there and challenged by knowing they are potentially the "turning point" in young adolescent lives. There are middle school teachers who experience the satisfaction of guiding their students in making choices which lead them in the direction of meaningful, productive futures. These teachers are the ones to whom research must turn and ask the questions: "How does a middle school teacher get this way?" "What are the significant factors that promote and maintain effective teachers at the middle school?" Perhaps the answers to these questions will shed some light on how to better develop "expert" middle school teachers in the future and thus inform and reform teacher training institutions, school districts, and staff development specialists. Effective teachers already in the system also need to be maintained and constantly exposed to new thinking regarding early adolescent education. In fact, with the dramatic growth of the middle school movement, the urgency for developing and maintaining effective teachers at the middle school has never been greater.

A review of the literature revealed that the following are five of the most important potential enablers: (a) intensive early adolescent training through universities or staffdevelopment, (b) leadership, (c) peers, (d) time and reflectivity, and (e) attitude and commitment. 


\section{PROFESSIONAL TRAINING}

\section{Pre-service Training}

The preparation of new middle school teachers is critical to the middle school reform movement (Erb, 1991). Quality teacher training helps to insure effective teaching at any level. However, as the middle school concept evolves as a unique level with a unique identity and as research provides new information about serving the unique needs of the middle schooler, it seems reasonable that a stronger knowledge base would be built by requiring a specific middle school certificate (Caught in the Middle, 1987; Carnegie Council on Adolescent Development, 1989).

Although the challenges of effective teaching in the middle school are markedly different both in kind and in number from the challenge of teaching at other grade levels, a national study by McPartland (1990) showed that most middle grade teachers are certified for secondary school instruction with departmentalized subject matter orientation. Less that half the nation's middle school teachers have elementary credentials which, according to McPartland, is preferable to a secondary credential because it is more student centered and holistic.

To become an "expert" middle school teacher, therefore, one needs to have the special training which may be represented by a middle school certificate. According to the California middle level emphasis credential standards (Kramer, McKibben, and Dumas, 1990), completion of this certificate would include:

1. Academic preparation in two or more disciplines;

2. Various experiences working with young adolescents such as being a camp counselor, athletic coach, or other youth work;

3. Focus on intellectual, social, emotional, and physical developmental characteristics; 
4. Understanding of the middle school philosophy, organization, and pedagogical approaches;

5. Preparation for the role of teacher/advisor,

6. Student teaching at the middle school;

7. Experience in a variety of instructional and extra-curricular activities within a middle school;

8. Experience organizing a classroom environment that promotes active, responsible citizenship;

9. Experience working with parents of young adolescents.

These standards echoed the report, An Agenda for Excellence at the Middle Level, published by the NASSP's Council on Middle Level Education in 1985. This report also emphasized the additional importance of completing a year of field experience at the middle level as well. Focusing one's training and certification specifically on the middle level makes a major difference in teaching effectiveness and student outcome (McPartland, 1990). Bolster (1983) wrote that because teaching at the middle level involves so much situational decision making and includes more common sense than theoretical knowledge, training at the school site is particularly essential. "Only through authentic interaction with our 10-to-14-year-olds can we come closer to being assured that our teachers go into classrooms in middle schools with 'no doubts' about the significance of the age and about the value of class and school experiences that are tailored to the developmental characteristics of young adolescents" (Sheppard, 1991, p. 51).

The Carnegie Council on Adolescent Development's Turning Points (1989), also suggested a paid internship or apprenticeship in which the candidate would spend half a day with a mentor in the classroom and the other half taking graduate courses dealing specifically with early adolescent education and based on actual classroom experiences. 
After completing this year, candidates would be screened and only the best selected to become licensed teachers. Continuing graduate course work would be a requirement for obtaining and retaining a middle grade endorsement or certificate.

The goal is to create middle school educators who start with a common mind-set about the uniqueness of the middle grades, know and understand early adolescence, and apply recommended principles of teaching and learning (Lounsbury, 1990). As the torchbearers of reform, teachers must become experts either by pre-service education and/or by continuing their education through staff development. According to a study by Epstein, Lockard, and Dauber (1989), pre-service education focused on middle schools has a direct impact on the success of staff development later. "When teachers have a commitment to the middle grades, as evidenced by their choice of pre-service education and separate certification, they may also be more committed to in-service staff development to enhance their expertise at the middle level" (p. 5).

\section{In-service Training}

Currently, staff development is perhaps the most common way in which middle school teachers are re-trained and encouraged to experiment with new techniques found to be effective in the middle school. Because the middle school movement is still fledgling, many districts have invested a great deal of time, money, and emphasis on staff development to supplement teacher knowledge and skills regarding new theories, methods, and policies.

The Center for Research on Elementary and Middle Schools (Epstein, et al., 1989) reported that because middle schools have so many "displaced" teachers (either elementary or high school teachers who are assigned to the middle level), staff development becomes an even greater necessity. However, to be most useful, staff development needs to put increased emphasis on teacher participation and assist teachers in learning to be more professional, proficient in a skill, or collaborative. According to 
the authors of this report, staff development must consider first and foremost the impact it has on students, be provided continually, relate to a specific student need or condition of teaching, be led effectively, and be focused in its purpose and content. It can and mist produce better teaching and better learning (Epstein, et al., 1989).

Wiles and Bondi (1986a) concurred with the Epstein report and accused too many staff development programs of being little more than entertainment or practice in unrelated teaching techniques. Not only must staff development be specifically tied to the skills and understandings needed by middle school teachers, they say, but it should also lead to an in-district middle level certificate. Because middle school teachers need to feel they are specialists, they should eventually be awarded an "internal" certificate which would endorse the teacher as being a middle school specialist (Wiles \& Bondi, 1986a).

Does staff development make a difference? Does it make the teacher more effective? The literature suggests that much of the success depends on the content, the quality of the program, duration, incentives, and teacher input and commitment (Epstein, et al., 1989).

\section{LEADERSHIP}

Another enabler is leadership, usually that of a school principal. By now most researchers agree that the organization of schools is "loosely coupled" and that most successful school principals are "lead" managers (Glasser, 1990). They are normative rather than coercive in their leadership style, have a clear vision, are effective communicators of that vision through multiple means, and share their power by empowering others. Murphy (1988) called this the "norm of reciprocity." Leaders can 
achieve results, he said, by acting like followers and depending on followers to act like leaders. This develops a sense of responsibility in others and encourages teachers to take risks.

This type of leadership is important at every level-elementary, middle, or secondary. However, it is even more critical at the middle level that the principal be an articulate visionary and instructional leader because of the newness of the middle school concept (McDonough, 1991). Many educators are still trying to give the middle school a precise definition and to specify exactly what are best practices. The principal must know the needs and characteristics of young adolescents better than anyone else. This must give direction and clarity to everything the principal does and believes. Middle school principals must promote risk-taking and experimentation by encouraging the use of new ideas and materials. They need to support the team concept through designating time and scheduling, facilitating peer interaction and coaching, and recognizing publicly and frequently outstanding teacher effort and success. In the changing and developing milieu of the middle school, principals need to be active and sensitive listeners, receptive to others, flexible, and supportive when teacher efforts fail. Middle school teachers need principals who appreciate classrooms filled with activity, sometimes "messy;" who understand and encourage lessons which seem "unorthodox;" and, above all, who trust the professional judgment of the teacher. Teachers also benefit from timely feedback. At no other level is being an instructional leader as important for the principal as at the middle level. They need to be well-read in the latest middle school practices and promoters of change and innovation.

Middle school principals enable others through their ability to empathize-to stand in the other person's shoes. They understand and appreciate the daily demands of a middle school classroom, share in the good times and the bad, and work with the teacher 
in a spirit of collaboration to tackle the tough problems. Enabling principals develop with their faculties a collective commitment to the young adolescent and are vigilant in their pursuit of academic excellence. No matter how well things are going, they continue to inspire others to keep trying to do even better.

These principals know individual teacher strengths and weaknesses and consciously put into the teacher's hands professional articles or information about programs, workshops, or curricular ideas that will contribute to teaching effectiveness. This kind of awareness demands principals who visit classrooms, consult with teachers, and maintain a high degree of visibility in a non-judgmental, non-threatening collegial kind of way (Glasser, 1990; Sergiovanni, 1987; Stronge \& Jones, 1991; Wilson \& Firestone, 1987).

Glasser (1990) pointed out that "being an effective teacher may be the most difficult of all the common jobs in our society" (p. 429). Being an effective middle school teacher may be even more difficult. Those fortunate enough to teach with an exceptional principal to guide, sustain, and give meaning to their daily efforts to do their jobs may discover that they are inspired to work even harder to get quality results from their highly resistant early adolescent students.

\section{PEER COLLEGIALITY AND COLLABORATION}

Peer collegiality and collaboration also contribute significantly to teaching more effectively at the middle level. Caught in the Middle (1987) stated, "The investment in collegial faculty relationships is the hallmark of the most successful middle schools" (p. vi).

Empirical evidence supports the use of teacher teams to improve teacher-student contacts and increase student achievement (Epstein \& MacIver, 1989). However, organizing teams will not necessarily create the dynamics and esprit de corps which result in greater teacher effectiveness. In order for peer teams and collegiality to enable 
significantly more effective teaching, they need to break down the barriers so often built by teachers: physical and psychological isolation, protectionism, fear of failure, and even arrogance. Positive and constructive peer relationships open doors both physically and attitudinally. They must build a collective desire to do what is best for the student rather than the teacher. Meaningful collaboration is a relationship with other professionals who welcome new ideas, solutions, techniques, and information. It invites objective peer review and feedback, trusts the instincts of experienced teachers, and values the insights of mentor teachers (Johnson \& Johnson, 1987; Poole, 1988). This type of collaboration discusses alternatives, mutually solves problems, and cooperatively makes decisions. As a group, these teachers also function as a problem solving role model for students.

Strong and effective peer support groups are of great benefit to professionals whatever the level they teach. However, at the middle school it is especially critical to build positive collaboration. If caring for the whole child is a number one priority, then concerns for the welfare of each student must be the focus of all teachers who share that student. Teachers who work together to provide constructive interventions and respond to individual needs become enablers of teacher morale and satisfaction as each goes about the daily task of turning early adolescent lives around. Moreover, their shared vision communicates to the students, "We all care about you."

Finally, past research (Poole, 1988) revealed that middle school teachers need personal friends on the staff and supportive colleagues who listen and who praise each other. This greatly helps to sustain their enthusiasm and commitment.

\section{TIME AND REFLECTIVITY}

Another potential enabler-having adequate time to reflect over teaching-was a major issue raised as necessary for more effective teaching by the Carnegie Task Force (1986), A Nation Prepared: Teachers for the 21st Century. The pressures of daily 
school demands and lack of resources, however, almost eliminate this as an enabler in the real world of teaching. Many teachers probably consider having additional time to plan and reflect an unrealistic and utopian dream. Nonetheless, there are teachers who experience individual daily preparation time plus regularly scheduled compensated team time who will confirm that this is one of the greatest enablers of effective teaching. It is highly unlikely that interdisciplinary and thematic units will be developed over the long term unless time is formally allocated to work together. Lack of time is a major barrier to teachers who want to share ideas meaningfully, consult with others, and discuss class or student related problems. Although committed professionals may volunteer extra time for planning, this does not significantly contribute to the on-going support of teaming which is so vital to the middle school.

The myriad extra-curricular demands placed on teachers such as hall or bus duties, collecting fees, supervising dances, and attending meetings further compound teacher overload. Moreover, the complexities of middle school teaching and the dual nature of being both a teacher and a "social worker" require that teachers communicate with professional peers, parents, counselors, and support staff. Yet, the reality is that these collaborative attempts are frustrated by physical barriers, rigid schedules, and lack of access even to a telephone. A recent report conducted at middle schools on workplace communication (Hart-Landsberg, S., Schwab, R.G., \& Reder, S., 1991) found that middle school teachers juggle more tasks and interact with more adults every day than most engineers or top-level corporate managers. Opportunities to do so, however, are wedged into three minute breaks between classes, half hour lunches, or stolen during a quick dash to the office or bathroom.

Closely tied to the time issue is reflectivity. This refers to one's ability to reflect over current research or professional materials and past practices or decisions. Porter and Brophy (1988) contend that many teachers never change in their profession because they 
simply have no time for reflection. Change, flexibility, and spontaneity at the middle level is required daily. However, many teachers survive only by shutting their classroom doors and continuing to do what has always worked for them without regard for student outcome. Teaching takes great energy, particularly at the middle level where one is constantly making split-second decisions often in very volatile and tense situations, attempting to teach to a wide range of different cognitive levels and learning styles, utilizing multiple strategies, and trying to motivate very reluctant learners, while at the same time attempting to model values, attitudes, and behaviors. Taken as a whole, this is an awesome and challenging responsibility.

It is extremely important that teachers have the time to be alone and to reflect. Teachers who are reflective examine the results of their teaching based on their own classroom research, study other research, consult with others, solicit feedback, and take the time to be introspective and to question.

Grant and Zeichner (1984) described the three attitudes that are necessary for reflective teaching: open-mindedness, responsibility, and wholeheartedness. Openmindedness means having the ability and willingness to reevaluate one's own practice, listen to others, and modify old practices. Responsibility involves making moral choices and accepting the consequences. Wholeheartedness refers to teachers who take control over their own education, fight for their beliefs, and, most of all, accept all students. Grant \& Zeichner (1984) claimed that there is no alternative to reflective teaching if a teacher wants to be the best they possibly can be. Their research concluded, "... if there is more that we can do to make our schools and our society more enriching, humane and just, then we need reflective teachers to play an integral role in this process" (p. 13). 


\section{ATTTTUDE, SELF-CONCEPT, AND COMMITMENT}

The final enablers come from within-one's own attitude, self-concept, and commitment. A middle level teacher's attitude determines whether middle schoolers are perceived as animals in a zoo who must be forced into submission, or as emerging, discovering, questioning young adults with needs to be met in the most humane and supportive environment possible. Middle level teachers' attitudes predispose them to view their role narrowly (as dispensers of subject matter) or to see it as multi-faceted (as teachers, counselors, friends, and exemplars). Teacher attitude is the catalyst which inspires some to be energized by their students each day, and causes others to dread every class they face. Students are sensitive to teacher attitude and their reactions to perceived negative feelings about them often precipitates a vicious cycle which further erodes teacher efforts to teach effectively.

Wiles and Bondi (1986b) emphasized that teachers' honest desire to work with this age group is an essential quality. Unfortunately, the reality is that middle schools are often dumping grounds for secondary or elementary teachers who agree to work there only temporarily while they await a "real" job. They have neither the training nor the interest to work with early adolescents. This attitude usually colors their perspectives and affects their performances. On the other hand, teachers with a positive and empathetic view of middle schoolers see this age as a time of excitement and discovery. They perceive the early adolescent as an emerging adult with both a child and an adult inside. They are challenged by the child's potential and their own special role in helping to tap and develop it. Wiles and Bondi (1986b) suggested that teachers who genuinely care about and accept young adolescents are able to resurrect individual experiences at that age and relate to the students by "getting inside of them." This quality has been referred to as "with-itness"- - something which says to another, "I know what you are going 
through; I have been there too." This heightened sensitivity to what life was like for them as 12 - or 13-year-olds enables teachers to empathize, understand, and react more effectively to student behavior.

An attitude of acceptance means that the students' needs for love and connectedness precede teaching academics. Doda (1991) wrote that before these students can be taught mentally, teachers must first find ways of reaching out and touching them. Teachers must get to know their students and allow the students to know them. They must be able to develop this professional intimacy without becoming "buddies." Teachers such as these, insisted Lounsbury, et al. (1980), are an entitlement of young adolescents.

Teachers who enthusiastically and genuinely like young adolescents and desire to work with them play a critical role in shaping their adult lives. They "project a contagious spirit of optimism which spells the difference between mediocrity and high levels of physical and intellectual energy among both teachers and students (Caught in the Middle, 1987, p. 82)." These teachers view the challenges of teaching the early adolescent with an attitude of confidence, competence, and commitment.

Positive self-concept is also essential to teacher effectiveness. Before teachers can build up their students, they must know themselves (Buan \& Olson, 1988; Good \& Brophy, 1987; Johnston \& Markle, 1986; McEwin \& Thomason, 1989). Teachers must have the self-confidence to accept and share their own personal strengths and weaknesses. They must model a capacity to respond to mistakes maturely, including the ability to laugh at themselves (Caught in the Middle, 1987). Moreover, humor is particularly beneficial at the middle school where one must be spontaneously flexible and flexibly spontaneous. As such, teachers are more likely to positively shape and transform the lives of the young people in their classrooms in a positive manner.

A high sense of commitment and efficacy also contributes to effective teaching. Committed teachers are willing to step outside their comfort zones and are committed to 
their students both in and out of school. They view their students holistically in the broader context outside their classrooms, willingly make home contacts, and endeavor to involve the family whenever possible. They purposefully make themselves accessible. They welcome new information and practices and carefully monitor the impact it has on student achievement. Committed teachers never stop leaming.

Committed teachers are driven by a high sense of personal efficacy-a conviction that they do make a difference in early adolescent lives. The impact that this attitude has on student achievement was confirmed in a longitudinal study conducted by the University of Michigan (Midgley, 1991). The study showed that high-efficacy teachers produced students who achieved at higher levels. Teachers who choose the middle school and are dispositionally suited to it do "make valuable contributions to youngsters' lives, from which they accrue the satisfying benefits of professional efficacy" (George, et al., 1992, p. 17).

Finally, committed teachers view their teaching role in the middle school as an "exalted" one (George \& Oldaker, 1985), referred to by some as a "calling." These teachers consider their middle school teaching a position which can be filled by only a special few. They are proud to function as a successful middle school teacher, fully aware that it is a unique speciality.

\section{CONCLUSION}

Most middle level teachers know that they are probably the last significant adults, aside from possibly those in the family, who will have such a strong influence on the direction of these young adolescent lives. This great responsibility is both sobering and thrilling. The literature suggested that those teachers who are most effective in achieving positive life-long results in their students are teachers who enter the profession specifically desiring to work with early adolescents, are equipped with a thorough 
knowledge of the needs and characteristics of middle schoolers, continue to develop and hone their professional skills, are enabled by supportive leadership and peers, and find time for planning and reflection. Such teachers possess a positive attitude and selfconcept, high sense of efficacy, and a deep commitment toward helping these young adolescents experience a smooth and productive transition into adulthood.

In an effort to meet the demand for more "expert" middle school teachers and to replicate the factors which seem to encourage, support, and maintain expert middle school teaching, it is imperative that researchers listen to the teachers in the classrooms who demonstrate uncommon knowledge and effectiveness in their practice. Researchers and educators must pay more attention to what the teachers perceive contributes most to their being able to teach effectively in the middle school classroom. 


\section{CHAPTER III}

\section{METHODOLOGY}

The purpose of this chapter is to describe the methodology used to address the major question of this study: What are the most significant factors which practicing middle school teachers perceive as promoting and maintaining effective middle school teaching? This study began by using a questionnaire to identify a sample of teachers who described themselves as having the knowledge, practices, attitudes, and beliefs which the literature stated was characteristic of effective middle school teaching. All of the respondents were middle school teachers employed by a major urban school district. Those teachers who scored highest on the self report survey of middle school knowledge, practices, attitudes, and beliefs were invited for oral interviews. The content of the interview results was analyzed for ideas about what factors the teachers perceived as contributing most to promoting and maintaining effective practice. This chapter will describe the subjects and the setting in which they teach, the study research design, the type of data collection, the instrument development, and the analysis used.

\section{DESCRIPTION OF SAMPLE}

\section{Questionnaire Subjects}

The subjects for this study were all middle school teachers in the Portland Public School District, Portland, Oregon. Approximately 750 teachers employed full or half time received questionnaires. These were delivered to the 17 middle schools with directions that they be given to all the teachers. The fact that questionnaires were returned from every middle school would indicate that this was done across the district. 
Of the approximately 750 questionnaires, 326 (or 43\%) were returned. Of this number, 19 were considered invalid because of failure to answer enough of the items. Those questionnaires with fewer than five unanswered items were accepted and an average score of 2.5 replaced the missing data. The number of valid questionnaires used in this study totaled 307. Respondents ranged in score from a high of 76 to a low of 30 out of a possible 80. There were 104 male and 203 female respondents.

Based on studies which have shown the response rate is often higher among those who are more interested in or generally more favorable to the issue involved (Ary \& Jacobs, 1985), the researcher assumed that the disproportionate number of nonrespondents represent those who neither perceive themselves to be uncommonly effective middle school teachers nor care to share their views on middle school teaching. Because the purpose of the questionnaire was to determine an elite interview group of 20 teachers who perceived themselves as uncommonly effective, the 400 or so non-respondents should not bias or seriously skew the findings.

Although anonymity was promised, respondents had the option of signing their names which indicated their willingness to participate in follow-up interviews should they be selected.

\section{Interview Subjects}

The 20 subjects who were interviewed were drawn from the teachers who scored the highest totals on the survey and who also signed an agreement to be interviewed. These emerged out of the top scoring 33 respondents to the survey. Thus, those selected for interviews represented the top $10 \%$ of the middle school teachers who responded to the survey. The highest ranking interviewee scored 76 out of a possible 80 and the lowest scored 65 . One of the 20 interviewees was disqualified because he had too little 
classroom experience ( 3 months) in which to test his knowledge, practices, attitudes, and beliefs.

This final elite interview group of 19 ( 5 male and 14 female) represented 12 of the 17 middle schools with no more than two from any one school, represented all socioeconomic areas of the city, and ranged from 1 to 13 years of middle school teaching experience. Nine of the subjects had 5-7 years of experience, 6 had 10-13 years experience, and 4 had 3 or fewer years of experience. These interviewees, therefore, comprised a fairly representative sampling of teachers with experience in the middle school from its early formative years to the more clearly defined school organization of the present.

This group was also representative of the spectrum of teaching areas, variety of teaching time blocks, and various classroom settings typical in most middle schools. Ten of the 19 taught language arts and/or social studies and spent 1-3 or more hours with the same group of students. Four taught either math and/or science, one taught foreign language and health, one taught science and language arts, and one each taught home economics, art, and music.

The ratio of male to female subjects approximated the returned questionnaire population ratio. The slightly greater proportion of females in the sample was also consistent with the finding that females scored significantly higher mean scores than males on the questionnaire. These findings indicate that females perceive themselves as more effective teachers.

Interviewees were highly motivated to participate in the study since (a) they were made aware that they comprised an elite sample of effective teachers and (b) they expressed deep interest and commitment to the purpose of the study. 
Setting

The Portland Public School District, the largest in the state of Oregon, serves more than 55,000 students in 89 regular schools and 23 alternative schools. It is located in a metropolitan area encompassing 152 square miles and a population of approximately 405,000 in 88,000 households. As of 1991, ethnic groups within the district were $71.3 \%$ European American, 15.3\% African American, 7.8\% Asian, 3.3\% Hispanic, and 2.2\% Native American. The largest socioeconomic group served was low or low-middle with $48 \%$ of the households earning less than $\$ 22,500$ per year. This qualifies a family of 4 to receive free or reduced lunch in the Portland school district. Middle income families whose earnings range from $\$ 22,500$ to $\$ 52,500$ comprised $40.3 \%$ of the population. The highest economic level, those earning more than $\$ 52,500$ per year, represented $11.8 \%$ (Portland Public School District, 1991).

There are 17 middle schools in the district. Ethnic distribution tends to be uneven throughout Portland's middle schools. The greatest number of African Americans are enrolled in middle schools located in north and northeast Portland; the greatest number of Asian and Hispanic students are in southeast Portland schools. The overall district population, however, is predominantly European-American and low-to-middle socioeconomic class. Ethnic distribution in the middle schools approximates that of the district: 70.8\% European-American, 16.6\% African American, 7.5\% Asian, 3.1\% Hispanic, and $2.1 \%$ Native American.

According to Middle School Profiles (Portland Public Schools, 1991), in 1991 the 17 middle schools had a total student population of 11,684 with a $21: 1$ student/teacher ratio. About $16 \%$ of the students were enrolled in Chapter 1 classes, $8 \%$ in the Talented and Gifted program, and 3\% in the English as a Second Language/Bilingual program.

As a large urban school district, Portland has a reputation of being progressive and successful. It was among the national pacesetters in converting its K-8 schools into K-5 
elementary and 6-8 middle schools. Late in the 1960s the district started conducting extensive community and professional informational forums about the purpose and organizational concepts of the middle school. A massive effort was invested in conducting internal studies and in clarifying for both teachers and the public the unique differences between middle schools and junior high schools (Blanchard, 1969; Portland Public School District Public Information Office, 1977). Although each of the 17 middle schools now in existence has its own distinct personality, they all adhere to the general recommendations and goals which the middle school literature espouses is most appropriate for schools striving to best meet the needs of this unique client - the early adolescent.

Because Portland was one of the early urban districts to embrace the middle school design and concept, it is clearly past many of the organizational and conceptual issues characteristic of the first wave of reform. Thus, after more than twenty years of developing a clearly identifiable level in the middle called "middle school," Portland represented an excellent setting of "seasoned" teachers for a study such as this which is focused more on the teacher, a critical component of the second wave of reform.

\section{RESEARCH DESIGN AND PROCEDURES}

\section{Design}

This study is a descriptive research design conducted in two phases:

1. A questionnaire specifically created for this study which measured middle school teachers' self-perception of their knowledge, practices, attitudes, and beliefs regarding middle school teaching,

2. An interview instrument which examined relationships between effective middle school teaching and the factors reported to enable it.

These factors might be formal such as pre-service training at a university, a 
certification program, or in-service staff development. Factors might also be informal, e.g., one's personal attitude or commitment, an influential mentor, or a supportive principal. The overall research goal was to establish which factors "expert" middle school teachers perceived to be most significant and critical in developing and maintaining effective middle school teaching. An outline of the research procedure is shown in Figure 1.

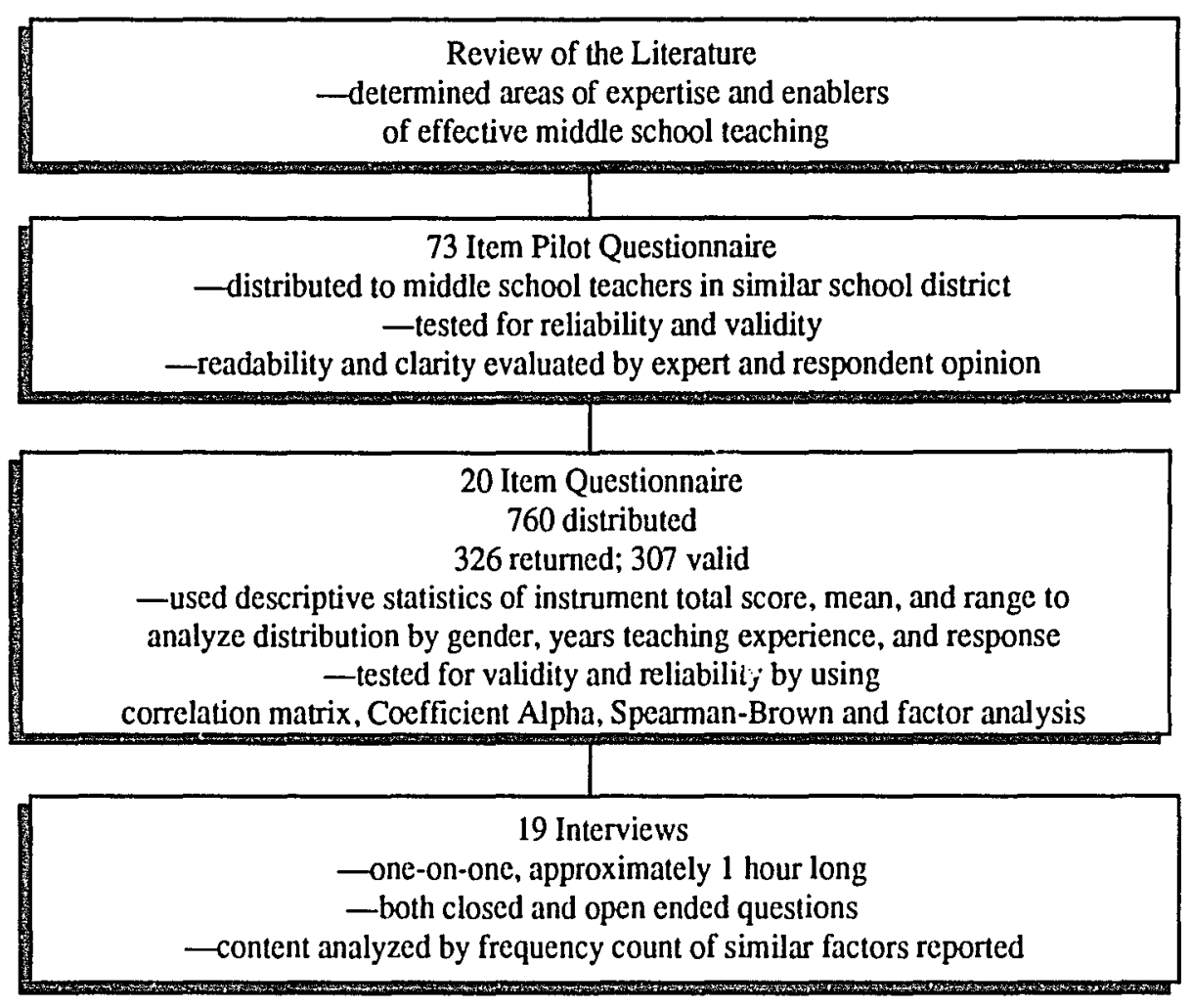

Figure 1. Flow chart showing the research procedure.

Data

A questionnaire instrument produced quantitative and descriptive data which indicated self-perception about middle school knowledge, practices, attitudes, and beliefs. Subjects marked 20 items using a number scale of " 1 " for strongly agree, " 2 " for agree, 
"3" for disagree, and "4" for strongly disagree. For analysis, these items were recoded so that all desirable outcomes were statistically entered as a "4." Thus, the higher the total score, the more indicative it was of effective middle school teaching. The questionnaire also asked respondents for the following demographic data: gender, total years teaching experience, total years teaching middle school, and teaching certification.

The interview instrument was semi-structured with three closed and eight openended questions. It also asked each interviewee to define "effective middle school teaching." The instrument produced more complex qualitative data which was organized so that the results could be more easily analyzed and interpreted. Using a modification of a technique developed by Robertson (1989), the data were synthesized and organized so as to reveal the most noteworthy themes or areas of agreement and disagreement.

\section{Data Gathering}

Phase I of this study involved distribution of the questionnaire instrument. A formal proposal was sent to the district office and scrutinized by a committee of the Evaluation and Research Department. The committee also sent a letter to all middle school principals explaining the purpose of the research and asking for any objections. After receiving no objections, district permission to conduct the research was subsequently granted. Via district mail service or personal delivery, 760 questionnaires were distributed to the 17 middle schools. A second cover letter accompanied the questionnaires and requested that each teacher be given one and encouraged to respond to it. Principals were reminded again that they were under no obligation to do so. A brief note attached to each questionnaire requested honesty, promised confidentiality and anonymity, and stated that completing it was entirely voluntary. A self-addressed envelope facilitated its return.

The requested date of return allowed only about 1 week turn-around time. The 
assumption was that this would demand more immediacy in completing it rather than setting it aside for later and possibly forgetting about it. However, getting the questionnaire into the hands of the teachers was dependent on immediate action by the principal. One school was reported to be undergoing a major administrative trauma which clearly affected questionnaire distribution. Also, several teachers who returned their questionnaires after the date wrote that they had received them belatedly. This obviously would cause many to assume that because it was too late there was no point in completing and returning it. Many responded anyway and questionnaires continued to be received up to 4 weeks following their distribution. Although a 43\% return is strong, without the previously mentioned handicaps, the return rate would probably have been much greater. All valid returned questionnaires were included in the study.

Phase II involved 19 interviews intended to discover what this elite sample of effective teachers reported to be the most significant factors that enable effective middle school teaching. This data was gathered using a semi-structured guide conducted personally by the researcher and which lasted approximately 45 minutes to 1 hour. The interviews were scheduled by telephone and conducted one-on-one. Although most lamented the tremendous demands on their time, all were extremely cooperative in setting up an appointment conducive to both parties and were anxious to contribute to the research. Sixteen interviews were completed at the teacher's workplace after the school day was over, two in their homes, and two in the evening by telephone. Notes of the interviews were taken as close to verbatim as possible. Interviews took 15 days to complete, all in the month of February.

\section{INSTRUMENTS}

\section{Pilot Questionnaire}

A pilot questionnaire was created based on a review of current literature and an up- 
to-date view of effective middle school teaching. Expert opinion was solicited from two middle school principals and one teacher to examine and edit individual survey items. They focused on clarity of each item and redundancy within the instrument. This 73-item pilot instrument was then sent to 2 middle schools in neighboring Vancouver Public School District, Vancouver, Washington. Although smaller, this district is similar to the Portland area socio-economically and has had grade 6-8 middle schools since converting from a 7-9 junior high school system in 1986. Eighteen questionnaires were completed and returned, several with written comments about various survey items which seemed ambiguous, redundant, or double-barreled.

\section{Questionnaire}

A final questionnaire was developed based on the statistical results of the pilot test, teacher comments, expert opinion, and literature review. In addition to the 17 items which showed high reliability in the pilot, the final questionnaire included 3 items which reported at $\mathrm{a} \geq .512$ reliability score. These were added in order to reflect a balance of the five dimensions of middle school teaching discussed in the literature review: (a) knowledge of the early adolescent's needs and development, (b) teaching and learning strategies, (c) discipline and classroom management, (d) middle school organization and concepts, and (e) attitudes and commitment.

The specific purpose of the questionnaire was to determine a teacher's selfperception of his or her knowledge, practices, attitudes, and beliefs regarding middle school teaching. The time required to complete the questionnaire was approximately 5 minutes.

Respondents were instructed to mark "1" for strongly agree, " 2 " for agree, " 3 " for disagree, and " 4 " for strongly disagree. Items were randomly ordered and phrased so that 
the desired outcome for some of the items elicited "strongly agree" and others "strongly disagree." There was no option for "no opinion," thus forcing the respondent to make a decision pro or con.

The questionnaire also included four demographic items: gender, total years teaching, total years teaching at the middle school, and certification. However, in the final analysis only gender data and total years teaching were used. Gender data compared total male with total female scores and found females scored significantly higher on their self-perception of effectiveness. Total years teaching was compared to total score to determine if there was any correlation between years of experience and greater self-perceived teaching effectiveness.

Demographic data regarding years of middle school experience were discarded because respondents' interpretation of "middle school" was too broad for this study. Some documented years teaching early adolescents in junior high schools or K-8 schools rather than in the current middle school organizational concept. Data referring to certification was also discarded because so many certification programs either overlapped or the respondent failed to report. The researcher decided that this information would be more meaningful within the context of the interview instrument, particularly if type of certification became a major factor contributing to teaching effectiveness. Moreover, such information was irrelevant to the purpose of the questionnaire which was to determine an elite sample of effective teachers to interview.

\section{Interview}

The interview instrument included three closed questions which elicited the following data: (a) years teaching in a middle school, (b) teaching assignment or area, and (c) answer to the question, "Do you consider yourself to be an uncommonly effective middle school teacher?" Open-ended questions created more depth, complexity and 
understanding of the interviewee's opinions. First, the subjects stated their personal definition of effective middle school teaching. Second, they shared what they considered to be the most significant factors which enable their teaching effectiveness. The remaining six questions inquired more specifically about the following middle school issues and/or factors: (a) the principal, (b) teaming and collaboration, (c) counseling and advisory, (d) staff development, (e) knowledge and understanding of the early adolescent, and (f) pre-service teacher training. Interviewees were asked to consider and report which factors contribute most significantly to promoting and maintaining effective teaching within the current middle school organizational context with the aforementioned middle school characteristics. In synthesizing the results, one should note that most teachers gave random responses which were not hierarchically ordered. Thus, in the final analysis the frequency that a particular enabler was mentioned became the criteria for listing the enablers in a particular order of importance.

The interview instrument was intended to generate a wide variety of information and to probe more deeply. It also allowed for immediate follow-up questions and clarity. Using a tape recorder was found to be interruptive and unnecessary since, by using a form of shorthand, notes could easily be taken almost verbatim by the interviewer. Some interviewer discretion was used in determining when not to record responses. Sensitivity to researcher bias, however, minimized slanting the data or being selective in their inclusion. Transcripts of the interviews were transcribed and systematized within 24 hours of each interview using a word processor. This process facilitated more accurate and organized synthesis of the data. Each interview generated three to four pages of typed notes. A thank you note was sent to each interviewee within one day of the interview. 
Because the interviewer could clarify the definition of middle school, the demographic item which reported total years teaching at a middle school was much more reliable. It contributed to the overall research question in that it raised two issues:

1. Was there a difference in what was reported as significantly enabling effective teaching between those who had taught a short time versus those who had taught for several years?

2. Did all the interviewees have enough experience to reflect adequately upon and address the research question?

The answers to both of these questions emerge from the content of each interview and confirms that, there $i s$ a difference in what inexperienced versus experienced teachers report as significant factors. The answers also confirm all interviewees had valuable contributions to make toward identifying factors critical to enabling more effective middle school teaching.

To some degree, the present context of each interviewee had an impact on his or her responses, e.g., if the current building leadership were weak or staff morale were low, these issues would emerge as more critical than if the opposite were true. Nonetheless, the interview process also allowed the researcher to elicit responses cognizant of the larger picture.

\section{Limitations}

First, school district policy did not allow the selection process to ask for teacher identification or confirmation of effectiveness from other knowledgeable peers or administrators. Neither could effectiveness be confirmed by students or student outcome data. Thus, the elite group for interviews was based solely on self-reported responses to the questionnaire.

Second, because the purpose of the questionnaire was to generate an elite sample of 
effective teachers, the introductory note attached to each questionnaire was purposefully brief and general so as not to bias responses. Some teachers objected to this and insisted on knowing specific intent of the questionnaire, while others wrote that they feared district reprisals if they answered honestly. This also caused a few teachers who scored high (indicating effectiveness) to decline volunteering for an interview.

Third, the elite sample of interviewees was entirely European-American. Thus, it was not representative of the more ethnically diverse student population. The findings, therefore, possibly also reflect this bias in the sample.

Fourth, the distribution of the questionnaire was entirely dependent on each school principal. If, by chance, the envelope of questionnaires with the accompanying principal cover letter got buried under a stack on someone's desk, the teachers would probably not receive them on time and thus be unable to return them by the requested due date. $A$ greater response rate would most likely have resulted if a cover letter had been sent separately to the principal and if a telephone call had been made directly to the principal immediately following the dissemination of questionnaires reminding him or her to distribute them.

\footnotetext{
ANALYSIS

Two-Phase Analysis

The aim of this study was to determine significant factors which prepare, support, and maintain effective middle school teaching. These factors might be formal such as pre-service training at a university, a certification program, or in-service staff development. Factors might also be informal such as one's personal attitude or commitment, an influential mentor, or a supportive principal.

This two-phase study involved both a questionnaire and an interview instrument.
} 
Items on the questionnaire were written to reflect current literature and an up-to-date view of effective middle school teaching. Its purpose was to survey teachers presently employed in a large urban school district with a more than 20 -year history of middle schools and to determine which teachers self-reported the most desirable knowledge, practices, attitudes, and beliefs concerning effective middle school teaching.

The interviewees were selected because they most closely approximated the knowledge, practices, attitudes, and beliefs presented in the literature as most critical for effective teaching. These teachers comprised an elite interview group and were the ones to whom the following question was directed: What are the most significant factors which enable you to be effective?

School district policy did not allow the selection process to ask for identification of effective teachers from others or to confirm effectiveness by using any form of student outcome data. Thus, the elite group for interviews was based solely on self-perception as reported in the survey. Interviewees were determined by a instrument total score on the 20-item-plus demographics questionnaire developed specifically for this study.

\section{Questionnaire Analysis}

Following development and distribution of the questionnaire instrument, valid completions were obtained from 307 volunteers. In order to determine its empirical characteristics, the results of the completed surveys were analyzed. This analysis was necessary to support the case that the instrument did in fact discriminate among the respondents. Empirical evidence for the way in which the survey worked can be used to defend its use in identifying the elite group.

The survey instrument was analyzed by item and for the distribution of the instrument total score. In addition, the instrument total score was analyzed by years of teaching experience and sex of the respondent. 
Item analysis began with descriptive statistics by item (range, mean, population distribution). This analysis enabled inspection of population levels of agreement with individual ideas, e.g., items such as: "I view my main task in the classroom as teaching academic content." and "The middle schooler's extreme need to socialize often interferes with my teaching." Item analysis continued with a correlation matrix of the 20 items. If the items were responded to thoughtfully, similar topics should have higher correlations than unrelated topics. Such findings would strengthen the argument that the instrument discriminated as designed. Next, the item analysis included an estimate of internal reliability. The purported theme of the questionnaire (effective middle school knowledge, practices, attitudes, and beliefs) should result in some defensible degree of internal agreement if all of the items generally addressed the overall perspective. Coefficient Alpha and Spearman-Brown were computed for the survey administration. Finally, assuming that the design of the questionnaire with a range of dimensions of middle school teaching (pupil needs and development, teaching and learning strategies, discipline and classroom management, school organization and concepts, and attitudes and commitment) would show some level of underlying patterns of response, a factor analysis was done. Both common factor and principle components models were used with varimax rotations.

Instrument total scores on the 20 items were used to identify interview subjects who responded with the most positive views and practices (according to the literature) of middle school teaching. Instrument total score analysis for all 307 valid respondents began with descriptive statistics. This analysis examined the distribution of the population; characteristics of the "elite" high scorers depended to some extent on the nature of the population. For example, it would be of interest if the entire population were more normally or bimodally distributed, or if the high scorers were outliers or at the high end of a continuum. Instrument total score analysis was concluded with 
investigation of associations between instrument total score and years of teaching experience, and mean scores between sexes. Often experience influences teachers' views. Also, slight differences frequently exist between men and women in attitude measures. All of these analyses had the potential to add to what could be said about the survey instrument, how well it discriminated along the lines of its design, and what confidence could be placed in the assumption that respondents used it thoughtfully and accurately to express the true differences in their views.

Chapter IV will present the findings of the analysis of the questionnaire instrument. Conclusions drawn from these findings influenced the subsequent interview protocol designed for the elite high scorers.

\section{Interview Analysis}

After transcribing all the interviewee's responses as close to verbatim as possible, each interview was given a number (1-19) and the content was analyzed for areas of agreements and disagreements.

First, the demographic data were tabulated: (a) gender, (b) years of experience at a middle school, (c) teaching area. It was important that the years of experience reflect time teaching in a middle school organizational setting since the overall research question was not about effective teaching per se, but about effective middle school teaching. Thus, a specialized kind of teaching was implied.

Second, responses to the more open-ended questions were examined and placed in certain categories. For example, the question "What is your definition of effective middle school teaching?" generally fell into five different areas. However, 16 of the 19 interviewees all stated in various ways that it is defined as balancing academic and affective concerns. When one considers that all the interviews were conducted separately, the strength of this agreement is powerful. 
The major research question in the interview, "What are the most significant factors that support and maintain effective middle school teaching?" generated eight clearly different areas of agreement which were mentioned by six or more of the interviewees. The interview analysis discusses these factors as well as those which were named by four or five of those interviewed.

In continuing to discern major areas of agreement throughout the rest of the interviews, the following method was used: First, the responses were analyzed and given a short description. Each time an interviewee shared in that response a frequency mark was given. Second, a grid was created which listed the interviewees along the horizontal axis and the areas of agreement along the vertical axis. This grid revealed frequency and distribution among the interviewees. Third, a horizontal bar graph was designed to show areas of greatest agreement down to least agreement, thus visually presenting the range of opinions. This graph allowed the researcher to determine which questions elicited strong agreement in fewer areas or a more even distribution of responses over a wider range of answers. When the interview findings are presented in Chapter IV, the general areas of agreement are discussed along with actual quotes from the interviews. These quotes act as exemplars of what the elite group of interviewees actually said and to reveal the deeper, more complex findings of the interviews.

\section{RESEARCH QUESTIONS}

The major research question was: What are the most significant factors which practicing middle school teachers perceive as promoting and maintaining effective middle school teaching?

Research questions related to the interviews were:

1. In what ways does the school principal promote and maintain effective middle school teaching? 
2. What are the major factors which enable effective team teaching in the middle school organization?

3. What are the major factors which enable a middle school teacher to be effective in an advisory role?

4. What factors are most critical in creating staff development programs which encourage effective teaching?

5. What do self-perceived effective middle school teachers say about the importance of knowing early adolescent needs and characteristics?

6. What should a middle school program at the university level include which would better develop expert teaching at the middle school?

7. Do effective middle school teachers believe a middle school certificate should be required for teaching at the middle school?

Research questions related to the questionnaire were:

1. Is there a significant difference between the self-perceived effectiveness of male and female middle school teachers?

2. Is there a significant difference between experienced and less experienced middle school teachers and their degree of job satisfaction? 


\section{CHAPTER IV}

\section{RESEARCH FINDINGS}

The purpose of this chapter is to present the findings of the questionnaire instrument, to defend its use in generating an elite sample for interviews, and to discuss the results from the interviews which probed the major research question, "What do effective middle school teachers say are the most significant factors which promote and maintain effective middle school teaching?" Other research questions addressed in the interviews and whose findings are discussed are:

1. What is effective middle school teaching?

2. How does the principal contribute to teacher effectiveness?

3. What are major factors enabling effective teaming?

4. What most enables teachers to effectively fill a teacher-advisor role?

5. What factors are most critical in creating staff development programs which encourage effective middle school teaching?

6. What is the importance of knowing early adolescent needs and development?

7. What should a university teacher training program consist of in order to better promote effective middle school teaching?

8. Should a middle level certificate be required?

\section{QUESTIONNAIRE FINDINGS}

A 20-item questionnaire concerning middle school teachers' knowledge, practices, attitudes, and beliefs was analyzed to substantiate the expectation that it discriminated 
among the survey population as designed. A description of this expectation appeared at the end of Chapter III. Conclusions drawn from the analysis of the questionnaire instrument influenced the subsequent interviews that formed the most important data gathering instrument for this study. The following is a list of the 20 items on the questionnaire:

1. The middle schooler's extreme need to socialize often interferes with my teaching.

2. I prefer teaching and having the school counselor deal with the personal problems of my students.

3. I think it is unrealistic to expect every student to experience success.

4. I am not comfortable with too much activity or talking in the classroom.

5. I allow nuy students many opportunities to socialize and relate to their peers within my classroom.

6. A big barrier to my being able to teach more effectively is lack of student interest.

7. I prefer a quiet, orderly classroom with little or no talking.

8. I genuinely enjoy going to work each day.

9. Although I occasionally use cooperative learning activities or strategies, I prefer having each student sit at his or her own desk and work independently.

10. To prepare young people for the twenty-first century, middle schools should concentrate more on academic education.

11. Developing and using interdisciplinary and/or integrated teaching units is both important and stimulating to me.

12. I am deeply committed to the middle school concept and to the students.

13. I believe that teachers should be freed up to teach and counselors should deal with student problems. 
14. I am always searching for new ways to teach or present the curriculum.

15. I view my main task in the classroom as teaching academic content.

16. I think "advisory" is basically a waste of time.

17. Students who can and want to learn should be separated from the nonacademically oriented.

18. I usually use objective tests because they are more efficient and less timeconsuming to correct.

19. I could be a better middle school teacher if I taught only in my specialty area.

20. I use cooperative and collaborative learning strategies almost daily.

Findings for the item analysis of the questionnaire are presented in Table I. (Item descriptors appear in Appendix A). Mean values of items are presented as scaled in the direction of positive views about middle school teaching, with higher values representing views more aligned with the literature. Mean values ranged from a low of 1.959 (on a scale of 1-4) ("The middle schooler's extreme need to socialize often interferes with my teaching.") to a high of 3.472 ("I am always searching for new ways to teach or present the curriculum.") to most agreement (0.995) on "I think 'advisory' is basically a waste of time."

Overall scale internal reliability was computed to be 0.856 per Spearman-Brown and 0.834 per Coefficient Alpha. Item-total correlations ranged from a low of 0.297 ("I am always searching for new ways to teach or present the curriculum") to a high of 0.624 ("I prefer a quiet, orderly classroom with little or no talking"). The mean item-total correlation for the 20 items was 0.490 .

A correlation matrix of items is presented as Table II. Correlations ranged from a high of $r=0.69$ ("I prefer teaching and having the school counselor deal with the personal problems of my students" and "I believe that teachers should be freed up to 
TABLE I

ITEM ANALYSIS OF SURVEY INSTRUMENT

\begin{tabular}{|c|c|c|c|c|c|c|c|c|c|}
\hline \multirow[b]{2}{*}{ ITEM } & \multirow[b]{2}{*}{ MEAN } & \multirow{2}{*}{$\begin{array}{l}\text { STANDARD } \\
\text { DEVIATION }\end{array}$} & \multicolumn{2}{|c|}{ ITEM-TOTAL RELIABILITY } & \multicolumn{2}{|c|}{ EXCLUDING THIS ITEM } & \multicolumn{3}{|c|}{ FACTOR LOADING } \\
\hline & & & $\Gamma$ & INDEX & $r$ & ALPHA & 1 & 2 & 3 \\
\hline 1 & 1.959 & 0.777 & .570 & .443 & .500 & .822 & 0.502 & 0.221 & 0.265 \\
\hline 2 & 2.463 & 0.797 & .520 & .414 & .442 & .825 & 0.713 & -0.019 & 0.141 \\
\hline 3 & 3.050 & 0.867 & .532 & .461 & .448 & .824 & 0.284 & 0.169 & 0.433 \\
\hline 4 & 2.751 & 0.861 & .539 & .464 & .456 & .824 & 0.187 & 0.014 & 0.693 \\
\hline 5 & 2.936 & 0.788 & .413 & .325 & .327 & .830 & -0.128 & 0.259 & 0.582 \\
\hline 6 & 2.702 & 0.840 & .391 & .328 & .297 & .832 & 0.526 & 0.206 & -0.091 \\
\hline 7 & 2.779 & 0.811 & .624 & .506 & .556 & .819 & 0.331 & 0.067 & 0.652 \\
\hline 8 & 3.072 & 0.790 & .514 & .406 & .436 & .825 & 0.348 & 0.570 & 0.068 \\
\hline 9 & 2.919 & 0.811 & .589 & .478 & .517 & .821 & 0.142 & 0.248 & 0.642 \\
\hline 10 & 2.383 & 0.812 & .388 & .315 & .298 & .831 & 0.287 & -0.109 & 0.364 \\
\hline 11 & 3.236 & 0.759 & .412 & .312 & .329 & .830 & 0.071 & 0.674 & 0.092 \\
\hline 12 & 3.124 & 0.804 & .507 & .408 & .427 & .825 & 0.287 & 0.633 & 0.061 \\
\hline 13 & 2.388 & 0.756 & .535 & .405 & .463 & .824 & 0.701 & -0.096 & 0.228 \\
\hline 14 & 3.472 & 0.696 & .297 & .207 & .216 & .834 & -0.180 & 0.793 & 0.065 \\
\hline 15 & 2.389 & 0.740 & .430 & .319 & .351 & .829 & 0.328 & -0.088 & 0.410 \\
\hline 16 & 2.505 & 0.995 & .480 & .478 & .376 & .829 & 0.530 & -0.011 & 0.191 \\
\hline 17 & 2.780 & 0.942 & .619 & .583 & .538 & .819 & 0.549 & 0.139 & 0.340 \\
\hline 18 & 2.884 & 0.789 & .459 & .362 & .376 & .828 & 0.234 & 0.264 & 0.296 \\
\hline 19 & 2.288 & 0.930 & .479 & .446 & .383 & .828 & 0.511 & 0.170 & 0.109 \\
\hline 20 & 2.915 & 0.829 & .492 & .407 & .408 & .826 & -0.111 & 0.570 & 0.485 \\
\hline
\end{tabular}


TABLE II

CORRELATION MATRIX OF SURVEY ITEMS

\begin{tabular}{|c|c|c|c|c|c|c|c|c|c|c|}
\hline & Q1 & Q2 & Q3 & Q4 & Q5 & Q6 & Q7 & Q8 & Q9 & Q10 \\
\hline Q1 & 1.000 & - & - & - & - & - & - & - & - & - \\
Q2 & 0.227 & 1.000 & - & - & - & - & - & - & - & - \\
Q3 & 0.285 & 0.237 & 1.000 & - & - & - & - & - & - & - \\
Q4 & 0.382 & 0.208 & 0.268 & 1.000 & - & - & - & - & - & - \\
Q5 & 0.116 & 0.049 & 0.265 & 0.250 & 1.000 & - & - & - & - & - \\
Q6 & 0.381 & 0.171 & 0.173 & 0.059 & -0.009 & 1.000 & - & - & - & - \\
Q7 & 0.363 & 0.293 & 0.264 & 0.563 & 0.267 & 0.174 & 1.000 & - & - & - \\
Q8 & 0.305 & 0.227 & 0.098 & 0.181 & 0.159 & 0.257 & 0.243 & 1.000 & - & - \\
Q9 & 0.262 & 0.202 & 0.254 & 0.341 & 0.262 & 0.097 & 0.392 & 0.238 & 1.000 & - \\
Q10 & 0.147 & 0.120 & 0.134 & 0.133 & 0.134 & 0.198 & 0.238 & 0.103 & 0.234 & 1.000 \\
Q11 & 0.164 & 0.100 & 0.187 & 0.120 & 0.172 & 0.044 & 0.121 & 0.274 & 0.207 & 0.036 \\
Q12 & 0.187 & 0.174 & 0.184 & 0.150 & 0.192 & 0.150 & 0.233 & 0.362 & 0.195 & 0.088 \\
Q13 & 0.231 & 0.690 & 0.287 & 0.237 & 0.084 & 0.172 & 0.317 & 0.184 & 0.245 & 0.229 \\
Q14 & 0.042 & -0.071 & 0.095 & 0.003 & 0.221 & 0.001 & 0.056 & 0.303 & 0.201 & -0.069 \\
Q15 & 0.144 & 0.286 & 0.143 & 0.217 & 0.073 & 0.039 & 0.287 & 0.151 & 0.282 & 0.316 \\
Q16 & 0.226 & 0.291 & 0.270 & 0.194 & 0.157 & 0.209 & 0.176 & 0.145 & 0.164 & 0.182 \\
Q17 & 0.347 & 0.359 & 0.304 & 0.347 & 0.151 & 0.258 & 0.418 & 0.207 & 0.279 & 0.258 \\
Q18 & 0.277 & 0.165 & 0.282 & 0.080 & 0.114 & 0.095 & 0.183 & 0.181 & 0.331 & 0.148 \\
Q19 & 0.316 & 0.282 & 0.160 & 0.198 & 0.076 & 0.158 & 0.277 & 0.195 & 0.215 & 0.103 \\
Q20 & 0.167 & 0.067 & 0.260 & 0.285 & 0.356 & 0.137 & 0.228 & 0.312 & 0.413 & 0.059 \\
\hline
\end{tabular}


TABLE II

CORRELATION MATRIX OF SURVEY ITEMS

(continued)

\begin{tabular}{|c|c|c|c|c|c|c|c|c|c|c|}
\hline & Q11 & Q12 & Q13 & Q14 & Q15 & Q16 & Q17 & Q18 & Q19 & Q20 \\
\hline Q11 & 1.000 & - & - & - & - & - & - & - & - & - \\
Q12 & 0.405 & 1.000 & - & - & - & - & - & - & - & - \\
Q13 & 0.036 & 0.140 & 1.000 & - & - & - & - & - & - & - \\
Q14 & 0.421 & 0.376 & -0.079 & 1.000 & - & - & - & - & - & - \\
Q15 & 0.102 & 0.128 & 0.304 & -0.038 & 1.000 & - & - & - & - & - \\
Q16 & 0.029 & 0.213 & 0.321 & -0.093 & 0.216 & 1.000 & - & - & - & - \\
Q17 & 0.178 & 0.291 & 0.312 & 0.032 & 0.194 & 0.323 & 1.000 & - & - & - \\
Q18 & 0.156 & 0.143 & 0.173 & 0.174 & 0.208 & 0.199 & 0.197 & 1.000 & - & \\
Q19 & 0.129 & 0.176 & 0.307 & 0.099 & 0.149 & 0.202 & 0.304 & 0.181 & 1.000 & \\
Q20 & 0.296 & 0.241 & 0.043 & 0.448 & 0.082 & 0.057 & 0.152 & 0.252 & 0.057 & 1.000 \\
\hline
\end{tabular}


teach and counselors should deal with student problems") to a low of $\mathrm{r}<0.01$ ("I am not comfortable with too much activity or talking in the classroom" and "I am always searching for new ways to teach or present the curriculum"). The mean correlation between items was 0.204 .

The rotated principle components factor analysis identified three factors with eigenvalues greater than 1.0: Factor 1 eigenvalue 3.133 (15.67\% explained variance), Factor 2 eigenvalue 2.535 (12.68\%), and Factor 3 eigenvalue 2.801 (14.01\%). These three factors explained $42.4 \%$ of the variance in instrument total scores. The three factors were named after the analysis presented in Table III. Factor 1 dealt with views of

\section{TABLE III}

\section{UNDERLYING FACTORS OF SURVEY INSTRUMENT}

\begin{tabular}{|c|c|c|}
\hline Item & $\begin{array}{l}\text { Factor } \\
\text { Loading }\end{array}$ & \\
\hline \multirow[b]{2}{*}{2} & \multirow[b]{2}{*}{0.713} & Factor 1: Separate teaching and dealing with student problems \\
\hline & & I teach, counselor deals with problems \\
\hline 13 & 0.701 & Teachers freed to teach, counselors deal with problems \\
\hline 17 & 0.549 & Students who want to learn should be separated from others \\
\hline \multirow[b]{2}{*}{14} & \multirow[b]{2}{*}{0.793} & Factor 2: Eager to innovate, especially interdisciplinary, integrate \\
\hline & & I search for new ways to teach and present curriculum \\
\hline 11 & 0.674 & Developing interdisciplinary and integration important \\
\hline 12 & 0.633 & I'm committed to middle school concept and students \\
\hline \multirow[b]{2}{*}{4} & \multirow[b]{2}{*}{0.693} & Factor 3: Preferences for activity and/or quiet in classroom \\
\hline & & Comfortable with talking and activity \\
\hline 7 & 0.652 & Prefer a quiet, orderly room \\
\hline 9 & 0.642 & Prefer students to sit at desks, work quietly \\
\hline
\end{tabular}


Separating issues of teaching and dealing with student problems. Factor 2 addressed views of Eagerness to innovate, especially interdisciplinary and integrated curriculum. Factor 3 referred to Preference for activity and/or quietness in the classroom.

Instrument total score distributions are presented in Figure 2. Scores ranged from 30 to 76 , out of a possible 80 . Other descriptive statistics for instrument total scores include a mean of 54.955 , standard deviation of 8.078 , skewness of -0.027 , and kurtosis of -0.200 . The instrument total scores for the elite interview group ranged from 65 to 76 . Their mean was 69.8 , the median was 69 , and the standard deviation was 2.81 .

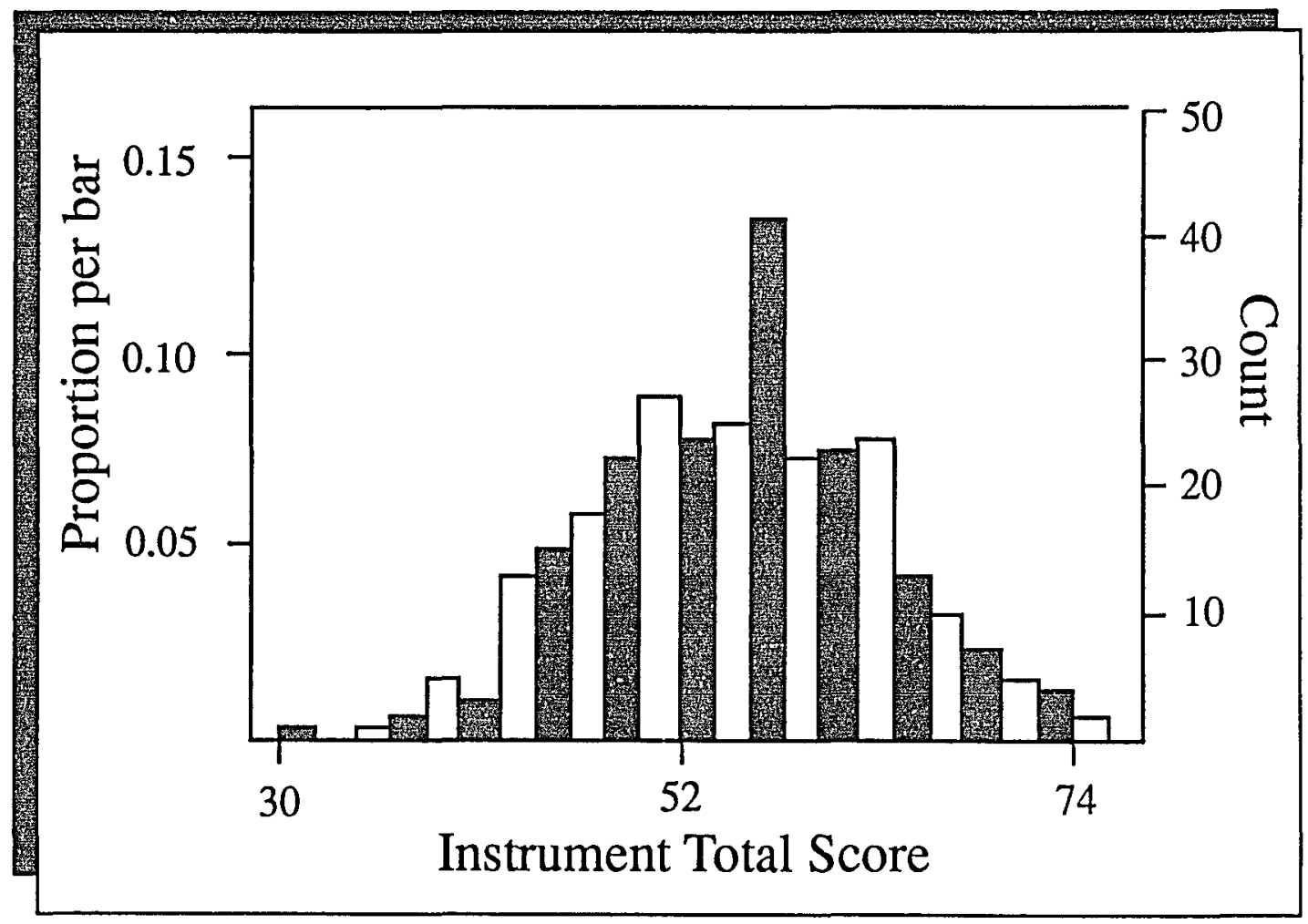

Figure 2. Distribution of instrument total scores. 
Possible relationships between instrument total scores and demographic variables of years of teaching experience and the sex of the teacher were investigated. The correlation between years of experience and instrument total score was found to be $r=-.22$. Females out scored males on instrument total scores with statistical significance $(\mathrm{t}=-2.73, \mathrm{df}=305, p \leq .01)$. Differences between males and females are illustrated in Figure 3.

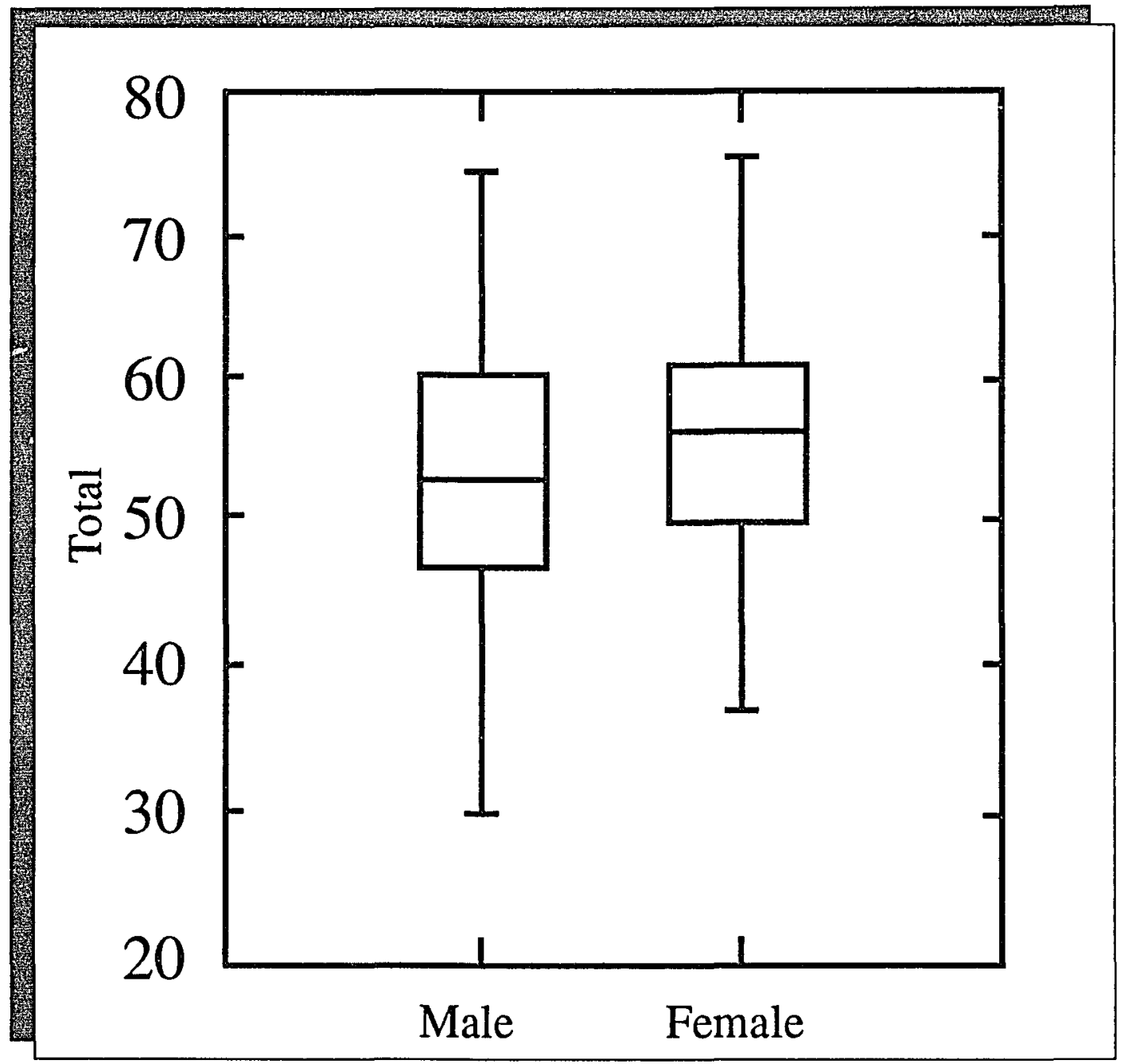

Figure 3. Differences between males and females in total instrument scores, mean and standard deviation. 


\section{INTERVIEW FINDINGS}

\section{Introductory Questions and Responses}

The order of the interview guide (see Appendix B) was intended first to get each teacher's spontaneous definition of effective middle school teaching. Next they were asked, "Do you consider yourself to be effective?" Equally important to an affirmation was the conviction with which each interviewee answered.

\section{Elite Sample Defines Effective Middle School Teaching}

In view of the fact that none of the teachers was prompted or prepared to give a definition and each interview was conducted privately, the response to the question "What is effective middle school teaching?" was amazingly similar among the interviewees. Most summed it up simply as a balancing of academic concerns with affective concerns. One teacher stated: "It is having the ability to balance between a knowledge base and teaching skills; it is also having some fire in the gut and heart so you can relate to kids at that age." Another stressed, "It is more than subject area; it includes the social aspect of teaching the middle school kid." The strength of this shared conviction was underscored by the following comment: "It is essentially affective teaching that will in the end be most effective. In fact, teachers almost have to ignore academics."

\section{Interviewees Perceive Selves as Effective}

The follow-up question which asked the elite group of interviewees if they considered themselves to be effective resulted in all but one responding enthusiastically with "Yes!" or "You bet I am!" or "Absolutely!" One exclaimed, "Effective? I'm terrific!" Only 1 of the 19 gave a more modest answer: "I am more effective than most, but not as much as I still want to be." 
Thus, the individuals in this elite sample revealed first through their responses to the questionnaire that they agreed with the knowledge, practices, attitudes, and beliefs espoused by current literature as necessary for effective middle school teaching. Then, through their own definitions of effective middle school teaching, they confirmed their alignment with the literature and the beliefs of other middle school experts. Finally, they each testified to their own uncommon level of expertise.

Given the information above, this researcher is convinced that the elite interview sample has valuable contributions to make in dealing with the larger research question: "What do effective middle school teachers say are the most significant factors which promote and maintain effective middle school teaching?"

Aside from a few introductory comments and a reminder that the teachers consider the entire scope of middle school teaching and not just their present school context, it was important that the aforementioned question was left very broad and open-ended. The rationale was that the interviewees' immediate "gut" responses would be the most valid and meaningful in addressing the research question. Subsequent interview questions would be more specific. They would direct teachers to consider certain aspects of middle school teaching in order to focus more directly on those specific areas and the factors which seem to be most essential as contributors to effective teaching.

\section{Most Critical Enablers of Effective Middle School Teaching}

Of the myriad responses concerning which factors are most critical in promoting effective middle school teaching, five factors were mentioned significantly more often than the rest. Three of them had to do with personal attributes and attitudes, the others had to do with teaching strategies and classroom management.

The first three factors represent what is often referred to as the "art" of teaching. Many would suggest that these factors are not "teachable." They include: (a) having a 
positive attitude about early adolescents, (b) feeling genuine empathy for this age, and (c) being driven by a commitment to the early adolescent who is at a pivotal juncture in life as an emerging adult.

Positive Attitude Toward Early Adolescents. Eighteen of the interviewees stated that in order to be an effective middle school teacher it was absolutely essential that the teacher first have a positive attitude about this particular age student. They must genuinely like and care about them. "I am really glad when the kids are coming in," boasted one teacher, "and I always greet them at the door." Another stated, "I like the early adolescent! There is so much going on with them socially and physically and it is fun to share this time with them." "I love kids-especially middle schoolers," testified another, "and I care about their struggles to become a person and what they are going through." One teacher said this attitude is manifested as a "mutual sense of respect." "Kids will trust you," stated another. "After that, teaching is pure joy. Kids know exactly where I'm coming from. I'm honest and they trust me. I don't use cutesy words or euphemisms. They see me not as a buddy but as an adult who cares."

Empathy for the Early Adolescent. Second, most of the interviewees reported that it is critical to have a sense of empathy for the early adolescent. Specifically, one commented, this is "having the ability to step into their shoes." "Teachers must be able to remember what life was like for them when they were early adolescents," emphasized another. "They know I am on their team," another stated. "They come in with a pile of stuff," she went on, "and I have to give them slack because they have such a burden as a teen, in their home life, with their needs, and with nutritional problems. I must work with them as they are, build their self-esteem and show I'm interested in them as human beings. I need to stop to take opportunities to bond and build human connections." One of the teachers laughingly admitted, "I make a point of seeing their movies, watching 
their TV shows, and listening to their music specifically to keep myself more in tune with the kids I teach."

Commitment to the Early Adolescent. Finally, most of the teachers stressed that it is necessary to have a strong commitment to teaching specifically at the middle school and a belief that the teacher really does make a difference. Two teachers referred to teaching at the middle school as a "calling." "I believe it is critical to believe both that early adolescents are worthwhile to challenge," stated one, "and that I am contributing to their lives. I do have something to offer." Others commented on the importance of feeling that they make a difference in the early adolescent life. For them, that became a driving force toward their efforts to teach more and more effectively. One teacher summed this up: "I am enabled to be effective because of my belief that I really am a turning point in my students' lives."

Multiple Teaching Strategies. The elite interviews also revealed that in addition to caring about the early adolescent and being empathetic and deeply committed to them, middle school teachers must be able to employ multiple teaching strategies and know how to manage and organize a classroom effectively. These two themes represent what is often referred to as the "science" of teaching.

Fifteen of the interviewees stated that middle school teachers need a wide range of teaching strategies in order to better meet individual students' needs and to insure that all students have an equal chance at experiencing success. They reported that this involved up-to-date knowledge about different learning styles and cooperative learning techniques, individualization of instruction, minimal reliance on textbooks, and great liberty in developing and implementing the curriculum. "Teachers have to be able to change the focus, activity, or tempo a lot," stated one. "Teachers need to create multiple opportunities for kids to be social and work with peers. They must know how to meet individual needs—go with the flow-but within boundaries." This teacher-magician 
"must have the ability to create a structured program which is also flexible," reported another. This kind of teacher is enabled by being able "to think on their feet," another stated, "and have alternative teaching strategies constantly at their disposal." One teacher said, "The early adolescent of the 21 st century lives in a world of 12-minute time increments interrupted only by commercials." Thus, he insisted, teachers must be able to deal with short attention spans, match teaching strategies to the students, and somehow connect it all together and to the real world. One of the interviewees alluded to Bruner's (1960) concept of "scaffolding" when she pointed out that multiple teaching strategies includes "recognizing the magic edge of learning and the ability to know when to push it."

Classroom Management and Organization. The last of the most frequently mentioned enablers of effective middle school teaching has to do with classroom management and organization. According to many of these teachers, this too was something the effective teachers simply did naturally. It was not a specific model or technique to be followed, although most agreed a broad variety of strategies was useful. Rather, it was born out of the teacher's understanding of the needs and development of the early adolescent and the teacher's belief in fairness, consistency, mutual respect, and sense of caring about the middle schooler as a human. For these teachers, classroom management rarely becomes a major issue. "Rules and consequences must be fair," said one teacher, "and students must know that each day is a fresh start. Classroom management is hidden-underlying; it is more like relationship management. If it ever becomes an issue, it must be dealt with privately, one-on-one with the student." Another stated that effective teachers are not over-reactive: "You need to be a little laid back when the kids are trying to get your goat." "Good teachers have a plan and are comfortable being in charge," said another. "They are firm but in a friendly way, and the kids have a good feeling about that." One interviewee said that students should be 
participants in the decision-making within the classroom, and another advised, "Middle schoolers need to be empowered to make choices and take responsibility for them." Several teachers mentioned the importance of having a special education background. One claimed, "This gives me more insight as to what I'm looking at, i.e., is the trouble maker emotionally disturbed? Does the student have attention problems? A special education background helps me pick up on this and treat the child differently."

Clearly, most of the teachers in this elite group saw their heightened sensitivity to the early adolescent and their ability to choose from a wide repertoire of teaching strategies as a significant enabler of effective teaching. It almost eliminates the discipline and management problems which so many consider the most difficult part of teaching this age student population.

\section{Qther Important.Factors}

In addition to the preceding factors which were named as enablers of effective middle school teaching by most of those in the elite interview group, the following were identified as significant by at least half:" (a) supportive administration, (b) a schedule which allows regular time for team planning, (c) strong peer collegiality, (d) district support, (e) more time and (f) a high sense of self-esteem and self-confidence. The first three factors were part of the original interview protocol and are discussed in greater depth later in the findings. The other factors are presented below.

District Support. Many of the interviewees stated that district support for the middle school organization and more time for teachers to plan and reflect are significant enablers of effective teaching. One said, "We have to do away with lead-bottomed bureaucracies - those who do not really want to find answers." Another stated, "We 
must get rid of district policies that stand in the way of meeting the needs of the kids." "We need districts," observed another, "which give more than lip service to really meeting and nurturing the needs of the early adolescent."

Time for Planning and Reflection. Having more time to plan and to reflect was also mentioned by several interviews. If team planning is to be taken seriously at the middle school, one of the teachers cautioned, "then we need to be able to do teaming with adequate time to meaningfully plan and share ideas, and we also need enough personal time to reflect on our teaching." Another emphasized the importance of longer blocks of sustained teaching time. Innovative student assessment also requires more time, pointed out another. The need for more time was a critical factor to another interviewee who stated that teachers "must evaluate more with portfolios, individual conferences, and with written comments." Although scantrons are more time-efficient, this teacher admonished that, "Middle school teachers must get away from computerized report cards."

Teacher Self-esteem. A fact worth noting is that about half the interviewees mentioned self-esteem as an enabler of effective middle school teaching. One teacher observed, "Specifically because this age of kids often does not express affection toward adults, a middle school teacher has to have personal strength within." This factor seems to point out the uniqueness of dealing with early adolescents. The interviewees suggested that a high sense of self-esteem may be desirable for all teachers. They implied, however, that it may be even more for middle school teachers to be confident and comfortable with themselves because of the unique nature of the middle schooler to make mincemeat of any teacher who is vulnerable, insecure, or lacking in "with-itness." This confidence includes the ability to admit mistakes. One of the teachers commented, "You must have the ability to admit you have clay feet to the kids." She further advised, "You have to be able to laugh at yourself in order to keep a proper perspective. You can't take yourself too seriously." 
Less Frequently Mentioned Factors

Other factors frequently mentioned by several interviewers as enablers of effective middle school teaching were: a sense of humor, enthusiasm, energy, a feeling of empowerment, and an ability to adapt to change. The idea of adaptability and flexibility was expressed variously:

- "Teachers must work within the unexpected."

- "Teachers must be ready and willing to change."

- "Teachers need a youthful way of getting along with kids."

\section{Strong Qpinion and Level of Agreement}

What is worth noting here is that responses to the open-ended question at the beginning of the interview_-"What do you consider are the most significant factors which promote and maintain effective middle school teaching?"--revealed such strongly held opinions and such a high level of agreement among those in the sample. Almost all of the interviewees stated emphatically that the middle school teacher must really care about the early adolescent. About three-fourths responded that commitment to the early adolescent and genuine empathy for what they are going through are critical factors. The same support was voiced about the need to have a variety of teaching strategies and to maintain a flexible but strong classroom management style.

It is equally note-worthy that only a couple teachers mentioned the importance of being knowledgeable in a subject area. Two speciality teachers, one math and one music teacher, voiced strong opinion about this as an enabling factor. A third teacher stressed that what really mattered was that the teacher be knowledgeable enough to be freed up from over-reliance on a textbook. Another added that background in more than one subject area was very helpful at the middle level. 
Thus, the implication is that most of the effective teachers in the interview group do not feel strongly that subject expertise is among the most critical factors. In fact, one of the interviewees who has taught early adolescents for 18 years emphasized that teachers should spend less time becoming knowledgeable about a subject and spend more time learning how to teach. "Only by affective teaching strategies," she declared, "can a teacher successfully relate to the 'rocks' [the brain-dead] and the 'hormones' that fill middle school classrooms." It was her conviction that almost anybody could learn the subject matter: "What really matters is whether the teacher can relate to the kids and creatively teach."

\section{Brincipal. Teaming Advisory, and Staff Development}

After the initial question which invited a random variety of responses as to what contributes most significantly to effective middle school teaching, the interviewees were directed to focus their attention more specifically on (a) the middle school principal and the role he or she plays in supporting effective teaching, (b) the middle school concepts of team teaching and advisory and what factors seem to contribute most to a meaningful practice of them, and (c) staff development programs and how they positively encourage more effective teaching.

The Principal as Enabler. An analysis of the 19 interviews revealed that principals contribute most to effective middle school teaching (a) by listening, caring, and taking action, (b) by being a visionary, and (c) by respecting the teacher as a professional. In addition to the above, several of the interviewees $(7-9)$ voiced agreement that principals support effective teaching in two other ways: by assisting teachers in their need to collaborate and function as instructional teams and by demonstrating in word and action a personal understanding of the early adolescent. 
1. Enabling principals listen, are concerned, and active. The area of greatest agreement was that principals help teachers most by listening, showing concern, and by taking action. "Middle schools must have principals who will listen, take time with teachers, and deal with the problems," was a sentiment shared in various ways by 14 of the 19 interviewees. Principals were generally considered the main part of the teacher support system. One interviewee said that the best principals were those who "always know what their teachers are doing and what they need." Moreover, "They have the organization and management skills which allow them to get teachers what they need." One teacher pointed out that enabling principals support their teachers' overall programs and encourage them to take risks. "The principal must be willing to go out on a limb," added another. This kind of principal "supports the teacher even if the teacher has made a mistake," declared another. Finally, supportive principals are proactive in helping their teachers personally. One teacher commented that these principals "are attuned to teacher burnout or weariness and are even willing to take their class for a period or half a day." Such principal support emerges out of a " deep sensitivity to the pressures that are on middle school teachers," underscored another interviewee.

2. Enabling principals are custodians of the vision. Interview analysis revealed that the second most frequently mentioned way in which principals support effective teaching is by being "the custodian of the vision." "The principal must provide the leadership, the consistency, and the sense of mission," stated one of the interviewees. "The supportive principal has rules and expectations," another agreed, but then added, "however, he is willing to reevaluate and be flexible." A number of others shared a belief that the principal must set the tone for the building and "must hire personalities with complementary qualities who share in the vision." They have the right "fit," said another. "It is important that the school personnel all share the same high expectations for academic achievement and it is the principal who establishes that and sets the general 
tone for the building," one teacher emphasized. Another teacher added that a principal who supports effective teaching not only creates the tone and atmosphere for the building, but makes certain that it is "positive" and "kid oriented."

3. Enabling principals respect teachers as professionals and peers. Third strongest as an area of mutual agreement was that principals promote effective teaching when they show respect for teachers and treat them as professionals and as peers. Several interviewees described this as a principal who never acts superior or manages top-down. Rather, this principal is one who is willing to get into the trenches and experience what teachers do. Some consciously make it a point to do so. They might teach a class regularly or periodically so as not to lose touch with the real world of teachers and students. The enabling principal respects the knowledge of the teacher and, added an interviewee, "trusts that if the teacher decides something for the good of the kids, they should be supported." Such principals give autonomy to teachers and, in the words of one of the interviewees, "empower teachers to do their job as they know it best."

4. Enabling principals promote collaboration. About half of the teachers also agreed that principals promote and maintain effective teaching by creating schedules which are conducive to meaningful teacher collaboration and planning. They can accomplish this goal either by giving teachers the same hours to work together or by granting adequate blocks of sustained time in which to seriously develop curriculum, plan integrated units, and share ideas. Principals also promote collaboration by the way they budget money resources. Several interviewees noted that as more principals are being given autonomy over how they distribute the building's money, principals have more opportunities to allocate the funds necessary to hire substitutes so teachers can have release time for collaboration or teaming or to observe other experts teaching. Principals also promote effective teaching by providing (or knowing how to get) the resources necessary to 
support teachers in program development and self improvement both in the summer or after school.

In addition to time and money factors, principals promote effective teacher collaboration by actively " developing positive attitudes among the staff through programs that foster collegiality and cooperation," stated one interviewee. Another pointed out that principals produce more effective teacher collaboration "when they really know their staff and create teams based on that knowledge." In other words, they know how to put the right people together. The importance of the principal to promoting collaboration and overall positive staff morale was summed up by one interviewee who exclaimed, "Principals make all the difference! Once the staff feels good about itself, miracles happen!"

5. Enabling principals like early adolescents. Several of the interviewees responded that it is important to have principals who understand and genuinely like the early adolescent and, as one teacher stated it, are able to "tolerate their "in-betweenness." "I want a principal who comes into my classroom, observes, and actually knows what is going on," affirmed one veteran teacher. "They understand kids who are active, busy, talking, and self-managing." For another this meant that principals, like teachers, must give kids the opportunity to make decisions concerning the whole school-to run the school more as a "partnership." "We need principals who know about middle school kids and their issues," said another. A general consensus was that this knowledge has a great impact on disciplinary decisions and school rules and expectations. Also, "the principal must recognize how important the affective domain is to effective teaching," added another interviewee, while another commented, "The principal must feel compassion for the early adolescent and be proactive with them." Still another teacher concluded, "The principal must want to be at the middle school, like the kids, understand them, and support the value of helping to meet the child's emotional needs." 
6. Enabling principals are knowledgeable, empowering, visible, and sensitive. Finally, a number of the interviewees reported strong feelings about four additional ways in which principals significantly support effective middle school teaching. First, the principal needs to exhibit broad knowledge about middle school curriculum and instructional strategies. This principal is then better able to assist the staff and support curricular and classroom management decisions. Second, an enabling principal empowers teachers as decision makers. Third, enabling principals maintain high visibility - get out of the office, walk the halls, and visit the classrooms. Fourth, a supportive principal is highly sensitive to teacher overload and stress and takes action to do something about it.

Eactors which Contribute to Effective Teaming and Collaboration. Accepting the fact that team teaching and collaboration is a preferred practice in current middle school organizations, the interviewees were asked to consider this concept and to discuss which factors they believe contribute most to meaningfully working in teacher teams.

1. Team members have adequate planning time. Most of the interviewees responded that the major contributor to a meaningful practice of teaming was having adequate compensated planning time together, both daily and in special extended planning sessions outside the school day or academic year. Few interviewees, if any, reported having enough time; rather, most complained that their present schedules had too little or no time in which to collaborate with other teachers and usually that time was voluntary. Most agreed that time to plan together needed to be scheduled on a daily basis as well as on weekends or days in the summer. The extra time is necessary for more comprehensive, long-term planning. Teachers pointed out that their team planning time should be in addition to individual planning time. Another teacher added that more time with the team was necessary not just for planning but for building "cohesion so teachers won't be fearful of sharing space, kids, or ideas." 
2. Team members are compatible and complementary. The second most significant factor which fosters effective team teaching is making certain that team members are compatible and complementary. This was voiced in a number of different ways. For some, compatibility was simply getting along, understanding each other, and "having a good personality fit between teachers." For others, it was sharing philosophy and goals. It meant teachers who "know how to work with a win-win attitude." "Teachers must want to work together and be able to work with others," stated one teacher. This takes "willingness to give as well as take," said another. "One must be able to disagree without destroying the group," added another. Another suggestion about team members was that "They should like each other." One teacher pointed to the need for administrators who are sensitive to personality types so as to insure compatibility of team members. "We need administrators who know their staff to get the right match," agreed another. Two teachers posed an interesting difference in opinion as to how to achieve this match, however. One suggested that teams ought to be more involved in the hiring process and placement of new team members in order to get teams who function effectively together. In contrast, another teacher cautioned that if teams chose their own members, the team might become too homogeneous and consequently more resistant to change.

3. Team members want to share. The third most frequently mentioned factor in achieving effective teaming and collaboration was having team members who have a common desire to share ideas and practices and to receive feedback. Several interviewees pointed out that isolationist teachers would probably not work well on a team. "Teachers must want to collaborate," they agreed. "Teachers must buy into teaming," one stated, "and they need to be trained to do so." Most interviewees supported the need for teachers who were eager to share units, help each other, and to guide; they also need to be equally eager to receive. Another teacher added, "Team members must like sharing ideas but be allowed personal choice as to how or if to use 
them." Another teacher observed that teachers not only must be willing to share ideas, but they also must be willing to share their students. The give and take dynamic in a highly functioning team is beneficial, observed one of the teachers: "It is important to bounce things off one another; it is good for the kids and the teachers who work with common kids." A willingness to share ideas and practices also "allows colleagues to validate teaching practices and strategies," added another.

Other factors cited by several of the interviewees included (a) having more material resources and money to support team plans, (b) having space and facilities in close proximity with other team members, and (c) having effective team leadership. "Specifically," stated one of the teachers, "the leader needs to know how to organize and run a meeting, manage people, and delegate duties."

Eactors which Contribute to Teacher-Advisor Role. A major concept of middle school teaching is that each teacher is responsible for an "advisory" and must assume a greater counseling role. This aspect involves far more than simply teaching. An advisory is a specific time set up in addition to the regular academic class schedule which includes activities specially designed to help students achieve a greater understanding of themselves and others. The goal of this understanding is for the students to become more responsible, creative, and productive.

Although schools differ in their actual programs, it is a common practice for them to assign students so that all three grades are mixed together and for their programs to require the teacher to work with the same students for the three years they are in the middle school. The overall philosophy is that teachers should play a strong role as student advocate, guide, and counselor. Teachers are to create a "home base" for students where they get to know each other and themselves better both formally and informally, and promote bonding so as to form a community within a community. 
The elite interview group was asked to reflect on this advisory/counseling role of middle school teaching and consider what factors enable them to function most effectively in this capacity. Responses revealed very strong feelings, both negative and positive, and a wide variety of opinions.

1. Teachers build trust. About half the teachers reported the most significant factor is the teacher's individual ability to build trust between the teacher and the student and among student peers. "Teachers have to be willing to share bits of themselves-just like we expect students to do," stated one teacher. Another referred to this as "showing the human side." "The teacher must have respect for kids," said another. "Trust comes through teacher modeling and maybe this will rub off," stated one of the teachers who then added, "A teacher must show respect, control of temper, and patience." Another commented, "Teachers as counselors must be willing to wade in with the children." Teachers need to build confidentiality and trust "by being good listeners and respecting the students," added another.

Many agreed that much of a teacher-advisor's success was dependent on the teacher's personality. Some just seem to have the "magic" and others do not. One of the teachers claimed, however, that the most successful teacher-advisors were those who had an elementary certificate "because they tend to deal more with the whole child." The importance of the teacher-advisor's dealing with the whole child was implied in another teacher's comment, "Somehow middle school teachers need to know what to ignore and what not to ignore."

2. Teachers care about the student and are committed to the advisory concept. Another factor rientioned by several of the interviewees was the importance of genuinely caring about the students and being personally committed to the value of advisory. Perhaps because advisory requires more personal, one-on-one relationships, this care factor is a critical one. "Teachers must really give a damn," one of the teachers 
emphasized. Another voiced her frustration about teachers who did not share her passion, and then posed the idea that maybe the teachers who really cared about the kids and liked advisory should teach it all day to different groups. "It is important for the teacher to both like the kids and want to deal with the counseling aspect," added another. "Sadly," lamented another, "there are some teachers who are totally resistant and their kids suffer."

3. Teachers have adequate time to work with the students. Many of the teachers pointed out the importance of time as a factor and the need for more of it with the students on a daily basis. "Too often advisory seems stuck in extra," complained one teacher. "Students need to stay with a teacher longer," another pointed out. "Kids need time just to interact." "The students can hardly share," said one, "because time is too short." Another added, "Too short a period hinders being able to counsel; it is harder to be an advocate." One teacher suggested that if advisory were for a longer period of time, then maybe it would not be "the last thing teachers tend to plan for and treat seriously."

4. Teachers are committed to advisory. Commitment to advisory was also a significant factor. Real personal and school commitment "would result in the focus of advisory being as important as the other classes," asserted one teacher. "Too often advisory is resented by teachers as taking away teaching time," stated another. "If it is such a priority then it should be treated as such." The commitment factor also has implications regarding where advisory is scheduled into the overall daily routine. Several pointed out that if advisory is at the beginning of the school day it serves as little more than a homeroom for reading announcements, taking attendance, and completing other house-keeping chores. On the other hand, if it is at the other end of the school day it functions more as a study hall. The sentiment of several of the interviewees was that the placement of advisory communicates a subtle but powerful message about how important advisory really is to the school building. 
5. Teachers have district and administrative support. District and administrative support for advisory was also reported to be an important factor. "The district must take advisory seriously," stated one teacher. "We need money from the district to plan our program," said another. "School administrators must support and promote it also," added another. Many suggested that the district specialists and building principals must do more to train teachers how to carry out their advisory role effectively. "Teachers must be taught primitive counseling techniques," said one. "They must be brought to a point of understanding as to the purpose of advisory and what it really is," added another. One teacher suggested that schools must help teachers "who either can't or won't be effective in advisory." Several proposed the idea that teachers might pair up and share advisories. Others mentioned the importance of hiring teachers with advisory in mind. In other words, no middle school teacher should be hired without first making certain that they were willing and able to take on advisory responsibilities. In addition to district and administrative money, training, and hiring practices, one teacher suggested the need for creating a peer support group which she called an "agony" group where one could go to debrief some of the heavy issues teachers deal with on a daily basis. Perhaps the district or school leaders could play a larger role in developing such support groups for middle school teachers.

Less agreement was voiced about other possible enabling factors such as letter grade usage, advisory focus, or class make-up. Some felt that letter grades were inappropriate for advisory while others were convinced that letter grades contributed to the class being taken more seriously. Equally divided on which focus advisory should have, some claimed that it should be less programmed, more interpersonal and relaxed, and more concentrated on affective issues. Others insisted it should be more structured, academic, and tightly centered around a specific theme or curriculum. Many stated their support for the heterogeneous mix of 6-8 graders; others felt advisory would be better if it included 
students from only a single grade level. A number also shared the belief that in large urban middle schools such as in Portland's, advisories would be more effective if integrated into the core curriculum rather than being a segmented component in the daily schedule with yet another group of students. The rationale was that rather than fragment student schedules and adult contacts even more, students would be better served by having "advisory" be an outgrowth of their core class where there was a greater chance for bonding among the peers as well as between the teachers and students.

Staff Development Practices which Promote More Effective Teaching. The final question in this portion of the interview inquired into staff development issues. Interviewees were asked to discuss what programs they believe have been most useful in promoting effective teaching and what suggestions they had for improving staff development in the future.

1. Teachers have a choice. The strongest consensus concerned the issue of teacher choice. Teachers respond best, the interviewees agreed, when they are given the right to choose what to study and whether or not they will participate. Most expressed the belief that this was an issue of "profession," and that mandatory attendance and arbitrary agendas caused teacher resentment. "Staff must be involved in deciding the needs and concerns on which to focus," stated one, "and teachers should have the choice whether to participate." Too much administrative decision as to what staff development should be and who should attend erodes the professional status of teachers, observed one of the interviewees. "Staff members need to be in charge of their own learning," another insisted, and then hastened to add, "It is good to make teachers aware of certain issues, but the principal should not tell them what they must learn or do."

Another aspect of voluntary attendance was pointed out by one of the interviewees who believes that this also helps administrators delineate between good and not-so-good 
teachers, "A good teacher is always growing; always willing to grow." Moreover, added another teacher, the choices teachers make can be used as criteria for recognition or promotion, "Those who voluntarily attend should be recognized and rewarded-made mentors, given leadership roles, or raised up publicly."

Several of the teachers commented that staff development planners and administrators would be well advised not only to give teachers a choice concerning participation, but also a choice of options. Those in charge need to listen to what teachers need and want, and then try to meet that need. A suggestion voiced by many was that staff development programs should offer a number of options or alternatives from which teachers might choose.

2. Teachers are involved. Many interviewees also stated that staff development would result in greater teacher buy-in if teachers had more control over its design and implementation. The importance of who does the instruction or "developing" was mentioned by several. "Middle school experts should do the teaching," stated one, "and it must model good middle school instruction." "Staff development should be led by other teachers or practitioners," said another who then pointed out, "The administrator can encourage, challenge, and stretch the teachers, and many staff on the inside are better than outside speakers." Several interviewees also suggested that instructors needed to involve the faculty in more role playing and actual teaching strategies which are expected in the middle school classroom. Such strategies include cooperative learning, bonding techniques, and simulations.

3. Staff development does not waste teacher time. Staff development promotes effective teaching when teachers do not perceive it as a waste of time. It must deal with "usable stuff," said one teacher, "what you can really put in your classroom, what deals with what I'm doing now." The following is a compilation of the most frequently 
mentioned areas of concern which the interviewees presented as relevant to the world of middle school teaching:

1. Special education kids

2. Dysfunctional families

3. Multi-cuitural and racial-ethnic consciousness raising

4. Instruction for new teacher inductees

5. Anger management for self and relating to student

6. Learning styles

7. Demographic changes and implications

8. Stress management

9. Effective communication

10. Curriculum alignment

11. How to deal with the students

12. Gender sensitivity

13. Alternative teaching strategies

14. Whole language

15. Writing process

16. How to funnel middle school energy

17. Classroom management

4. Staff development needs more sustained time. Several teachers mentioned that staff development would be more meaningful if it was given more time, not on a rigid weekly basis, but in longer weekend or overnight retreats more conducive to quality sharing, development, and follow-up. They also commented that systemic changes would be more likely to occur with longer periods of time available for concerns such as "building positive teacher attitudes and behaviors regarding middle school kids" or for dealing with "staff cohesion or the breaking down of faculty cliques." Another 
suggestion from an interviewee was that "more staff development ought to be scheduled in the summer when teachers are not so stressed." Many of the teachers agreed that conducting in-service at the end of a long teaching day is the least effective method of all.

Knowing Early Adolescents and Preparing to Teach Them. The last segment of the interview guide asked each interviewee to reflect on the middle school and its unique demands on the teacher and then to consider the following:

1. How critical to effective teaching is the teacher's knowledge of early adolescent needs and development?

2. How might a teacher be more fully trained to teach at the middle school?

"How important is a teacher's knowledge of early adolescent needs and development?" When asked to respond to this question, interviewees were practically unanimous in their chorus: "It is key! One could not effectively teach middle school without it!"

The following responses indicate the degree of unanimity and strength of conviction about this issue:

- "It is primary to teaching middle school."

- "It is number one."

- "It is crucial!"

- "The curriculum and academics must be based on early adolescent development."

- "Very! If you do not, you will not have realistic academic expectation."

- "It is important because it impacis teaching strategies."

- "If you do not know early adolescents, you will be frustrated and probably not survive middle school teaching."

- "It is an absolute!"

- "You have to understand early adolescents in the present. You need more current knowledge and must constantly revise it." 
- "You have to know where they are coming from and where they are going."

According to these comments, this elite group of effective middle school teachers considers knowledge of the early adolescent to be the absolute foundation of effective teaching at the middle school level.

\section{Teacher Training Institutions which Produce Effective Middle School Teaching}

Finally, the interviewees were asked to discuss what a teacher training program should include in order to produce more effective middle school teaching. They were also asked whether or not they supported requiring middle school certification before one could be hired to teach at the middle school level.

The interviewees revealed overwhelming agreement that prospective middle school teachers must (a) spend far more time in observations and practice teaching, (b) be extensively trained in early adolescent psychology, and (c) be required to have more training in counseling, teaching strategies, and behavioral issues which especially address early adolescent needs.

Exposure te the Early Adolescent. Most interviewees agreed that prospective middle school teachers need earlier exposure to early adolescents simply by being around them and by working with them individually and in the classroom. "Potential middle school teachers should begin a practicum from the very start," one teacher commented. "All of the [university] education should be based on actual application," stated another. One teacher endorsed requiring greater exposure to the classroom and the student client through a series of steps: observations of middle school classes, tutoring sessions with an early adolescent, pre-practicum only with a very effective teacher, and internship with time built in for conferences. Another suggested that prospective teachers "should take a case study of one middle school kid and track him or her all day and after school." The idea was to see how they really live and spend their time. Still another said, "More time 
should be spent just visiting a middle school before deciding you want to teach there." The general consensus was that no new graduates should be hired to teach at the middle school unless they also did their student teaching in one. Many others stated that teachers in training should spend lots of time observing all three school levels. For most, this was a critical issue-prospective middle school teachers, based on multiple exposure and experiences to the early adolescent and to the middle school, must knowingly choose the middle school as their preferred level. (Several added that visits to the elementary school would also be beneficial in another way: they would inform the teacher about what precedes middle school.) One teacher suggested that anyone interested in teaching middle school students could gain greater insight into the early adolescent by reading more youth literature (books written about and for today's teenagers) and watching movies and TV shows popular with early adolescents.

Specialized Middle School Training A need for more extensive course work in early adolescent psychology-their needs and development-was also a strong finding. One interviewee stated that teachers "need specific intellectual, developmental, physical, and social knowledge of middle school kids." What they need is more of an understanding of the whole child, said another. Moreover, added another teacher, universities must base this education "on actual case studiøs of real middle school kids."

This select group of teachers was emphatic about 'what must be included in a university middle school program. Once the prospective teacher is solidly grounded in early adolescent psychology, they said, then the program must include classes in counseling, teaching strategies, and classroom management techniques designed specifically for the middle schooler and the middle school. One teacher insisted that more classes were needed which taught "how to deal with middle school kids and their stresses-on the mind of the child." Another stated that university instruction should be more "situational." Classes must include cooperative learning techniques and application 
and learning styles theory. The interviewee interpreted this to mean that the students in the university classes actually engage in cooperative learning strategies themselves and the instructor not only teaches learning styles theory, but applies it to the students in the class. One of the teachers declared that the university "must get away from teaching about a subject area; rather, they must teach how to teach. The how is much more important." Then she added, "Teachers need to be inundated in affective teaching skills, learn more about assessment and evaluative strategies that deal with the whole child, and should have some special education course that teaches how to know what you are looking at." Another suggested that methods in subject areas are important, but should all be tested in actual middle school settings. One teacher pointed out that a grasp of subject matter should also include interdisciplinary teaching strategies and the application of teacher teaming. Another stated, "Teachers must plan curriculum and strategies to fit the early adolescent attention span and their needs for socialization," and "All materials and resources made and used at the university must be monitored by early adolescent needs and characteristics." Then she added, "Teachers must also be equipped to deal with problem solving issues and know how to teach problem solving strategies that have to do with behavior as well as content areas." Teachers need more training in group dynamics and motivational techniques, another stated. To all of these recommendations, another interviewee added that teachers "need to receive more classroom and behavior management classes which are oriented to the individual." "Also," she went on, "It is critical for teachers to know that these kids' feelings must be validated." One interviewee commented, "University programs need classes in dealing with student anger and stress and how to diffuse an escalating situation. Teachers need to understand early adolescent actions to avoid overreacting. What might look like murder," she cautioned, "may be two early adolescent kids saying 'Hello!'” Teacher training also needs classes 
on effective communication with early adolescents, noted another. Last, many agreed that the university must require assignments to be pilot tested on real middle school kids.

Interview findings revealed another area of agreement which had to do with the teacher candidate personally. One of the interviewees pointed out the need for a screening device to find out about the candidate's personal attributes. "There must be a way to weed out those who just can't and shouldn't teach middle school!" Candidates "have to really want to be in a middle school," insisted one, while another stated passionately, "Every candidate must believe he or she can make a difference." In addition to middle school candidates being committed to the middle schooler, said another, "they must have respect for student feelings."

University programs need classes that really get at "the nuts and bolts," summed up one of the teachers. One teacher suggested that these might include a course on stress management for the teacher, such as a class on how to maintain one's physical health and high energy level. Teachers must be able "to deal with the fast pace of the middle school," advised another. One interviewee pointed out an additional aspect of middle school teaching: learning how to juggle and manage multiple responsibilities such as duties, advisory, meetings, and paperwork. One must be taught how to stay on top of it, she insisted, and still be efficient.

The final piece of the university program which was mentioned by several of the interviewees had to do with the internship. Many of those interviewed agreed that after lots of exposure to the middle school and the early adolescent early in the program, after successfully completing extensive training in courses with direct application to real middle schoolers in real settings, and after making a personal commitment to teaching at this level, then the candidate must complete a full year of internship in a middle school. Equally important, stated several of the teachers, the mentor teacher must be an expert at middle school teaching and have quality time scheduled to meaningfully observe, confer 
with, and assist the teacher candidate. Moreover, there must be "a careful match between master and internee," added another. One of the interviewees advised that when the candidate is hired, that first year in the classroom should be considered an "apprenticeship" wherein the teacher is teamed up with a highly effective and experienced teacher who continues to guide and support the new teacher.

\section{A Middle School Certificate}

Should the university offer a middle school certificate? Reaction to this question elicited a "yes" from the majority of interviewees. The rationale was that a specific middle school certification program would provide the necessary specialization and training needed at the middle school. A number of others, however, were less certain and expressed various concerns: "A middle school degree may be too limiting," said one, and then hastened to add, "but we do need more middle school classes." A music teacher answered, "Yes and no. In music one has to know about all the levels if you want a job." Another stated, "It is nice to have the freedom of a K-8 certificate, but we do need more classes at the university level that deal specifically with middle school issues." One of the teachers hedged, "I might want to keep my options open."

It is important to note that although some were not sure about the middle school certificate issue, a number of the interviewees voiced their feelings about the uniqueness of teaching at a middle school and their personal bias concerning elementary versus secondary certification: "I am uncertain about a specific middle school certificate, but I am very certain that high school trained teachers should not be at the middle school!" exclaimed one interviewee. Another confessed, "I'm not sure [about the certificate], but I am sure they should not be secondary trained." Another stated that although K-8 and secondary certification overlap somewhat, " $K-8$ is a much better preparation than a secondary degree." A fourth teacher concluded that a middle school certificate "is not 
appropriate because a certificate might reduce the diversity that can better spark the kids. However," she continued, "experience at the high school is not as effective for working prior to the middle school. It is best to have been in the elementary school so you can see where kids have been and what works."

Thus, although there was no consensus about a middle school certificate, the interviewees seemed to heartily endorse a special teacher training program at the university level which focuses on the middle schooler and all the demands of the organization which include counseling, multiple teaching and learning strategies, interdisciplinary instruction, and teaming. They strongly agreed that this training program employ university instructors who are middle school experts and/or practitioners. finally, they insisted that universities require teacher candidates to have numerous exposures to middle schoolers in their own environment. Following this, the teacher candidate must decide, based on multiple observations, that this is the level they genuinely want to teach, and then invest one entire year in a practicum supervised by an expert mentor teacher. 


\section{CHAPTER V}

\section{SUMMARY AND DISCUSSION}

The purpose of this chapter is to summarize the methodology, research problems, and the most significant findings of the research. This chapter will identify and interpret the major findings of the questionnaire and the interviews, and summarize what the elite group of effective middle school teachers reported to be the major factors which promote and maintain expert practice in the middle school. It will also discuss the implications of these findings, particularly in the pre-service training and in-service maintaining of expert middle school teachers.

\section{QUESTIONNAIRE INSTRUMENT}

The questionnaire instrument used for Phase I of this study was used to discriminate among a pool of potential middle school teacher interviewees to determine those who reported the views most closely aligned with a review of the literature. The interviewee

pool was described in Chapter III. Topics for the questionnaire were derived from the literature and presented in Chapter II. An analysis of the empirical use of the instrument with 307 middle school teachers was made in order to defend the identification of subjects for interviews. As described in Chapter III, this study was designed to explicate the views of an elite group most likely to have pertinent and fruitful ideas for supporting good teaching practice.

Results of the item analysis of the questionnaire, presented in Chapter IV, showed sufficient variances and range in survey response to suggest that some discrimination 
occurred. The internal reliability and factor analysis suggested that the discrimination occurred in patterns which could be interpreted and defended.

\section{INTERVIEW INSTRUMENT}

Phase II involved interviewing an elite group of 19 teachers who were selected out of the 307 valid questionnaires. These interviewees both agreed to be interviewed and scored highest on an 80-point instrument total score. (The higher their instrument total score, the more closely their self-reported knowledge and beliefs were believed to be in alignment with the literature.) These teachers represented the top scoring $10 \%$ of the respondents to the questionnaire.

Although it was not possible to confirm their self-reported effectiveness in an objective way (i.e., by principal nomination, student or parent assessment, or by student outcome on standardized tests) the questionnaire was found to be statistically valid and reliable in discriminating among teachers whose self-reported knowledge, practices, attitudes, and beliefs were or were not aligned with the findings about effective middle school teachers in a review of the literature.

The Carnegie report, Turning Points: Preparing Youth for the 21st Century (1989), recommended eight ways in which schools can best serve early adolescents. One of those recommendations was to staff America's middle schools with "expert" teachers. This is certainly a fine goal. However, one needs to examine what "expert" teachers are, what makes them, and what maintains them.

The main goal of Phase I was to ferret out an elite group of effective teachers in order to get their input regarding the factors they believe are most beneficial to promoting and maintaining effective middle school teaching. The rationale was that since teachers are the practitioners, it seemed logical that their opinions would be more valuable than 
those outside the actual classroom and the middle school experience. Teachers represent an insider's point of view and their unique perspective and order of priorities may shed new light on why some middle school teachers are more effective than others.

Once teachers have identified what they perceive to be the most critical factors which contribute to effective middle school teaching, then one must ask the following: Are these factors replicable? Do some factors warrant greater attention than they are presently getting? Are there personal attributes which cannot be taught, but which should be considered in the early stages of screening out those who are dispositionally not suited for middle school teaching?

This researcher is absolutely convinced that the teacher is the key to having a major impact on and positively turning around early adolescent lives. One recent publication about middle schools stated, “... it is warranted to assert that no matter what textbooks, materials, curriculum guides, and such are employed, the teachers are the curriculum (George et al., 1992)." Moreover, in spite of grade configuration, teaming, staff development programs, or advisory, there is nothing a district, individual school, or principal can do that, once it passes through the classroom door, isn't filtered, interpreted, and shaped by the classroom teacher. State boards of education can pass mandates and state legislatures can require a certain curriculum be taught, but, all of it is screened and "personalized" by the teacher. They do hold the key.

It is precisely because of this fundamental belief that this study involved themteachers who are in the trenches daily struggling to teach one of the most difficult and challenging age groups. An elite group of uncommonly knowledgeable teachers was sought out for interviews with the hope that they would contribute to the body of knowledge concerning what most enables teachers to be effective at the middle school level. Their views deserve attention and thoughtful reflection as heightened national interest is focused on further developing the middle school organization which is rapidly 
becoming a full partner as the middle tier between the elementary school and the high school, and whose sole purpose is to better respond to the needs and characteristics of early adolescents.

\section{THE RESEARCH QUESTIONS}

The major research question was "What do expert middle school teachers identify as the most significant factors which promote and maintain effective middle school teaching?" Other questions concerned what middle school teachers are required to do in their job as a middle school teacher and asked what factors most enabled them to be effective in their roles as team members, teacher-advisors, and participants in staff development. Another question asked about how school administrators enable effective teaching.

Using a semi-structured interview protocol, these teachers were asked to respond to the preceding research questions. They were also asked for their opinions regarding the importance of knowing early adolescent needs and characteristics, whether a middle school certificate should be required, and what should be the fundamental components of a university middle school teacher training program which would most likely produce effective middle school teachers.

The subjects considered most useful to this study were those teachers who, through a questionnaire instrument, self-reported knowledge, practices, attitudes, and beliefs most closely aligned with the literature discussed in Chapter II. 


\section{MAJOR FINDINGS}

\section{Common Philosophy}

The first finding reveals that most of the teachers shared a common philosophy concerning effective middle school teaching. Every interviewee defined it as a balance of addressing academic and affective concerns. However, many hastened to add that if for some reason there had to be an imbalance, it must weigh more heavily on the side of the affective rather than the academic concerns. The general consensus was that if one cannot get beyond the personal issues-students' physical needs, attitudes, social or emotional problems, low self-esteem - then trying to teach academic content is a futile effort. Ideally, the curriculum embodies authentic learning which teaches academic content at the same time that it attends to individual needs and problems. The interviewees conveyed that this was not a dichotomy of academic versus affective. It was, rather, an overlapping, a "blending of the two," and expert teachers know how to do both. The authors of a recent publication, The Middle School-And Beyond (George, et al., 1992), alluded to this understanding when they wrote, "While expert middle level teachers appreciate and promote academic integrity, they assess achievement in light of students' developmental capabilities. These teachers know that laughter and even whimsy have a place in their students' experience" (pp. $27 \& 28$ ).

The strength of finding this shared understanding about middle school teaching is made even more compelling when one considers its congruence with the definition of effective middle school teaching set forth in Chapter I. These interviews were conducted separately one-on-one, without advance preparation as to which questions would be asked. Most interviewees responded with little or no hesitation. 


\section{Desire to Work with Early Adolescents}

Second, when asked what factors they perceived to be most critical as enablers of effective middle school teaching, these expert teachers responded almost unanimously with an overwhelming declaration of their desire and commitment to teach this early adolescent age. Some even professed "love" for these youngsters. Most, however, described their feelings as a sense of genuine concern for them as emerging adolescents; they shared a feeling of sincere empathy for their struggles, anxieties, and multiple growing-up issues. They felt needed by these youngsters and they believed they had something to give them. The very fact that these teachers liked working with early adolescents was apparent and they derived from it the satisfaction that they were somehow specially suited to working with these students. Indeed, the fact that these interviewees had made a conscious choice to devote their energies toward making a difference during these turbulent years, was one of the foremost factors which they perceived as enabling them to be effective.

This commitment to the young adolescent appears to be fundamental to effective middle school teaching and is supported over and over in the latest middle school studies as well as in these interviews. Students trust, respect, and want teachers who say to them in word and deed, "I value you, I understand you, and I believe I can make a significant difference in your life." Teachers who practice this level of commitment find their ability to reach and teach middle schoolers greatly enhanced. Stated in the reverse, these teachers support the assertion made by McEwin \& Thomason: "Teachers who are unable or unwilling to accept and accommodate early adolescent behavior can create tremendous barriers to educational change in middle grade schools" (1989, p. 9).

This kind of attitude and commitment is not teachable. It is, rather, part of the art of teaching. Some just have it and some do not. This group of effective teachers believe it is critical that middle school teachers search inwardly and examine one's level of 
commitment. Many teachers are definitely not cut out for middle school teaching; teachers are not interchangeable parts. For the sake of the students, no teacher should stay in a school where they find little or no satisfaction. Early adolescents deserve and require only the most committed.

\section{Teaching and Classroom Strategies Based on Needs of Early Adolescent}

Knowing how to teach the early adolescent effectively and how to manage a class full of them was another major factor identified as a contributor to effective middle school teaching. In addition, one should note that for every example of a problem situation to which the interviewees referred, the solution suggested was directly predicated on the teacher having a thorough knowledge of early adolescent needs and characteristics: The early adolescents' short attention span? Use multiple strategies. Their needs for physical movement? Build in action oriented activities such as role playing, simulations, or just plain "body breaks." Their varying learning styles? Intentionally plan a variety of visual, tactile, and kinesthetic activities. Their need for authentic or "real" learning? Develop curriculum activities tied to the real world and concerns and issues in the students' lives and community. Their different intellectual levels? Offer a mixture of concrete and abstract learning opportunities. Their extreme need to socialize and receive peer approval? Utilize cooperative learning and lessons that involve peer interaction. The need to experience success? Individualize, recognize, affirm, and offer such a diversity of experiences that every child can somehow succeed. Do more formative and less summative evaluation. Their need for independence? Give choices accompanied by responsibility, structure along with flexibility. The demands for justice and fair play? Listen, respect, and democratize authority by allowing students to participate in decision-making. 
The preceding problems and solutions suggest that middle school teachers are truly teacher-magicians. They must constantly walk a fine line trying to maintain a balance between academic and affective needs and individual and group needs. However, this is what effective middle teaching is all about. Although these practices are good at any level, at the middle school they are a intisit

\section{Middle School Teachers Need High Sense of Self-esteem}

Finally, an unexpected response from a number of the interviewees was the importance of high teacher self-esteem. This factor is worth pondering. At the elementary level, most classroom teachers are rewarded with much praise and "warm fuzzies" from both students and parents. It is the nature of the younger child to be less suspicious and critical than the early adolescent. It is a very different youngster who enters at the sixth grade. The early adolescent is more egocentric, selfish, and critical. It definitely matters to the student if the teacher notices a new pair of shoes or hair style. A student's mood swings and social squabbles can easily dominate the curriculum and subvert teacher efforts. Middle schoolers want and need teacher respect, acceptance, faimess, safety, trust, and recognition. However, at the middle school such factors often constitute a one-way street and can severely drain the emotional resources of a less confident adult. Based on this reality, these expert teachers pointed out the necessity for the middle school teacher to have a high sense of self-esteem, an essential in even the best of teachers who must deal with the numerous comments and criticisms of the typical middle schooler. Early adolescents have an uncanny ability to discover a teacher's vulnerabilities and to "push the right buttons." Many middle schoolers are intentionally rude, critical and extreme. Confident teachers with a strong positive self-concept and high sense of self-esteem have the ability to laugh at and to accept themselves, warts and all. They know how to deal effectively with their students firmly, sensitively, and fairly. 
They also know how to diffuse a potentially explosive or confrontational situation and turn it into a positive learning experience for the parties involved. A strong self-concept also allows teachers to admit that they make mistakes or that they do not have all the answers. Such admissions build the collaboration and reciprocal trust necessary for healthy interactions with young adolescents. However, in spite of having a high selfconcept, several of the teachers also pointed out that all of the preceding factors make teacher support groups very important to the maintenance of effective middle school teachers.

Other factors identified as important to promoting and maintaining effective middle school teaching included having supportive administrators; adequate time for teaming, planning, and reflecting; and strong peer collegiality. Factors identified as coming from within the teacher were the ability to adapt to change, possession of a sense of humor, enthusiasm, and energy; and a feeling of being empowered.

One might note that, to a large extent, few of these factors require large financial expenditures to develop or unrealistic demands. It seems ironic, therefore, that with the recent national focus on the middle school as the last best chance for at-risk students and the urgency presented by high numbers of these students, that with the cost so minimal more attenison is not given to fostering and/or nurturing greater effectiveness in the teachers charged with teaching these student.

The second portion of the interviews stressed commonly accepted middle school organizational components and practices: leadership, team teaching, advisory, and staff development. What do effective middle school teachers say are the most important factors which enable effective teaching and/or what factors maximize their effective involvement in each of these areas? 


\section{Principal as Enabler}

The elite interview group reported that the principal enables them by being a good listener and proactionary, the school visionary, and supporter of the teachers as professionals and peers. Preferred principals, they said, promote collaboration between teachers and demonstrate by example that they know, understand, and like the early adolescent. Enabling principals demonstrate a broad knowledge of the middle school curriculum and instructional strategies appropriate for this age. They empower others, maintain high visibility, and are alert to teacher stress and burn-out.

Although many of the teachers agreed that the principal is critical to the overall effectiveness of the school, it was interesting to note that for most of the interviewees the principal was a peripheral factor. For these self-confident and effective teachers faced with the daily task of teaching early adolescents, what seemed to matter most was that the principal was minding his/her own job, shared the teachers' concerns and affection for the students, and knew how to provide help whenever teachers needed it. Enabling principals did not create obstacles, unnecessary paperwork, or hamper the teachers doing their job. In summary, their perception of the enabling principal is summed up as being an expedient trouble-shooter, an efficient "go-fer" and the chief visionary.

\section{Effective Teaming}

The interviewees revealed that they felt enabled to be effective team members when they had meaningful blocks of time in which to plan; were compatible with other team members; and, as a team, shared a desire to collaborate, help each other, and receive feedback. The key factors to enabling this kind of effective teaming was creating the right mix of teachers on the team and committing to the team concept. Somehow, whether it is the job of the principal, members on the team, or a combination of both, the placing of teachers on a team necessitates intelligent and thoughtful consideration. The 
bottom line, implied the interviewees, is that if members are not cooperative or committed to the team concept, the team will be ineffective and dysfunctional.

\section{Advisory}

Advisory, like teaming, generated the greatest amount of variation in individual responses from the elite interview group. Some of the interviewees indicated their dissatisfaction with poorly structured programs which were nebulous in their purpose while others were whole-heartedly supportive and positive about their advisory programs and their participation in them. Nonetheless, there were many worthwhile suggestions as to how teachers can be more enabled to effectively fill their teacher-advisor role.

Trust Factors. The most frequently mentioned factor was a teacher's ability to build mutual respect and trust with the students. The fact that this emerges as a major factor for being effective as a teacher-advisor is significant. This finding is supported by the writers of The Middle School And Beyond: "Youngsters need not only someone they respect but someone who they believe is sympathetic, worthy of confidence, and who can be relied on as an advocate" (George et al., 1992, p. 21).

Holistic Approach. Effective teacher-advisors want to meet the needs of the whole child-their social, physical, emotional, and moral needs, as well as their cognitive needs. Teachers are more effective in this role when they are convinced of the value of advisory and committed to further developing the concept. Without this commitment, admitted the teachers, advisory becomes a sham.

Training and Suppert. Another contributor to effective advisories is district and administrative involvement in training and supporting teachers. Several interviewees pointed out that truly caring for the students in advisory, their emotional and social needs in particular, can create incredible stresses which need a constructive outlet. Teachers are 
sustained when there is some forum for feedback, affirmation, and reassurance that their efforts are not in vain.

\section{Staff Development Must Involve Teachers}

As for the issue of staff development, the interviewees' greatest concern was that it involve the teachers more. Teachers want to select what to study and have the professional right to choose whether or not to participate. True professionals do what is right, they argued. Therefore, personal choices which teachers make create a natural basis for promotion, recognition, and rewards such as merit pay or mentorships. More teacher input also results in greater teacher buy-in. they contended. Most of the interviewees generally did not favor using outside speakers or non-middle school practitioners.

\section{Teacher Training}

Based on the deep conviction that the bottom line of effective middle school teaching is knowing and understanding the client, this expert panel of teachers had several suggestions for improving the training of future middle school teachers. First, they must spend more time observing, interacting with, and practice teaching early adolescents at the beginning of their teacher training. This was based on a belief that prospective teachers need to discover early whether or not they are truly suited for this age level student. Second, the trainee must be thoroughly immersed in early adollescent psychology. Third, all the course work must be based on the needs and characteristics of the early adolescent and include the applied use of preferred teaching and learning strategies by both the trainees and the instructors. Thus, application of middle school teaching methods should be both modeled and practiced. Furthermore, the bulk of the methods classes must be taught by middle school experts. 
The final suggestion was that an internship should last an entire year from the opening day of school to the last and that interns must be paired with only the best teacher-mentors. Meaningful blocks of time must be built into this year for conferencing, observing, and problem solving. Meanwhile, because so much of one's ability and success in middle school teaching is predicated on one's personal attributes, those who are dispositionally unsuited for early adolescents should be weeded out early in the program.

Although a majority of the interviewees responded favorably to the university's offering a middle school certificate, the general sentiment was that as long as the state offers overlapping elementary and secondary certificates, it is unlikely that teachers will voluntarily limit their options with a more restrictive certificate. However, what most did agree on (some adamantly), was that teachers with a secondary certificate were the least prepared as teachers at the middle school.

\section{CONCLUSION}

The central argument in this research was not to discuss whether middle schools should contain certain grade configurations, have advisories, or use teacher teams. Nor was it to argue the case for making the middle school a legitimate partner in a three level educational system. The Portland school district was chosen for this study precisely because, after 20 years of development, it was well beyond those issues. Portland's

middle schools are in the second stage of development-one of fine-tuning and refining. It is the teacher who is now at the center. No matter what grades are included in a building or what organizational concepts are practiced, it is still the teacher who filters it all and has the potential to be the most significant player as a "turning point" for the student. The greatest goal, and possibly the most difficult, is the challenge set forth in the 
Carnegie report Turning Points: Preparing Youth for the 21st Century (1989). The challenge of the report is to ensure that America's middle schools are staffed solely with expert teachers-those who love and understand early adolescents, who teach in ways most effective with them, and who find their joy and job satisfaction from knowing they are significant contributors in turning these young people toward a meaningful, positive future. For too many students, middle school represents their last real opportunity to succeed.

As one visits the different middle schools, talks with the teachers and students, and observes teachers interacting with each other and the students, it is usually apparent that some teachers are tremendously successful, happy, and effective as life-changing agents. Why? That was the central question of this research. And rather than dwell on the negative - those factors that cause teacher failure, burnout, or ineffectiveness-this study went to those teachers who self-reported effectiveness and positive feelings about working with middle school students in order to ask of them what enables them to teach effectively and enjoy it at the same time.

The most significant overall finding was the amazing similarity between the responses of these expert teachers and the findings presented in the review of the literature. More significant, however, was discovering that the factor mentioned most was having a sense of commitment to and caring about the early adolescent. The interviewees' words which were transcribed could not possibly capture the light in the teachers' eyes or the enthusiasm written on their faces as they exclaimed, "You must love kids-especially middle schoolers!" and "You must have a commitment to each kid and refuse to let them fail!"

It is equally important to point out that these teachers never minimized the necessity of being knowledgeable in one or more subject areas. They always hastened to say that teaching the students academic information was essentially part of what makes a teacher 
an "expert." They felt, however, that the greatest difference between effective versus ineffective middle school teachers was commitment, empathy, and concern based on a thorough understanding of the early adolescent which most enabled them to reach the human first and then the human's intellect.

It was obvious that from these expert middle school teachers' points of view, this sense of commitment has to be the engine and not the caboose. After the facts and formulas are forgotten, these are teachers who students will long remember as those who genuinely cared about them had a positive impact on their lives academically, emotionally, socially, physically, and spiritually.

\section{IMPLICATIONS}

Based on the responses of the elite interview group, the implications of this study are these:

1. Middle school is not the place for "general practitioners;" it is for "middle school specialists who are expert." Only those teachers who want to teach middle school and have the necessary specialized knowledge, practices, attitudes, and beliefs should be hired to teach students at such a critical period of their lives.

2. Teacher training institutions must require that candidates demonstrate a positive desire to teach and a positive attitude toward early adolescents. They must receive extensive training in teaching and learning strategies most suitable for the early adolescent, and be exposed to multiple experiences with early adolescents in a variety of settings before deciding that middle school is their niche.

The Carnegie report on adolescent education stated that a major recommendation for transforming middle schools is to acquire specially selected and educated teachers to work with the young adolescent. It maintains that too many teachers of these young 
people dislike their jobs, never wanted to teach at the middle level in the first place, and view the middle school only as a way station leading to another teaching position.

Tragic, but true, many middle schools are used as dumping grounds (Carnegie Council on Adolescent Development, 1989).

The findings in this study reveal that teachers must first and foremost want to teach at this level. No matter how talented or educated, these teachers must have had a wide variety of experiences with early adolescents and, based on the success of these experiences, decided to commit themselves to working with them. In The Middle School-And Beyond (George, et al., 1992), the authors asked this question regarding middle school teachers: "How is it that so many teachers can be disappointed while others have found their professional niche and want to stay where they are?" Despite limited research, they offered the following conclusion: teachers with the greatest understanding of adolescent development prefer teaching middle school children. These are teachers who "enjoy working with students in developmental transition" (George et al., 1992, p. 24). This means they are energized by the middle schooler's exuberance for living, discovery, and challenge. Effective middle school teachers like the demands for variety and innovation, and they are comfortable with making schoolwork fun. Effective teachers feel validated because they know they make a difference. "When teachers are dispositionally suited for this work, they make valuable contributions to youngsters' lives, from which they accrue the satisfying benefits of professional efficacy" (George et al., 1992, p. 17).

A simple question or two on an application form asking why one wants to teach at the middle school level is not enough. Interviews by several people and observations of the applicant interacting in different settings with the students seems more advisable. Closer examination of past experiences and references might also be in order. Most 
important, however, is requiring a probationary period which would include multiple observations, conferences, and opportunities for peer and student feedback. Moreover, districts and schools should do much more to facilitate peer observation and interaction during this probationary period.

Additionally, as experienced teachers lose their sense of commitment for teaching early adolescents, districts should make it easier for teachers to transfer to a different level or to take a sabbatical. Even a one month leave of absence might be sufficient to revive an exceptional but burned out middle school teacher. Middle schoolers deserve to be taught only by those who really want to work with them and who have the personal qualities best suited for the early adolescent.

Teachers must also accompany their sincere desire to work with these youngsters with a demonstrable show of knowledge and practices known to be most effective in teaching early adolescents. Such a demonstration also implies that administrators or teacher-leaders must be expert middle school teachers in order for them to recognize and promote the best practices. Furthermore, teachers are more likely to respect and invite feedback from their leaders when they see in them the same levels of expertise and commitment that they expect in themselves. Seeing these parallel levels of expertise builds a reciprocal trust factor between teachers and their administrators which is critical to promoting professional growth and maturity in a middle school teacher.

Finally, this study has strong implications for teacher training institutions. The elite teacher interviews revealed three significant areas of agreement:

1. There must be a way of screening teacher applicants to find out which ones are most dispositionally suited for and have the desire to teach early adolescents.

2. Trainees must be completely immersed in middle school pedagogy and curricular strategies which are in direct response to early adolescent needs and development. 
3. Training institutions must require much more exposure and experience with early adolescents.

It may be that becoming an expert middle school teacher requires more extensive training both before and after beginning to teach than is required at other teaching levels. A middle school teacher might thus be considered more of a "specialist" than either an elementary or a high school teacher. Based on the law of supply and demand, this fact has considerable compensatory implications for the middle school "specialist." The demand for middle school teachers to be both a specialist in two or more subject areas as well as a child-centered generalist and advisor to students during the most tumultuous and vulnerable period of their lives, suggests that teachers at the middle level have to be even more capable, knowledgeable, and expert than teachers at other levels.

Although such suggestions may fall on deaf ears, recognition of the unique demands on the middle school teacher deserves some consideration for their being given additional planning time and/or smaller classes. Moreover, districts must no longer tolerate their middle schools being used as dumping grounds. Rather, they need to be institutions where only "experts" are allowed to practice. This would certainly do much to attract the very best teachers to the level where the best are needed the most.

\section{POTENTIAL APPLICATIONS}

One potential change which these findings suggest is the creation of a distinctly unique middle level program at teacher training institutions. This program should be sufficiently different from elementary or secondary level programs to merit its existence as a special field of study with its primary focus on the early adolescent. Considerable input from researchers, educators, and scholars would be necessary to develop the curriculum and continuum of hands-on experiences with early adolescents. Requiring a middle school certificate needs to be examined more closely, however. Although many 
interviewees endorsed having such a certificate, they were quick to point out that it should not limit the fluidity of moving up or down to other levels of teaching.

At middle school level, several potential applications may also be suggested. More attention needs to be focused on the teachers who presently staff the middle schools. In Goodlad's study of America's schools (1984) he wrote, "Talk of securing and maintaining a steady corps of understanding teachers is empty rhetoric unless serious efforts are made to study and remedy the conditions likely to drive out those already recruited" (p. 173). Although little research has been conducted on why some teachers choose the middle school, the researcher presumes that many are there because they enjoy the curiosity, energy, and challenge of the early adolescent client. However, it is also true that the leadership, peers, and staff development programs can do much to promote effective middle school knowledge and practices. Teachers need to be encouraged to experiment with new teaching and learning strategies. In fact, experimentation, risk-taking, and using non-traditional methods should constantly be applauded. If failure occurs, it should be accepted as part of the experiment. Greater efforts by schools to accommodate mentoring and observation of master teachers also need to be made. Effective teachers benefit tremendously both from being observed and by observing.

School leaders and staff development specialists also need to pay attention to the advice of these experts regarding staff development and allow teachers to have greater involvement in determining what they need to learn in conducting training and in choosing whether or not to participate. According to the interviewees, this communicates to teachers that they are respected professionals and encourages more teacher buy-in.

This study also has potential applications in hiring practices and teacher induction. First, school districts must make certain that only those who truly want to teach at the middle school are hired. The middle school must stop being the dumping ground. Early 
adolescents demand "specialists" who have chosen to work with that age, are committed to them, and know how to meet the needs of the whole child. Second, all beginning teachers should begin at an apprentice level. This apprenticeship should include close mentoring with an "expert" as well as on-going training in middle school issues or instructional techniques. The apprentice might also have a reduced teaching load in order to spend more time in observations and co-teaching assignments.

Third, districts should consider carefully their hiring policies regarding administrators. District policy should require middle school principals to have had classroom experience in the middle school. Moreover, assistant principals should be like apprentice teachers; they should be placed in that position to learn from the mentor principal and then move on into a middle school principalship. Why should the middle school be used as the jumping off place for administrators who really want to work at the elementary or high school level?

Finally, districts need to reexamine their student evaluation policies. In many middle schools today, great emphasis is still placed on summative evaluation. Yet, effective middle school teachers are aware of the unnecessary pressures grades place on their students. If given the time and forum to use alternatives which allow for more formative evaluations, many would choose them as being more meaningful, constructive, and conducive to meeting the needs of the early adolescent. The question as to the value of letter grades at the middle school level is worthy of another study.

Perhaps the preceding applications will better inform and give direction to those who want to provide the best possible education to students facing the most critical turning point of their lives. 


\section{SELECTED BIBLIOGRAPHY}

Aahar, J.M. (1990). Interdisciplinary teaming as a school intervention to increase the social bonding of middle level students. In J.L. Irwin (Ed.), Research in Middle Level Education (pp. 1-10). Columbus, OH: National Middle School Association.

Alexander, W.M. (1987). Toward schools in the middle: Progress and problems. Journal of Curriculum and Supervision, 2, 314-329.

Alexander, W.M. \& McEwin, C.K. (1988). Preparing to Teach at the Middle. Columbus, $\mathrm{OH}$ : National Middle School Association.

Alexander, W.M., \& McEwin, C.K. (1989). Schools in the Middle: Status and

Progress. Columbus, $\mathrm{OH}$ : National Middle School Association.

Ary, D., \& Jacobs, L. (1985). Introduction to Research in Education. Fort Worth: Holt, Rinehart and Winston, Inc.

Ausubel, D.P. (1960). The use of advance organizers in the learning and retention of meaningful verbal material. Journal of Educational Psychology, 51, 267-272.

Ayers, W. (1986) Thinking about teachers and the curriculum. Harvard Educational Review, 56, 49-51.

Beane, J.A. (1990). A Middle School Curriculum: From Rhetoric to Reality. Columbus, OH: National Middle School Association.

Beane, J.A. (1991). The middle school: The natural home of integrated curriculum. Educational Leadership, 49 (2), 9-13.

Beane, J.A. (1992). Turning the floor over: Reflections on a middle school curriculum. Middle School Journal, 23 (3), 34-40.

Beane, J.S., \& Lipka, R.P. (1986). Self-Concept, Self-Esteem, and the Curriculum. Boston: Allyn \& Bacon.

Becker, H.J. (1990). Curriculum and instruction in middle-grade schools. Phi Delta Kappan, 71, 450-457.

Blanchard, R.W. (1969, October). Thoughts on the middle school. Working paper for discussion with the Sweet Briar Group, Portland, OR.

Bolster, A.S. (1983). Toward a more effective model of research on teaching. Harvard Educational Review, 53, 294-308.

Brophy, J.E. (1987). Synthesis of research on strategies for motivating students to learn. Educational Leadership, 45 (2), 40-48. 
Bruner, J. (1960). Readiness for learning: The Process of Education (pp. 33-54). New York: Vintage.

Buan, C.M., \& Olson, T. (1988). An Oregon Guide to Middle-Level Schooling: Issues, Options and Resources. Salem, OR: Oregon Department of Education.

Carnegie Council on Adolescent Development (1989). Turning Points: Preparing America's Youth for the 21st Century. New York: Author.

Carnegie Task Force. (1986). A Nation Prepared: Teachers for the 21st Century. New York: Carnegie Foundation.

Caught in the Middle. (1987). Sacramento, CA: California State Department of Education.

Doda, N. (1991). Teacher to Teacher. Columbus, OH: National Middle School Association.

Doda, N., George, P., \& McEwin, K. (1987). Ten current truths about effective schools. Middle School Journal, 18 (3), 3-8.

Eichhorn, D.H. (1966). The Middle School. Columbus, OH: National Middle School Association.

Elkint, D. (1978). Understanding the young adolescent. Adolescence, 13, 127-133.

Elkind, D. (1981). Children and Adolescents: Interpretive Essays on Jean Piaget. New

York: Gyford University Press.

Epstein, J.L., Lockard, B.L. \& Dauber, S.L. (1989). Staff development in the middle grades. (Report No. 38). Baltimore: Johns Hopkins University, Center for Research on Elementary and Middle Schools.

Epstein, J.L., \& MacIver, D.J. (1989). Education in the Middle Grades: Overview of a National Survey of Practices and Trends. Baltimore: Johns Hopkins University, Center for Research on Elementary and Middle Schools

Erb, T.O. (1991). Preparing prospective middle grade teachers to understand the curriculum. Middle School Journal, 23 (2), 24-28.

Farris, R. (1990). Meeting their needs: Motivating middle level learners. Middle School Journal, (November), 22-26.

Fielder, R.E. (1978). A solution to the middle school problem. Clearing House, 51, 322326.

Fink, A., \& Kosecoff, J. (1985). How to Conduct Surveys. Newbury Park, CA: Sage Publications, Inc.

Gatewood, T.E. (1975). Towards a self-identity: The middle school and the affective needs of the emergent adolescent. Middle School Journal, I (2), 25-30. 
Gatewood, T.E., \& Dilg, C.A. (1975). The Middle School We Need: A Report from the $A S C D$ Working Group on the Emerging Adolescent. Washington, D. C.: Association for Supervision and Curriculum Development.

George, P. (1983). The Theory Z School: Beyond Effectiveness. Columbus, $\mathrm{OH}$ : National Middle School Association.

George, P., \& Oldaker, L. (1985). Evidence for the Middle School. Columbus, OH: National Middle School Association.

George, P., Stevenson, C., Thomason, J., \& Beane, J. (1992). The Middle School-And Beyond. Alexandria, VA: Association for Supervision and Curriculum Development.

Gilligan, C., Word, J., \& Taylor, J. (1988). Mapping the Moral Domain. Cambridge: Howard University Press.

Glasser, W. (1990). The quality school. Phi Delta Kappan, 71, 424-435.

Good, T.L., \& Brophy, J.E. (1987). Looking in Classrooms. New York: Harper \& Row.

Goodlad, J.L. (1984). A Place Called School. New York: McGraw-Hill.

Grani, C.A., \& Zeichner, K.M. (1984). On becoming a reflective teacher. In C. A. Grant (Ed.) Preparing for Reflective Teaching (pp. 2-18). Boston: Allyn \& Bacon, Inc.

Hart-Landsberg, S., Schwab, R.G., \& Reder, S. (1991). Teacher Collaboration and Constraint: Quantitative Ethnographies of Two Middle Schools. Portland, OR: Northwest Regional Educational Laboratory.

Henry, T. (1990, February 1). Bush presents six-goal program to upgrade education in U.S. The Oregonian, p. A14.

Hensley, R.B. (1985). Does brain-stage theory suggest a need for a major over-haul of junior high school curricula? The Clearing House, 59, 39-41.

Johnson, D.W., \& Johnson, R.T. (1987). Research shows the benefits of adult cooperation. Educational Leadership, 45 (3), 27-30.

Johnston, J.H., \& Markle, G.C. (1986). What Research Says to the Middle Level Practitioners. Columbus, OH: National Middle School Association.

Kramer, L.R., McKibbin, M., \& Dumas T. (1990). Collaborative efforts to improve teaching in California's middle grade schools. Middle School Journal, 22 (2), 7-13.

Lipsitz, J. (1984). Successful Schools for Young Adolescents. New Brunswick, NJ: Transaction Publishers.

Lounsbury, J.H. (1990). Middle level schools-once around the elephant. NASSP (May), 1-6. 
Lounsbury, J.H. (1991a) As I See It. Columbus, OH: National Middle School Association.

Lounsbury, J.H. (1991b). A fresh start for the middle school curriculum. Middle School Journal, 23 (2), 3-7.

Lounsbury, J.H., Maroni, J.V., \& Compton, M.F. (1980). The Middle School in Profile: A Day in the Seventh Grade. Columbus, OH: National Middle School Association.

Maciver, D.J. (1990a). Meeting the needs of young adolescents: Advisory groups, interdisciplinary teaching teams, and school transition programs. Phi Delta Kappan., 71, 458-464.

MacIver, D.J. (1990b). A national description of report card entries in the middle grades (Report No. 9). Baltimore: The Johns Hopkins University Center for Research on Affective Schooling for Disadvantaged Students.

Manning, M.L. (1989). Contemporary studies of teacher behaviors and their implications for middle level teacher education. Action in Teacher Education, 11 (4), 1-5.

Markle, G. (1990). Teaching for understanding. Middle School Journal, 22 (2), 53-57.

McDonough, L. (1991). Middle level curriculum: The search for self and social meaning. Middle School Journal, 23 (2), 29-35.

McEwin, C.K., \& Thomason, J. (1989). Who They Are-How We Teach. Columbus, $\mathrm{OH}$ : National Middle School Association.

McPartland, J.M. (Date unknown). How Departmentalized Staffing and Interdisciplinary Teaming Combine for Effects on Middle Grade Students. Baltimore: Johns Hopkins University, Center for Research on Elementary and Middle Schools.

McPartland, J.M., \& Wu, S. (1988). Instructional practices in the middle grades: National variations \& effects (Report No. 25). Baltimore: Johns Hopkins University, Center for Research on Elementary and Middle Schools.

McPartland, J.M. (1990). Staffing decisions in the middle grades. Phi Delta Kappan, 71, 465-469.

Merenbloom, E.Y. (1986). The Team Process in the Middle School: A Handbook for Teachers (2nd ed.). Columbus, $\mathrm{OH}$ : National Middle School Association.

Midgley, C. (1991). Teacher sense of efficacy and the transition to middle level schools. Middle School Journal, 22 (5), 10-13.

Mufson, L., Cooper, J., \& Hall, J. (1989). Factors associated with underachievement in seventh-grade children. Journal of Educational Research, 83, 5-10.

Murphy, J. (1988). The unheroic side of leadership: Notes from the swamp. Phi Delta Kappan, 69, 654-659.

NASSP (1985). An Agenda for Excellence at the Middle Level. Reston, VA: Author. 
National Center for Educational Statistics (1988). A Profile of the American Eighth Grader. Washington, DC: US Department of Education.

Office of Educational Research and Improvement (1990). Who is the American Eighth Grader? Washington, DC: U.S. Department of Education.

Neufeldt, V., \& Guralnik, D.B. (Eds.). (1988). Webster's New World Dictionary. Englewood Cliffs, NJ: Prentice Hall.

Piaget, J. (1972). Intellectual evolution from adolescence to adulthood. Human Development, 15, 1-12.

Poole, B.J. (1988). A study of the relationship between teacher maintenance and middle school effectiveness. NMSA Research Annual 1988 Selected Studies (pp. 52-71). University of Northern Colorado: National Middle School Association.

Porter, A.C., \& Brophy, J. (1988). Synthesis of research on good teaching: Insights from the work of the institute for research on teaching. Educational Leadership, 45 (8), 74-85.

Portland Public Schools District. (1991). Enrollment Report. Management Information Services: Author.

Portland Public School District Public Information Office. (1977). Middle schools in Portland: A report based on the findings of $C$. W. Williams and $V$. Wilson. Portland, OR: Author.

Portland Public schools. (1991). Middle school Profiles. Portland, OR: Author.

Robertson, D. (1989, November). Interview Analysis/Synthesis Techniques (Class notes). Portland, OR: Portland State University.

Sergiovanni, T.J. (1987). The Principal. Boston: Allyn \& Bacon, Inc.

Sheppard, R. (1991). Stories from the classroom: Preparing teachers for middle level schools. Middle School Journal, 23 (2), 49-51.

Silvern, S., \& Wiles, J. (1978). What do early childhood principles imply for the middle school? Educarional Leadership, 35, 661-666.

Slavin, R.E. (1981). Synthesis of research on cooperative learning. Educational Leadership, 38, 655-660.

Sparapani, E.F., Abel, F.J., Edwards, P., \& Herbster, D. (1991). Middle Grades Teacher Preparation: A Future Focus. Paper presented at the 71st Annual Meeting of the Association of Teacher Education, New Orleans, LA.

Stefanich, G.P. (1990). Cycles of cognition. Middle School Journal, 22, 47-52.

Stronge, J.H., \& Jones, C.W. (1991). Middle school climate: The principal's role in influencing effectiveness. Middle School Journal, 22 (5), 41-44. 
Strubbe, M.A. (1989). An assessment of early adolescent stress factors. Research Annual, Selected Studies (D. B. Strahan, ed.). Columbus, OH: National Middle School Association.

Thomason, J. (1984). Nurturing the nature of early adolescents-or a day at the zoo. Middle School Journal, 15 (4), 3-6.

Vars, G.F. (1987). Interdisciplinary Teaching in the Middle Grades. Columbus, OH: National Middle School Association.

Wiles, J., \& Bondi, J. (1986a). Making Middle Schools Work. Alexandria, VA: Association for Supervision and Curriculum Development.

Wiles, J., \& Bondi, J. (1986b). The Essential Middle School. Tampa, FL: Wiles, Bondi \& Associates, Inc.

Wilson, B.L., \& Firestone, W.A. (1987). The principal and instruction: Combining bureaucratic and cultural linkages. Educational Leadership, 45 (1), 18-23. 
APPENDIX A

QUESTIONNAIRE 


\section{SURVEY OF MIDDLE SCHOOL TEACHERS' \\ BELIEFS, KNOWLEDGE, AND PRACTICES}

The following statements will ask you to examine your beliefs, knowledge, and practices regarding early adolescents and teaching at the middle school. It is very important that you be honest in your responses. Absolute anonymity and confidentiality will be maintained.

Please place the number in the blank which you feel most closely represents your present feeling about each item:

\section{1 - Strongly \\ 2 - Agree}

\section{3 - Disagree}

4 - Strongly Disagree

1. The middle schooler's extreme need to socialize often interferes with my teaching.

2. I prefer teaching and having the school counselor deal with the personal problems of my students.

3. I think it is unrealistic to expect every student to experience success.

4. I am not comfortable with too much activity or talking in the classroom.

5. I allow my students many opportunities to socialize and relate to their peers within my classroom.

6. A big barrier to my being able to teach more effectively is lack of student interest.

7. I prefer a quiet, orderly classroom with little or no talking.

8. I genuinely enjoy going to work each day.

9. Although I occasionally use cooperative learning activities or strategies, I prefer having each student sit at his or her own desk and work independently.

10. To prepare young people for the twenty-first century, middle schools should concentrate more on academic education.

11. Developing and using interdisciplinary and/or integrated teaching units is both important and stimulating to me.

12. I am deeply committed to the middle school concept and to the students.

13. I believe that teachers should be freed up to teach and counselors should deal with student problems.

14. I am always searching for new ways to teach or present the curriculum.

15. I view my main task in the classroom as teaching academic content. 
16. I think "advisory" is basically a waste of time.

17. Students who can and want to learn should be separated from the nonacademically oriented.

18. I usually use objective tests because they are more efficient and less timeconsuming to correct.

19. I could be a better middle school teacher if I taught only in my specialty area.

20. I use cooperative and collaborative learning strategies almost daily.

\section{DEMOGRAPHICS:}

Gender: $\mathbf{M}$

$\mathrm{F}$

Specific Certification(s)

Total number of years

teaching at the

middle school

Total number of years

teaching altogether

Elementary K-5

Elementary K-8

Middle school

Junior High

High School

Post-Secondary

A small sample (20) of respondents to this survey will be requested for follow-up interviews. This is optional and voluntary. If you would be willing to do so, please sign the following consent form:

I would consent to an interview should my survey be selected.

Signed:

Date:

School: 
APPENDIX B

INTERVIEW GUIDE 


\section{INTERVIEW}

I. Demographic and introductory questions

1. How long have you been teaching middle school?

2. What is your usual teaching assignment?

3. Define effective middle school teaching.

4. Are you effective?

II. Open-ended interview protocol

Introduction:

As you respond to the following, consider the questions in the context of the larger middle school organization, now just in the context of your present middle school environment. Feel free to elaborate.

Questions:

1. Consider the many different factors that contribute to your being an effective middle school teacher. What are the most significant factors which come to mind?

2. How important is the role of the principal in contributing to teacher effectiveness and, if important, what are the most significant ways in which a principal promotes and maintains effectiveness?

3. Team teaching is an organizational concept in most middle schools tcday. What are the most critical factors which enable teachers to participate as a team member in a meaningful way?

4. Teacher-advisor is an important role which middle school teachers must fill. What factors most enable you to do so?

5. What staff development or professional training programs do you think have been or could be most useful in further developing effective middle school teaching? What factors do you see as essential for promoting more effective teachers?

6. How important to middle school teaching effectiveness is knowing and understanding early adolescent needs and characteristics?

7. Consioer university teacher training programs. What should such a program include in order to best prepare effective teachers for the middle school?

8. Should teacher training institutions offer and/or require a middle school cerifificate? 